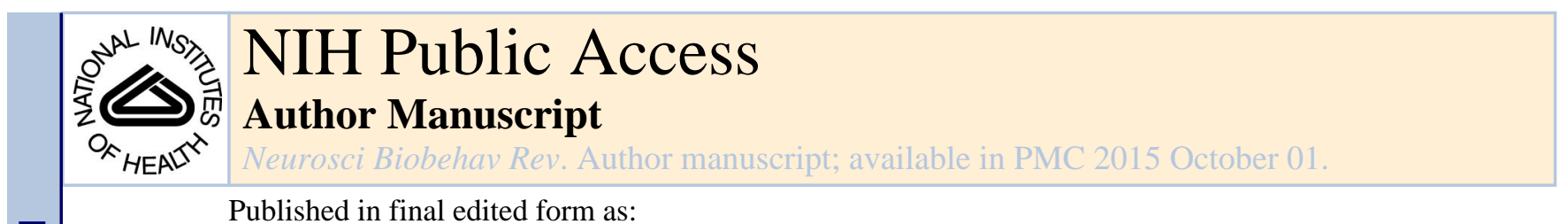

Published in final edited form as:

Neurosci Biobehav Rev. 2014 October ; 46 Pt 3: 429-454. doi:10.1016/j.neubiorev.2014.07.027.

\title{
ETIOLOGY, TRIGGERS AND NEUROCHEMICAL CIRCUITS ASSOCIATED WITH UNEXPECTED, EXPECTED, AND LABORATORY-INDUCED PANIC ATTACKS
}

\author{
Philip L. Johnson ${ }^{1,2,3}$, Lauren M. Federici ${ }^{1,3}$, and Anantha Shekhar ${ }^{2,3,4}$ \\ ${ }^{1}$ Department of Anatomy \& Cell Biology, Indiana University School of Medicine, Indianapolis, IN, \\ USA \\ ${ }^{2}$ Department of Psychiatry, Institute of Psychiatric Research, Indiana University School of \\ Medicine, Indianapolis, IN, USA \\ ${ }^{3}$ Stark Neuroscience Research Institute, Indiana University School of Medicine, Indianapolis, IN, \\ USA \\ ${ }^{4}$ Indiana Clinical and Translational Sciences Institute, Indiana University School of Medicine, \\ Indianapolis, IN, USA
}

\section{Abstract}

Panic disorder (PD) is a severe anxiety disorder that is characterized by recurrent panic attacks (PA), which can be unexpected (uPA, i.e., no clear identifiable trigger) or expected (ePA). Panic typically involves an abrupt feeling of catastrophic fear or distress accompanied by physiological symptoms such as palpitations, racing heart, thermal sensations, and sweating. Recurrent uPA and ePA can also lead to agoraphobia, where subjects with PD avoid situations that were associated with PA. Here we will review recent developments in our understanding of PD, which includes discussions on: symptoms and signs associated with uPA and ePAs; Diagnosis of PD and the new DSM-V; biological etiology such as heritability and gene $\mathrm{x}$ environment and gene $\mathrm{x}$ hormonal development interactions; comparisons between laboratory and naturally occurring uPAs and ePAs; neurochemical systems that are associated with clinical PAs (e.g. gene associations; targets for triggering or treating PAs), adaptive fear and panic response concepts in the context of new NIH RDoc approach; and finally strengths and weaknesses of translational animal models of adaptive and pathological panic states.

\section{Keywords \\ panic; anxiety; $\mathrm{CO}_{2}$; lactate; perifornical hypothalamus; periaqueductal gray; amygdala; insula}

(C) 2014 Elsevier Ltd. All rights reserved.

Address for correspondence Philip Lee Johnson, PhD, Department of Anatomy \& Cell Biology Indianapolis, IN 46202, philjohn@iupui.edu.

Publisher's Disclaimer: This is a PDF file of an unedited manuscript that has been accepted for publication. As a service to our customers we are providing this early version of the manuscript. The manuscript will undergo copyediting, typesetting, and review of the resulting proof before it is published in its final citable form. Please note that during the production process errors may be discovered which could affect the content, and all legal disclaimers that apply to the journal pertain. 


\section{Section 1: Preface}

The literature describing Panic Disorder (PD) is extensive and dates back many decades prior to PD being defined as a specific diagnostic syndrome in the Diagnostic and Statistical Manual of Mental Disorders (DSM III) in 1980. Although this review will not exhaustively address every aspect of PD, our aim here is to discuss the key concepts that have shaped our understanding of this illness, provide succinct evaluation of the present knowledge, and define a few areas of gaps in knowledge for future research. To this end, in section 2 we will initially discuss the cognitive and physiological symptoms that occur during panic attacks (PAs), and the criteria for panic disorder diagnosis in the Diagnostic and Statistical Manual of Mental Disorders V (DSM-V). In section 3 we will discuss the emerging empirical evidence supporting a biological basis for recurrent PAs in PD that will include discussion on heritability, and how there may be gene $\mathrm{x}$ environment and gene $\mathrm{x}$ hormonal development interactions that explain post-adolescent onset and higher prevalence of PD in women. Section 4 contains a review of the large body of work on the many laboratory methods of inducing PAs and how they provide insight into potential naturalistic triggers of uPAs and ePAs. Section 5 introduces the neural circuits implicated in naturally occurring and laboratory induced PAs, and how these neural circuits compare with adaptive panic and fear circuitry as it is emerging in the new NIH RDoc system. Section 6 will then discuss neurochemical systems implicated in PD through clinical studies involving gene associations and pharmacological triggers/treatments associated with those systems. Section 7 will assess strengths and weaknesses of translational animal models of adaptive panic and attempts to model pathological panic with deep brain stimulation or using trait approaches such as genetic knockout and systems biology approaches using interoceptive and exteroceptive panicogenic stimuli. Finally, Section 8 will address gaps in knowledge and future directions to advance our understanding of the etiology, triggers, and subtypes of PAs that could lead to novel therapeutic advances.

\section{Section 2 - Panic Disorder and Panic Attacks: Symptoms, Signs, Diagnostic Criteria (DSM-I through V)}

Within the anxiety disorder spectrum, recurrent PAs are the hallmark of diagnosis for PD, but PAs can also frequently occur in other severe anxiety disorders such as post-traumatic stress disorder and phobias (Jensen et al., 1998), and less frequently associated with other anxiety disorders such as generalized anxiety and obsessive compulsive disorders (Gorman et al., 1985; Liebowitz et al., 1985a), or pure depressive disorders (Cowley et al., 1987). The recurrent PAs are categorized in the DSM-V as being either unexpected (also called spontaneous) (uPA), or expected (ePA). The uPAs occur in the absence of a clear external trigger that can be identified by the subject and are estimated to account for $\sim 40 \%$ of PAs (Shulman et al., 1994). Another subtype, ePAs occur where an external cue (e.g., situation where uPAs have occurred, or when confronted with a generally feared phobic situation or stimulus) is associated with the induction of the PA (Shulman et al., 1994). Collectively, recurrent PAs (either uPA and ePA) can lead to agoraphobia, which is a conditioned avoidance response that occurs when people with PD begin to fear situations that are associated with PA or where escape might be difficult or help might not be available (e.g., 
planes, elevators etc.) if a PA were to occur. The majority of agoraphobia diagnoses occur in the presence of $\mathrm{PD}$, but it is important to note that it can occur independently [see review (Wittchen et al., 2010)]. Therefore, in the DSM-V, agoraphobia is considered an independent anxiety disorder.

Both uPAs and ePAs are comprised of an abrupt surge of symptoms that typically consist of cognitive symptoms like catastrophic fear of dying and/or losing control alongside autonomic-related symptoms such as palpitations, racing heart, hot flashes (heat sensations), and sweating. Other physical symptoms may include increased respiratory drive, paresthesias (numbing or tingling sensations), dizziness, and nausea. In the DSM-V, a PA consists of 4 or more of the 13 possible symptoms; two of these are cognitive/fear symptoms and eleven are physical symptoms. Typical PAs peak within $\sim 10 \mathrm{~min}$, have a duration of 25-45 min, and can occur during calm or anxious states (Taylor et al., 1986; Margraf et al., 1987; de Beurs et al., 1994). Even though PAs can occur in calm or anxious states, the severity and duration of the PA appears to be affected by such state-dependent variables. For instance, uPAs that occurred during relaxation therapy peaked within $\sim 3$ min and subsided shortly afterwards (Cohen et al., 1985), and in one study situational ePAs were considered more severe than uPAs (Margraf et al., 1987). Although PAs do occur at night, it is important to note that PD subjects are much more vulnerable to having PAs when awake, and PA vulnerability is highest from 10AM to 4PM, with 2PM - 4PM being the highest incidence (see Figure 1). This vulnerability coincides with many neurochemical systems becoming more active, such as the sympathetic nervous system, central serotonergic and noradrenergic systems, as well as increases in plasma concentrations cortisol, and norepinephrine (discussed further in sections $\mathbf{4 d}$, and $\mathbf{6}$ ).

Although some symptoms associated with PAs are more common than others, the specific cognitive and physical symptoms associated with uPAs and ePAs can vary greatly across PD subjects and during different episodes of PD within the same subject. Using a PA questionnaire on 212 PD subjects, Cox and colleagues found that cognitive symptoms had the highest frequency/severity rating, but it is important to note that these cognitive symptoms were not associated with DSM-V criteria for PD, and are arguably more associated with agoraphobia (i.e., feeling helpless, thoughts of escape, difficulty concentrating, and fear of causing a scene). In regards to the 13 accepted cognitive/physical symptoms associated with $\mathrm{PD}$, heart/autonomic disturbance related symptoms (i.e., tachycardia > heart pounding > sweating) were ranked as being most severe/prevalent; followed by cognitive symptoms (i.e., fear of dying > feelings of unreality > fear of going crazy > and fear of losing control); then respiratory-related symptoms (i.e., dizziness > dyspnea); and finally symptoms such as nausea and parasthesias ranked as being least frequent and severe. They also noted that there were differences in presentation of symptoms that is suggestive of subtype of PA, that could be related to etiology or trigger and is supportive of the causes of PD and repeated PA's being heterogenous (Cox et al., 1994).

Consistent with Cox's article, in a recent review by Craske and colleagues (Craske et al., 2010), heart-related symptoms were the most common during a PA [e.g., heart pounding $97 \%$, tachycardia $86.1 \%$, palpitations $78 \%$ ], with the other 11 physical symptoms having a prevalence rate ranging from $\sim 35-95 \%$. Even though heart-related symptoms are most 
commonly reported during a PA, the specific heart-related symptom reported varies. It is also important to note that these are self-reported symptoms and not objective measures of vital signs. Therefore, caution should be taken when interpreting these symptoms (e.g., a subjective feeling of tachycardia could be a more forceful "pounding" heart contraction). In objective measures of PAs, cardiac related symptoms also varied. For instance in 1987, Margraf and colleagues asessed naturally occurring PAs in 27 PD and 19 control subjects that wore ambulatory heart rate monitors for 3 days. The PD subjects reported 175 PAs that consisted primarily of self-reported palpitations, dizziness, sweating, and chest pain. They also noted that situational or ePAs were more severe than uPAs, and that heart rate increases (tachycardia) did not occur in uPAs, but did occur in ePAs and preceded ePAs by 15 min (Margraf et al., 1987). Another more recent study objectively assessed a total of 13 PAs in 4 male and 5 female PD subjects using ambulatory monitoring of heart rate, respiratory activity, and skin conductance (Meuret et al., 2005). The median length of the 13 PAs was 8 min, with $\sim 38 \%$ occurring when alone, $\sim 23 \%$ with a friend, $~ 39 \%$ with family; overall, $\sim 69 \%$ were unexpected. In this study, significant cardiorespiratory changes were occurring as early as 45 min prior to the onset of the PA. Specifically, tachycardia and bradypnea (and a subsequent drop in end tidal $\mathrm{CO}_{2}$ ) occurred around 50 min prior to PA. Twenty min prior to the PA, a decrease in tidal volume occurred that was followed by a marked increase in end tidal $\mathrm{pCO}_{2}$. In this study, a significant tachycardia was noted during the PA, as well as an increase in tidal volume and decrease in end tidal $\mathrm{pCO}_{2}$. Yet, the authors note that only a few of the subjects had a dramatic tachycardia during the PA. The severity of end tidal $\mathrm{pCO}_{2}$ during the PA was correlated with symptoms such as anxiety, fear of dying, and chest pain, whereas as the severity of the tachycardia was associated with symptoms such as fear of losing control and faintness. Although skin conductance did not vary prior to or during the PA, it was generally higher than non-PA periods at similar times of day. In other studies assessing ambulatory heart rate in PD patients with naturally occurring PAs also report such variability in symptoms reporting that tachycardia occurred in 3 out of 8 PAs (38\%) (Barr Taylor et al., 1982), and in 19 of 33 PAs (58\%) (Taylor et al., 1986). Thus, although the symptoms that occur during uPAs and ePAs are strongly suggestive of disrupted autonomic activity (e.g., heart related symptoms, sweating and heat sensation, light headedness or faintness, and abdominal distress), the symptom themselves are largely heterogeneous in nature (even heart-related symptoms), and may precede and/or occur during naturally occurring PAs.

Although fear-associated cognitive symptoms are present in the majority of PAs, some groups have hypothesized that there is evidence that the fear-associated cognitive symptoms are not always present in some PA despite 4 or more physical symptoms being present. Beitman and colleagues studied 32 subjects with angiographically normal coronary arteries that met the criteria for PD, and of those subjects, 13 (41\%) reported no fear (i.e., specifically fear of dying or going crazy) during the most recent PA, but did report significant discomfort (Beitman et al., 1990). Therefore, this type of PA is often referred to as a non-fear PA. When comparing symptoms of non-fear PA and fear PA, there was no difference in shortness of breath, chest pain, and palpitations; but hot flashes, paresthesias, and derealization (Beitman et al., 1990) were higher in fear PAs. In a national comorbidity survey, Chen and colleagues found that 589 subjects out of 8098 respondents met the 
diagnostic criteria for lifetime PA (Chen et al., 2009). Among the 589 subjects, 176 (30\%) met the criteria for a non-fear PA. In this instance when comparing of symptoms of non-fear PA and fear PA, there was no difference in the symptoms such as hot flashes, and paresthesias, but PD subjects with fear PAs had significantly higher incidence of depersonalization, shortness of breath, smothering, trembling, and a slightly higher incidence of heart pounding. The PD subjects with fear PAs were also almost twice as likely to develop agoraphobia and to abuse alcohol or drugs. Thus, even if meeting 4 or more symptoms criteria of the DSM-V, PAs in the absence of the cognitive fear appear to be less likely to results in recurrent ePAs, agoraphobia, substance abuse, and other comorbidities such as depression.

To further understand the biology mediating Pas, more studies are needed to assess cognitive symptoms and autonomic tone (e.g., heart rate, heart rate variability, blood pressure, skin sweating and flushes, and plasma catecholamines), and endocrine responses (e.g, cortisol) during naturally occurring PAs, and prospective studies in high risk populations (e.g, monozygotic twin or first degree relatives of PD subjects) during the premorbid period, i.e., prior to having had repeated PAs. The current knowledge surrounding autonomic tone will be further addressed in section 4 when discussing potential PA triggers and laboratory assessments of autonomic tone.

\section{Section 3 - Empirical Evidence for Biological Basis of Recurrent Panic Attacks}

\section{3a. Heritability}

Anxiety disorders are a heterogeneous classification that have a lifetime prevalence of about $20 \%$ in the general population Among the distinct syndromes that have been delineated based on clinical presentations, Panic Disorder represents one of the most severe anxiety disorders where recurrent uPAs and ePAs occur (DSM-V, 2013). Current estimates are that about $7-10 \%$ of the population experience occasional PAs and the prevalence of PD in the general population is $\sim 2-5 \%$ (Goodwin et al., 2005; Kessler et al., 2006). Although the etiology of PD is largely unknown, there is a strong heritability in first degree relatives ( 11\%) and monozygotic twins (30-40\%) [see meta-analysis and reviews by (Hettema et al., 2001; Schumacher et al., 2011)]. However, as discussed in section 6, Maron and colleagues conducted a meta-analysis of the use of linkage and candidate genes in association studies, which have found over 1000 polymorphisms and 350 candidate genes, for their association with PD (Maron et al., 2010). Although there are several promising, replicable candidate genes, most studies produced inconsistent results. Therefore, even though there is a strong genetic predisposition for PD in monozygotic twins and first degree relatives, the specific genes associated with PD and recurrent PAs may be more heterogeneous than the symptoms associated with PAs, and there is most likely multiple gene polymorphisms that may contribute small but cumulative risks for the symptoms and presentation of PD. Another consideration is gene $\mathrm{x}$ environment and gene $\mathrm{x}$ hormonal development interactions which is discussed in the following subsections in section 3. 


\section{3b. Age of onset (gene $x$ hormonal development and gene $x$ environment considerations)}

Another informative clue to PD etiology is the age of onset, which has a mean age range at diagnosis from 22-23 years in US population (DSM-V, 2013), but the incidence of PAs and PD show a gradual increase during adolescence [(Reed and Wittchen, 1998) see Figure 1] that coincides with sex hormone surges and sexual maturation that begins at $\sim 10-12$ and ends at $\sim 15-17$ years of age [see review (Kessler et al., 2010)]. This developmental stage is accompanied by critical cortical growth and remodeling which begins in pre-adolescence and continues to develop until early adulthood when PAs and PD typically get diagnosed (see Figure 2a). This developmental stage is associated with the development of greater cognitive maturation including more complex reasoning, a stronger urge for independence, and interest in the opposite sex. The specific cortical events that occur during this period is beyond the scope of this review, but overall there is massive pruning of excitatory synapses in the prefrontal cortex that occurs in pre-adolescence and continues until the offset of puberty when maximal inhibitory interneuronal activity begins to occur (see Figure $2 \mathrm{~b}$ ) (Huttenlocher, 1979, 1984; Spear, 2000; Insel, 2010). Of particular relevance to anxiety, fear, and panic states, there is also evidence that this is a critical period for development of connectivity of the prefrontal cortex with the amygdala and brain stem centers (Gee et al., 2012; Gee et al., 2013a; Gee et al., 2013b), all structures that are critical for developing fear and panic, and heavily implicated in anxiety disorders such as PTSD and PD. This connectivity with the prefrontal cortex appears to be critical for extinction of fear memories and preventing over-generalization of threatening cues (Kheirbek et al., 2012). The development and synchronization of this circuit is altered by stress and is discussed further in section 5. There is evidence that the ventromedial PFC (vmPFC) is also hypoactive in anxiety pathology, which can lead to loss of tonic inhibition of the amygdala or subcortical panic-generating brain regions such as the perifornical hypothalamus $(\mathrm{PeF})$ and dorsal periaqueductal gray (DPAG), which could contribute to the onset of PAs and PD. Furthermore, section 5 will also discuss how cognitive behavioral therapies (CBT) may be effective for treating PA and PD by enhancing vmPFC activity and restoring functional connectively with subcortical fear and panic centers.

Another striking feature of PD is that, compared to men, women show earlier age of onset (Reed and Wittchen, 1998) and are twice as likely as males to develop PD [see Figure 2a (Reed and Wittchen, 1998; Sheikh et al., 2002)]. The initiation of fluctuating sex steroid hormones over the menstrual cycle in women [see review (Nillni et al., 2011)] could be an important factor that contributes to the higher rates of PA and PD in women, but other factors such as early life stress or higher incidence of trauma such as sexual abuse or domestic violence in women could also account for this vulnerability. Evidence supporting a hormonal contribution includes a study demonstrating that female PD subjects with agoraphobia reported experiencing premenstrual exacerbations in anxiety symptoms, a pattern which could increase the rate of ePAs and contribute to the development of agoraphobia in these subjects (Breier et al., 1986). Furthermore, there is evidence that fear extinction retention is reduced during some phases of the menstrual cycle and increased in other phases (Milad et al., 2010; Zeidan et al., 2011). Thus fluctuating sex hormones in women may predispose them to persistent emotional trauma (e.g., PTSD) during aversive 
events. Finally, women with a genetic predisposition for PD may be more vulnerable to ePAs and agoraphobia during specific phases of the menstrual cycle.

In addition to gene $\mathrm{X}$ hormone interactions, pre-existing developmental anxiety states and early life stress are also environmental factors to consider in the etiology of PD. In structured psychiatric interviews of 55 subjects meeting DSM-III criteria of PD, childhood separation disorder was comorbid in $17 \%$ of the subjects (Breier et al., 1986).

\section{Section 4 - Panic Attacks Triggers: Laboratory and Potential Natural Triggers}

\section{4a. Adaptive panic and fear responses to threatening external and internal sensory events}

Normally a panic response is an adaptive survival response (Stein and Bouwer, 1997) that is conceptualized as a perception of an imminent external or exteroceptive threat (e.g., attack by a predator or conspecific aggressive male) that produces cognitive symptoms of fear or panic that are accompanied by: 1) somatic motor behavioral responses (i.e., fight or flight); 2) coordinated autonomic sympathetic responses and parasympathetic withdrawal to increase cardiovascular activity; 3 ) increased respiratory activity to oxygenate the body; and 4) hormonal responses [i.e., epinephrine, hypothalamic-pituitary-adrenal (HPA) axis cortisol response, etc.] to mobilize energy stores and suppress the immune system. Yet, internal sensory input (interoceptive) can also signal life threatening events and can elicit cognitive fear and physical symptoms similar to PAs (Street et al., 1989; Ehlers and Breuer, 1996). For instance, hypercapnia, which is a condition associated with increased plasma levels of $\mathrm{CO}_{2}$ resulting in peripheral and central acidosis initially just increases breathing to "blow off" excess $\mathrm{CO}_{2}$ [see review (Guyenet et al., 2010)]. However, if the hypercapnia becomes too severe, a feeling of suffocation and smothering arises and elicits additional symptoms very similar to a PA (Forsyth and Eifert, 1998; Forsyth et al., 2000b; Bailey et al., 2005). Most evidence supports that ePAs are provoked by exteroceptive threats (e.g., situations where PAs have occurred leading to anticipatory anxiety, or non-related stressful stimuli), but there is growing evidence that suggests that uPAs may be provoked by non-life threating changes in interoceptive internal sensory information that subjects are normally not aware of, but may yet elicit a response in PD subjects. Hence, the uPA appears to come out of nowhere, but may have detectable, subthreshold interoceptive cues that can be detected with appropriate monitoring of uPAs. Unfortunately, very few such studies have been conducted due to the obvious difficulties of timing and monitoring uPAs.

In this section we will initially discuss uPAs; laboratory studies that give insight into potential naturally occurring interoceptive triggers and the neural circuitry that is thought to be critical for the sensory input and cognitive and motor output. We will then discuss ePAs triggers and neural circuitry for ePAs. Finally, we will compare PAs to normal panic and fear circuitry in the NIH RDoc.

\section{4b. Unexpected panic attacks: interoceptive triggers}

In the de Beurs study mentioned in section 2, the investigators continuously monitored naturally occurring PAs in 97 subjects with PD + agoraphobia, with the subjects reporting 
the context in which they had their PA; 53\% of the PAs occurred in relatively nonthreatening and not agoraphobic contexts (i.e., $45 \%$ occurred at home and $8 \%$ while visiting a friend) (de Beurs et al., 1994). Thus, the PA was seemingly unprovoked or unexpected. So what was triggering these uPAs? One of the most consistent abnormalities seen in subjects with panic disorder under laboratory conditions is that they are hyper-responsive to normal interoceptive cues (Hoehn-Saric et al., 2004; Pollock et al., 2006) and are vulnerable to displaying panic attacks in response to mild interoceptive cues such as hypertonic $0.5 \mathrm{M}$ NaLac infusions (Liebowitz et al., 1984; Liebowitz et al., 1985b), inhalation of gas with increased $\mathrm{CO}_{2}$ concentration (Gorman et al., 1994), which normally do not elicit panic attacks in healthy controls. For instance, in 1984, Gorman and colleagues exposed 12 patients with a DSM-III PD diagnosis and 4 healthy subjects to $5 \% \mathrm{CO}_{2}, 0.5 \mathrm{M}$ sodium lactate (NaLac) intravenous infusions or had them hyperventilate room air, and found that in PD subjects $7 / 12(58 \%)$ had a PA to $\mathrm{CO}_{2}, 8 / 12(67 \%)$ to NaLac, and 3/12 (25\%) to hyperventilation (Gorman et al., 1984). This suggests that PD patients are either hypersensitive or hyper-responsive to these interoceptive physiological stimuli that would normally signal a life-threatening event, and elicit an adaptive 'panic' response, only when severely altered. Therefore, the initial pathology in these patients appears to be an alteration somewhere in the central neural pathways that normally regulate the initiation of an adaptive panic respons only in response to a life-threatening interoceptive stimuli, thus rendering the PD patients susceptible to 'unexpected' panic symptoms when exposed to ordinarily mild interoceptive stressors (Vickers and McNally, 2005). In the following subsections, we will discuss the different interoceptive sensory challenges that provoke panic attacks, and compare and contrast between them in regards to the sensory routes for these stimuli, the brain circuits that respond to them, the resulting cognitive perception of the challenge, and the motor (i.e., somatomotor, visceromotor and metabolic/endocrine) responses. We will discuss both clinical and preclinical data.

\section{4bi. Hypo- or hyper-ventilation induced PAs, suffocation, and respiratory abnormalities in PD}

Subtle increases in $\mathrm{CO}_{2}$ in the blood (i.e., hypercapnia) caused by hypoventilation or holding one's breath result in acidosis in peripheral and central brain structures that initially results in an increase in respiration activity to help "blow off" excess $\mathrm{CO}_{2}$ without much conscious awareness of the event [see review (Guyenet et al., 2010)]. However, if $\mathrm{CO}_{2}$ levels continue to increase, there is a sense of "suffocation" and additional physiologic responses are initiated, including adaptive behavioral and autonomic responses. For instance, having healthy human subjects inhale hypercarbic gas $\left(7.5 \% \mathrm{CO}_{2}\right.$ with normoxic air and balanced $\mathrm{N}_{2}$ ) for $20 \mathrm{~min}$ (compared to normal air) increased cognitive symptoms such as feelings of fear and being paralyzed, but also an urge to leave. Additional symptoms included self-reported breathlessness and cardiovascular symptoms (i.e., systolic blood pressure increase and tachycardia) (Bailey et al., 2005). Woods and colleagues also exposed healthy subjects to $7.5 \% \mathrm{CO}_{2}$ in normoxic air for $15 \mathrm{~min}$ which, compared to control air, led to an increase in subjective reports of fear, anxiety, and nervousness in a visual analogue scale (VAS: no report of fear of losing control or going crazy), as well as physical symptoms associated with PA criteria in DSM-V such as sweating, palpitations, paresthesias, choking feeling, and dyspnea (Woods et al., 1988). Similar to Gorman and colleagues findings in 
1984, Woods and colleagues then exposed healthy and PD subjects to $5 \% \mathrm{CO}_{2}$ with normoxic air for $15 \mathrm{~min}$, which in healthy subjects only increased nervousness, faintness, and dyspnea, and elicited no PAs, but did provoke a PA in 3/5 (60\%) males and 4/9 (44\%) female PD subjects. Compared to healthy subjects, PD subjects that experienced a PA had greater fear and anxiety in VAS, as well as greater dyspnea, fear of losing control, palpitations, sweating, but no differences in paresthesias, faintness, or dizziness. In studies using objective cardiovascular and endocrine measures, the $5 \% \mathrm{CO}_{2}$ challenge increased systolic blood pressure and respiration rate in both healthy and PD subjects that had a PA, but PD subjects that had a PA did have a greater heart rate response. It is important to note that PD subjects that did not have a PA to $\mathrm{CO}_{2}$ did not have a significant increase in systolic blood pressure, or an increase in heart rate. In a similar study, PD subjects showed a 73.3\% rate of mild fear (11/15) and a 40\% PA rate (6/15) to $5 \% \mathrm{CO}_{2}$ (Antony et al., 1997).

Hyperventilation is another method of altering acid-base homeostasis caused by blowing off excessive $\mathrm{CO}_{2}$ and inducing peripheral and central alkalosis (Friedman et al., 2006). Having PD subjects hyperventilate also induces PAs in some PD subjects, but this alkalosis seems to be less effective than acidosis in eliciting a PA in PD subjects. Hyperventilation provoked a PA in 3/12 PD subjects (25\%) (Gorman et al., 1984), and in another study elicited mild fear in $20 \%$ of PD subjects (3/15), and no PAs (defined as moderate to strong fear response) (Antony et al., 1997). In other studies using a hyperventilation challenge, PD subjects had a PA (defined as 4 or more symptoms of a PA in the DSM-IV, with at least one cognitive fear symptom) response rate of $46 \%(6 / 13)$ and healthy controls $10 \%(1 / 10)$ in one study (Nardi et al., 1999), and PD response rates of 46\% (16/35) compared to response rates of $7 \%$ (2/30) in healthy subjects in another study (Nardi et al., 2001). Specific physical symptoms were not reported, nor were objective autonomic and endocrine measures assessed. Overall, inducing acidosis, with hypercapnic gas inhalation (a suffocation cue) appears to be more effective in inducing PAs in PD subjects with an approximate response rate of 40\%-60\%, compared to hyperventilation which had PA rates in PD subjects ranging from 0-46\%. Another method of inducing PAs in PD subjects is to intravenously administer doxapram, which stimulates peripheral chemoreceptors in the carotid bodies and indirectly alters activity in the respiratory centers of the brain stem to stimulate increases in respiration rate and tidal volume, mimicking hyperventilation. In a small study, 6 patients with PD (compared to 4 healthy subjects) had a greater increase in panic symptoms as measured by the Acute Panic Inventory following doxapram administration (Gutman et al 2005). They also assessed cortisol and the norepinephrine metabolite MHPG and found that both were elevated at baseline in PD subjects, and only cortisol increased post-doxapram, but there was no difference in this response due to different baseline levels. In an elegant study, Abelson and colleagues (1996) demonstrated that cognitive-behavioral therapy can reduce the severity of PA response to doxapram, despite similar levels of physiological activation, further supporting that it is not simply a hypersensitivity to a respiratory stimulus that results in a PA (Abelson et al., 1996).

Overall, this suggests that, in some cases, uPAs could be provoked by subtle $\mathrm{CO}_{2}$-related cues $\left(\mathrm{PCO}_{2}\right.$, and peripheral and central acidosis) that signal air hunger and suffocation. The notion that uPAs could be triggered by small and non-threatening changes in peripheral and central acid-base homeostasis is suggested by the fairly consistent report of symptoms such 
as dyspnea, feeling out of breath, or suffocating during such uPAs. Other evidence comes from a timely meta-analysis of baseline respiratory parameters in PD, that determined that PD was associated with higher baseline hyperventilation and rate of sighing which are both suggestive of an over-reaction to increases in acidosis, a suffocation signal (Grassi et al., 2013). This hyper-reactivity to hypercapnia could be a relevant trigger of PAs in environmental settings where ambient $\mathrm{CO}_{2}$ levels are increasing such as people with asthma or obstructive lung diseases, and even physically healthy subjects with PD trapped in closed spaces such as an elevator with groups of people exhaling high levels of end tidal $\mathrm{CO}_{2}$ (approximately 5-6\% exhalation, compared to atmospheric concentrations of $\mathrm{CO}_{2}$ that are less that $0.05 \%$ ).

In light of this evidence, in 1993, Donald Klein proposed a $\mathrm{CO}_{2}$ hypersensitivity theory of panic where a "false suffocation alarm" produces respiratory distress following by hyperventilation "to blow off" $\mathrm{CO}_{2}$, then uPA's and an urge to flee (Klein, 1993). Klein compared the hypersensitivity to $\mathrm{CO}_{2}$ in $\mathrm{PD}$ as being the converse of Ondine's curse which is a condition associated with episodes of apnea during sleep that can be fatal and may be related to a hyposensitivity to $\mathrm{CO}_{2}$. Thus PA's in PD are argued as being due to a hypersensitivity to $\mathrm{CO}_{2}$ that triggers false suffocation, and potentially fatal sleep apnea's in Ondine's curse are a hyposensitivity to $\mathrm{CO}_{2}$ that fails to signal a real suffocation. Yet, some have countered that this hypothesis is not supported by empirical evidence (Ley, 1994), which is a valid point since the neural circuits and specific chemoreceptors critical for even normal $\mathrm{CO}_{2}$ induced breathing are complex and controversial, and as argued in a recent review are both most likely redundant and have heterogenous function (e.g., respiration drive, autonomic responses, somatic motor-related escape, and emotional arousal/panic) (Huckstepp and Dale, 2011). For instance, in the Huckstepp and Dale review they discuss the potential putative neural sites that are chemosensitive to $\mathrm{CO}_{2} / \mathrm{pH}$ which include: 1) medullary regions such as the PreBötzinger complex, retrotrapezoid nucleus, and raphe pallidus (contains serotonergic neurons) that mainly spinal cord projecting and are involved in respiratory drive; 2) midbrain/pontine regions such as the locus ceruleus (contains noradrenergic neurons), and dorsal raphe nucleus (contains serotonergic neurons) that are mainly forebrain projecting and are involved in arousal and vigilance; 3) hypothalamic regions such as the perifornical hypothalamus (contains orexin neurons) that are involved in arousal and is a panic-generating site in humans (see section 5); and 4) amygdala that is involved in fear associated memory acquisition. The specific types of chemoreceptors that are sensitive to $\mathrm{CO}_{2} / \mathrm{pH}$ are just as diverse [e.g., acid sensing ion channels (ASICs), connexin 26 (Cx26), and Twik related acid sensitive $\mathrm{K}^{+}$(TASK) channels, etc] as is their expression within the brain, and thus are just as controversial. Additionally, the specific chemoreceptors that are critical for fully functional $\mathrm{CO}_{2}$ response (e.g., respiratory, cardiovascular, emotional) most likely require several different chemoreceptor types that have been shown to sense $\mathrm{CO}_{2} / \mathrm{pH}$ to be intact. If uPA's were due to a hypersensitivity to $\mathrm{CO}_{2}$, it is odd that PA's begin to emerge during adolescence (coinciding with cortical development) and not at birth like other $\mathrm{CO}_{2}$ related disorders such as Ondine's curse and sudden infant death syndrome (SIDS). Another consideration is that the apnea episodes associated with Ondine's curse occur at night, and the majority of PA's associated with PD occur during wake periods. Thus, although the collective data suggest that baseline 
respiration activity and hyperactive responses to changes in acid-base disruption are very informative about potential triggers of uPAs, a major flaw in the "false suffocation alarm hypothesis" is that PA responses to these interoceptive triggers range from $40-60 \%$ in most PD subjects, and as discussed in section 4biii, other non- $\mathrm{CO}_{2} / \mathrm{pH}$-related interoceptive stimuli such as $\mathrm{Na}^{+}$also triggers PA's in $88 \%$ of PD patients, which suggests additional interoceptive and exteroceptive factors may be involved, and argues that PA vulnerability in the majority or all of PD patients is not simply a hypersensitivity to $\mathrm{CO}_{2} / \mathrm{pH}$.

Another argument for a cognitive component to $\mathrm{CO}_{2}$-induced PAs comes from a study where healthy college students subjects inhaled air with either 13 or $20 \% \mathrm{CO}_{2}$ eight $20 \mathrm{sec}$ epochs spaced 60-180s apart (Forsyth et al., 2000a) whilst measuring both objective physiological variables (cardiovascular, skin conductance) and subjective psychological variables. Even in healthy subjects, repeated inhalations of $13 \% \mathrm{CO}_{2}$ produced variable cognitive and physical symptoms differences such that clinically recognized subtypes of PA's were present in only $75 \%$ of subjects, including the 'prototypical' fear and physiological symptoms in $\sim 25 \%$, 'cognitive' panic with only subjective psychological symptoms in $\sim 25 \%$, and 'non-panic' attacks where the objective physiological symptoms were present but no fear presented in $\sim 25 \%$. The prototypical and cognitive panic groups rated their symptoms as most severe and had the highest rating of a sense of uncontrollability. It is interesting to note that there was a sex difference such that $77.3 \%$ of the prototypical subtype responders were female whereas $75 \%$ of the non-panic subtype group were male.To attempt to explain the differences in fear and autonomic responses in the healthy subjects, Forsyth and colleagues asked participants to rate their perceived control they had over their bodily sensation produces following the $\mathrm{CO}_{2}$ challenges, and found that the group displaying the most severe panic responses also had the highest rating of a sense of uncontrollability, compared to the group that did not show pronounced panic responses. Thus, a reduced feeling of control of a situation or visceromotor responses in combination with additive changes in diverse internal sensory input that are different in their signaling pathways could create a "perfect storm" for a PA. An example of another interoceptive trigger of PAs is NaLac, which is discussed in section $4 \mathbf{c}$ and is a salt and lactic acid. Although lactate is thought to be the main panicogenic interoceptive cue, there are clinical data showing that sodium is an equally potent a panicogen. Another consideration of a "perfect storm" are subtle changes in interoceptive homeostasis in addition to pre-existing anxiety (non-agoraphobic cue related), and potentially even intake of fluids containing caffeine for instance (discussed in section 5).

\section{4bii. Are $\mathrm{CO}_{2}$-induced PAs due to hyper-sensitivity to $\mathrm{CO} 2$ or hyper-responsive panic system?}

In 1986, Woods and colleagues wanted to assess respiratory responses to hypercapnic gas between 14 medication-free PD subjects with agoraphobia and healthy subjects, to determine if there was an increase in respiratory drive in response to hypercapnia induced by a rebreathing technique. Similar to inhalation of hypercapnic gas, rebreathing induced greater anxiety and nervousness in an Analogue Scale, but there were no differences in their ventilatory responses, upon which they concluded that abnormal $\mathrm{CO}_{2}$-chemoreceptor sensitivity did not explain the increased anxiety-associated behavioral sensitivity PD 
subjects (Woods et al., 1986). An alternative hypothesis is that PAs are a result of a hyperactive panic response system where sensory input (both interoceptive and exteroceptive) converge on. This hypothesis is attractive in that it could explain how divergent sensory input such as interoceptive $\left(\mathrm{CO}_{2}, \mathrm{Na}^{+}\right.$, lactic acidosis), and exteroceptive stimuli (situational cues, stressful events) lead to panic responses.

\section{4biii. Sodium lactate induced PAs}

In 1967, Pitts and McClure noted that during exercise, subjects with anxiety neurosis had developed anxiety symptoms that coincided with a rapid increases in plasma lactic acid (Jones and Mellersh, 1946), and hypothesized that lactic acid may trigger anxiety attacks (Pitts and McClure, 1967). They then recruited subjects that had severe feelings of anxiety on a near daily basis, and 10 of 16 symptoms similar to those used to define PAs now (e.g., fear, palpitations, dyspnea, and parasthesias). Infusing $0.5 \mathrm{M}$ racemic sodium lactate solution (NaLac) elicited anxiety attacks (defined as catastrophic fear with $>5$ physical symptoms) in 13 out of $14(93 \%)$ anxiety neurosis subjects and in 2 out of $10(20 \%)$ healthy controls. The predominant physical symptoms most often reported were paresthesias, tremors, palpitations, dizziness, and dyspnea with tremors; palpitations, and paresthesias were ranked as most severe. A glucose saline infusion failed to induce anxiety attacks in any subject. Later studies using subjects with a now-recognized diagnosis of PD using the DSM-III, also observed that $0.5 \mathrm{M} \mathrm{NaLac}$ challenge elicited PAs in the majority of PD subjects compared to healthy controls or other neuropsychiatric disorders. For instance, administering i.v. infusions of 0.5M NaLac to 24 PD subjects (no controls used) elicited PAs (defined as abrupt fear accompanied by physical symptoms associated with a PA such as palpitations and shortness of breath, and sweating) in 7/10 (70\%) males and 7/14 (50\%) females (Goetz et al., 1989).

Later studies determined that, at baseline, PD subjects (36 men and 40 women) had higher venous $\mathrm{pH}$ and lower $\mathrm{PCO}_{2}$ levels compared to controls (18 men and 4 women) (Gorman et al., 1986) and although $0.5 \mathrm{M} \mathrm{NaLac}$ infusions induced an alkalosis and decreased $\mathrm{PCO}_{2}$ in all groups, there was no group $\mathrm{x}$ time interaction, nor were baseline differences in $\mathrm{pH}$ or $\mathrm{PCO}_{2}$ different between PD subjects that had a PA and those that did not. A subsequent study assessed arterial $\mathrm{pH}$ and $\mathrm{PCO}_{2}$ levels prior to and during a $0.5 \mathrm{M} \mathrm{NaLac}$ challenge to $12 \mathrm{PD}$ and 8 control male subjects determined that only the 5 PD subjects that had a PA (42\%) to NaLac had increased $\mathrm{pH}$ (alkalosis) and decreased $\mathrm{PCO}_{2}$ levels. However, this effect may have been due to an outlier in the scattergram which showed a PD subject that had a PA to NaLac with baseline alkalosis where $\mathrm{pH}>7.45$ (pH 7.55 and $~ \mathrm{PCO} 2$ of 24mm $\mathrm{Hg}$ ). Post-NaLac, only control subjects and PD subjects that did not have a PA were assessed due to cessation of infusion in PD patients that did panic. Consistent with Gorman's findings, NaLac increased $\mathrm{pH}$ and decreased $\mathrm{PCO}_{2}$ levels in both controls and $\mathrm{PD}$ subjects, but they did observe significant group (but not group $\mathrm{x}$ time) effects on $\mathrm{pH}$, and group $\mathrm{x}$ time effects on $\mathrm{PCO}_{2}$ which declined more severely in PD subjects independent of a PA. It is unfortunate that respiratory parameters were not assessed alongside these plasma variables since this may have explained the subtle differences in these studies. Overall, the significant baseline differences between PD and healthy subjects is consistent with higher baseline hyperventilation and rate of sighing as shown in a recent meta-analysis (Grassi et 
al., 2013), but unlike a $\mathrm{CO}_{2}$ challenge in normoxic air, NaLac is a multisensory challenge (e.g, alkalosis, lactate itself, osmotic stress, or potentially even hypernatremia) and the specific sensory trigger or triggers associated with NaLac that provokes the PA is not entirely clear.

Previous clinical studies conducted on Panic Disorder patients suggest that increased sodium, not lactate or osmotic stress, may be the critical change for provoking panic attacks. Peskind and colleagues challenged 8 PD and 7 healthy subjects with i.v. infusions of $0.5 \mathrm{M}$ NaLac, hypertonic sodium chloride $(\mathrm{NaCl})$, or isotonic $\mathrm{NaCl}$, which respectively provoked PAs in 6/8 (75\%), 7/8 (88\%) and 0/8 (0\%) subjects (Peskind et al., 1998), and noted that serum $\mathrm{Na}^{+}$was equivalently increased following $\mathrm{NaLac}$ and hypertonic $\mathrm{NaCl}$. They also noted that even though both produced PAs, only NaLac increased venous $\mathrm{pH}$ and decreased venous $\mathrm{PCO}_{2}$ concentrations, which suggests $\mathrm{Na}^{+}$may be panicogen. Additionally NaLac and hypertonic $\mathrm{NaCl}$ both increased arginine vasopressin, but hypertonic (3\%) $\mathrm{NaCl}$ caused a greater increase. Sodium bicarbonate (Gorman et al., 1989) provoked equivalent panicassociated responses in Panic Disorder patients. Furthermore, 11 of 20 PD subjects (65\%) were more likely to experience a PA in response to lactate dissolved in $0.9 \% \mathrm{NaCl}$ versus lactate dissolved in 5\%dextrose, which induced a PA in 4 of 20 PD subjects (20\%) (George et al., 1995).

Overall, most evidence suggests that various interoceptive triggers such as lactate, sodium, $\mathrm{CO}_{2}$, etc. are capable of triggering PAs, but the response rate may depend on additional factors such as the anxiety state of the individual, cognitive coping skills, and the environment (e.g., agoraphobic situation). Yet another consideration is how much of the PA vulnerability to interoceptive challenges is attributed to environmental factors such as an occupation associated with higher stress. For instance, in healthy subjects, NaLac induces a PA in $\sim 0-20 \%$ of the time, but higher anxiety states or cognitive bias in healthy control subjects in the absence of a diagnosis of PD or any other history of neuropsychiatric problems also appears to increase the likelihood of PAs in response to interoceptive stimuli such as NaLac. Yeragani and colleagues recruited 41 healthy subjects that consisted of medical and paramedical personnel, and informed them that the infusion they would receive may provoke a PAs if a person had a history of previous PAs (Yeragani et al., 1987). They found that a higher $1 \mathrm{M} \mathrm{NaLac}$ solution dissolved in 5\% glucose induced a PAs in 5/23 (22\%) males and 5/18 (28\%) females, and noted that the responders had higher panic symptoms measured with a panic description scale (PDS), than non-responders. The common panic symptoms rated most severe were catastrophic fear and shortness of breath.

\section{4biv. Sense of control on $\mathrm{CO}_{2}$ and NaLac-induced PAs in PD subjects}

In healthy control subjects, heightened self-reported fear responses to 20 seconds of $20 \%$ $\mathrm{CO}_{2}$ inhalation is a strong predictor of the later development of spontaneous panic attacks (Schmidt and Zvolensky, 2007). Finally, healthy controls also show habituated autonomic and self-reported anxiety across sessions, but not within session, after repeated inhalation of air containing $20 \% \mathrm{CO}_{2}$ (Forsyth et al., 2000a), suggesting that these sessions could be used to stabilize existing heightened anxiety sensitivity to changes in acid-base homeostasis that may occur from altered breathing during stress. Conversely, pairing a threatening 
exteroceptive visual cue (i.e., snake photo), but not a neutral exteroceptive cue (i.e., flower photo) with a $20 \% \mathrm{CO}_{2}$ exposure (unconditioned stimuli) leads to exacerbated autonomic responses and self-reports of anxiety in humans (Forsyth and Eifert, 1998). Thus, heightened anxiety sensitivity to interoceptive stimuli could lead to phobic avoidance responses depending on whether or not the environmental context was threatening (e.g., crowded room or heavy traffic) during mild acid-base disruption such as occurs during irregular breathing.

In PD subjects, the illusion of control over a panicogenic interoceptive challenge appears to alter the degree of anxiety response and potentially catastrophic cognitive fear symptoms. For instance, Sanderson and colleagues exposed $20 \mathrm{PD}$ subjects to $15 \mathrm{~min}$ of $5.5 \% \mathrm{CO}_{2}$ in normoxic air. The subjects were told that if a light came on they could turn a dial and decrease the amount of $\mathrm{CO}_{2}$ they would receive. The light turned on for the duration of $\mathrm{CO}_{2}$ challenge for half of the subjects and never turned on for the other half. They were not told the dial would not actually decrease the $\mathrm{CO}_{2}$ flow. Compared to PD subjects that had an illusion of control, PD subjects that thought they could not control the $\mathrm{CO}_{2}$ flow rate reported more DSM-III panic symptoms, greater perceived anxiety, and rated that the event was more like a naturally occurring PA (Sanderson et al., 1988).

\section{4c. Expected panic attacks: exteroceptive triggers and agoraphobia}

Expected PAs differ from uPAs in that there is an external cue (e.g., situation where uPAs have occurred, or during stressful situations) that is associated with the induction of the PA (Shulman et al., 1994). As mentioned in uPA section, 53\% of naturally-occurring PAs occur in relatively non-threatening situations, but the remaining PAs occur in more stressful situations such as work (5\%) or driving (11\%), and the remaining $31 \%$ of PAs occur in typical agoraphobic situations (i.e., $13 \%$ shops, $9 \%$ in street, $6 \%$ restaurants, and $3 \%$ in public transportation) (de Beurs et al., 1994). Woods and colleagues exposed 18 medicationfree PD subjects with agoraphobia and paired 13 healthy subjects (most cases) to typical agoraphobic situations (e.g., parks, malls, restaurants, and bridges) and assessed subjective anxiety and physical symptoms and measured heart rate and blood pressure prior to and after exposure. They determined that PD subjects had higher anxiety, fear, and nervousness symptoms at baseline and greater physical symptoms such as palpitations, parasthesias, dyspnea (Woods et al., 1987). Post-exposure, 13 of 18 PD subjects reported having a PA while no PAs were reported in healthy subjects. Thus, if uPAs are the initial type of PA in $\mathrm{PD}$, these could eventually become associated with contextual environmental cues where previous PAs have occurred, such as bridges, crowded spaces, or situations where rapid exit is difficult (Wilson and Hayward, 2005). This development of cognitive bias towards threat perception (McNally et al., 1990) and conditioning of fear responses to panic cues (van den Heuvel et al., 2005) could then lead to phobias which are the likely mechanisms underlying recurrent ePAs in later stages of the illness.

From a treatment perspective, the gold standard for assessing the effectiveness of a treatment for PD is its ability to reduce the frequency and severity of PAs, but another important factor that should be considered is avoidance behaviors associated with PD subjects that develop in agoraphobia [see Contextual Learning Section from (Gorman et al., 
2000)]. Thus, an ideal medication and/or cognitive behavioral therapy (CBT) that reduces the frequency and severity of PAswould ideally also reduce phobic avoidance.

\section{4d. Sympathetic, parasympathetic, and endocrine responses during adaptive panic}

During a normal adaptive panic response, imminent threats elicit strong emotional responses that coincide with somatic motor responses (e.g, fight or flight), but also robust autonomic responses where key panic-generating brain regions (e.g., the PeF and DPAG which are discussed in detail in sections 5 and 7) increase blood pressure and heart rate, initiate heat dissipation (sweating and increased blood flow to skin), and suppress gastrointestinal activity. In order for the sympathetic nervous system to simultaneously induce a pressor and tachycardia response, the baroreflex (which is driven by the rise in blood pressure and initiates vagally-mediated, parasympathetic bradycardia) needs to be desensitized [see review (McDowall et al., 2006)]. Among the panic-generating brain regions, the PeF and DPAG are both capable of doing this. Most sympathetic responses occur from postganglionic release of norepinephrine directly onto target systems (e.g., heart and blood vessels), but in some cases epinephrine (and to a lesser extent norepinephrine) can also be released as a hormone into the blood stream to reach targets. In addition, there may be a hypothalamic-pituitary-adrenal (HPA) axis stress endocrine response where cortisol is released into the bloodstream to mobilize energy resources and suppress the immune system, especially if the threat is persistent. However, most PAs occur rapidly enough, or a PA immediately evokes an escape response such that HPA activation may not be engaged routinely during a recurrent PAs. Yet, even under normal conditions, not all stress-related stimuli initiate the same type of panic response, and in many instances interoceptive stressors do not seem to consistently initiate a significant HPA axis response. It has also been hypothesized that sense of 'novelty' of the stress may also contribute strongly to HPA responses during a PA (Abelson et al., 2007). Thus, understanding the hormonal responses during the initial uPAs is another major gap in the field.

\section{4di. Autonomic and endocrine responses during natural PAs and ePAs}

During a PA, the physical symptoms most often reported are related to cardiovascular, thermoregulatory, and gastrointestinal disturbances, as well as paresthesias. As discussed in section 2, amongst the self-reported somatic symptoms associated with PAs, heart-related symptoms are the most common during a PA [e.g., heart pounding $97 \%$, tachycardia $86.1 \%$, palpitations 78\%] (Craske et al., 2010). However, as discussed in section 2, the few studies that used objective measures of ambulatory cardiovascular activity surrounding natural PAs show a lower incidence of events such as tachycardia that occur in 38\% (Barr Taylor et al., 1982) to 58\% (Taylor et al., 1986) of PAs. In the Magraf study, tachycardia did not occur in uPAs, but preceded ePAs (Margraf et al., 1987). Panic attacks clearly consist of physical symptoms associated with autonomic events. Yet, in some cases the autonomic response precedes the self-reported onset of the PA and arguably contributes to the PA, and/or occurs during the subjective experience of the PA (Margraf et al., 1987; Meuret et al., 2005). The majority of the physical symptoms are strongly associated with visceromotor or autonomic systems, which are comprised of the sympathetic and parasympathetic nervous system. However, the evidence for sympathetic and/or parasympathetic involvement in cardiovascular events during PAs (when present) are mixed, and in many instances the 
specific results are not reproducible, which, as we will discuss, may reflect the complexity of the underlying causes of PAs (e.g,. genetic vulnerability and environment interactions).

There have been many studies that have objectively assessed autonomic responses by assessing cardiovascular and thermoregulatory activity in response to interoceptive or pharmacological challenges, but here we will review studies that assessed the sympathetic and parasympathetic activity using plasma assays prior to and during a PA, as well as utilizing accepted autonomic tests such as orthostatic tilt table tests and the Valsalva maneuver. The advantages of using standardized autonomic tests, such as postural orthostatic challenges, is that these are physiologically relevant, naturalistic, and fairly benign tests, compared to interoceptive or pharmacological challenges which can be stressful and assumes a priori that the stimuli or target is relevant to natural PAs. Some of the reviewed studies also assessed the stress hormone cortisol.

There have been few studies that have assessed neuroendocrine responses during naturally occurring PAs. A small study by Cameron and colleagues measured multiple plasma variables prior to and during 9 naturally occurring PAs (where one patient had one panic attack, two patients had two attacks each, and one patient had four attacks), and did not see any overall significant changes over time in norepinephrine, epinephrine, or norepinephrine metabolite MHPG, but there was also no significant change in heart rate or diastolic or systolic blood pressure. In individual assessments of cardiovascular activity during each PA, they noted high variability in data where heart rate increased in only 5 PAs, and blood pressure primarily rose during PAs, but decreased in others. They subjectively reported that norepinephrine consistently went up in 2 subjects during the 2 PAs they had, and was increased in another PA, but did not change in the others. There was a consistent lack of response of epinephrine in all cases. Cortisol appeared to increase in 7 PAs.

In order to get a more direct measure of sympathetic tone, direct nerve recordings of muscle sympathetic nerve activity in combination with plasma norepinephrine and epinephrine were done on 13 PD subjects and 14 healthy controls at baseline, and during a PA in 4 PD subjects (Wilkinson et al., 1998). They did not observe differences in sympathetic nerve activity, or total and cardiac plasma norepinephrine, and total epinephrine spillover rate at baseline, but did find increased anxiety symptoms in PD subjects prior to testing, as well as increased cardiac plasma epinephrine spillover. During the PA, the PD subject's heart rate increased by $27 \%$, and mean blood pressure also increased by $7.2 \%$. Two of the four patients had large increases in sympathetic nerve activity during PAs, with no change in the two patients that has less intense PAs. During the 3 PAs where arterial plasma was collected, epinephrine total and spillover was respectively increased by $\sim 35-67 \%$ and $\sim 44-70 \%$ in all 3 PD subjects following a PA. Norepinephrine total and spillover was respectively increased by $\sim 5-7 \%$ and $\sim 6-28 \%$ the 3 PD subjects following a PA.

The nature of the PA may also be relevant to the autonomic and endocrine response. In the previously discussed studies, it is not clear if the PAs assessed were completely uPAs or in some cases ePAs, but another study provoked ePAs in agoraphobic PD subjects by exposing them to agoraphobic situations. In this previously-mentioned Woods study in 1987, they exposed healthy and agoraphobic PD subjects to typical agoraphobic situations which 
induced PAs in 13 out of 18 PD subjects, and no PAs in healthy subjects (Woods et al., 1987). Assessments of autonomic and endocrine responses revealed that, post-exposure, both PD and healthy subjects had an increase in heart rate, but this response was greater in PD subjects. Although there was no difference in blood pressure responses post exposure in PD and healthy subjects, the PD subjects had higher systolic blood pressure at baseline and during pre-exposure. Exposing PD, but not healthy subjects to phobic situations increased cortisol, but the authors stated that there was only a trend for a between-subjects comparison and so concluded that the hypothalamic-pituitary-adrenal (HPA) axis response was not exacerbated in PD subject in agoraphobic situations. They also assessed norepinephrine activity by measuring MHPG, but did not see a baseline difference or a change postexposure.

\section{4dii. Autonomic and endocrine responses in PD subjects during vasculomotor testing}

A number of studies have examined orthostatic challenge with PD patients in an attempt to elucidate autonomic nervous system disturbances in this condition. This section is not meant to be a comprehensive meta-analysis of these findings, but rather highlight the inconsistencies in results and challenges in assessing autonomic and endocrine activity in PD. One common way of assessing the integrity of the autonomic nervous system (ANS) is through an orthostatic challenge, which employs a postural change from lying supine to being raised vertically (head-up). This can be done passively (motorized table) or by having the patient lie down and then stand on his/her own volition (after achieving a stable baseline). Continuous monitoring of blood pressure, heart rate, heart rate variability, and catecholamine levels permits a thorough assessment of the ANS, and other measures, such as anxiety instruments, can be used as well.

In a study of orthostatic challenge and the Valsalva maneuver, Weissman and colleagues compared 17 healthy control subjects to 20 patients experiencing PAs, and in pretesting determined that patients with PA had notably higher symptoms of anxiety. Following 20 min of supine rest they found that there were no baseline differences in heart rate or resting blood pressure. However, patients with PD had greater increases in heart rate, mean blood pressure, and cardiac output index (product of the heart rate and mean arterial blood pressure), during each minute of quiet standing, and during the early phase of the Valsalva maneuver, which increases positive intrathoracic pressure stress (Weissman et al., 1987), which they conclude is suggestive of hyperactive sympathetic responses. They did not report if PAs occurred during the autonomic testing, but did make a note that they maintained a calm, quiet environment prior to and during testing. Yeragani and colleagues examined 30 PD patients and 30 healthy controls, and after 10 min of supine rest found higher diastolic $\mathrm{BP}$, higher HR responses to standing, and higher cardiac output in PD subjects (primarily female PD) (Yeragani et al., 1990). No patients experienced a PA during the study procedures. In a study by Stein and colleagues, 20 PD subjects and 20 age- and sex-matched healthy subjects performed voluntary orthostasis; they werereminded of benign nature of procedure and remained supine for 30 minbefore standing for $5 \mathrm{~min}$ with arms at their sides (Stein et al., 1992). Baseline anxiety symptoms were higher in PD subjects, but no difference in baseline HR or MAP was detected. However, PD subjects had a greater increase in HR in response to the orthostatic challenge. In a different subgroup, they did not 
observe differences in sympathetic NE responses to postural change, but acknowledge that plasma norepinephrine levels may poorly reflect sympathetic activity (Folkow et al., 1983; Goldstein, 1983). Coupland and colleagues assessed BP and HR in 56 sex-matched PD subjects and 56 healthy controls, where they observed a higher dBP and sBP response in PD subjects when standing, but no difference in HR response, which they conclude supports an increase in sympathetic reactivity in PD subjects (Coupland et al., 2003). Stein \& Asmundson noted that previous studies had not controlled for physical fitness, so they controlled for fitness, and examined 24 medication-free PD patients, of which $71 \%$ were agoraphobic, and 26 healthy controls in a number of autonomic challenges, including postural shift, isometric handgrip, Valsalva test, and cold pressor test (Stein and Asmundson, 1994). PD subjects did have increased anxiety symptoms, but failed to have differential cardiovascular responses to the autonomic tests. Plasma norepinephrine response also did not differ. However, the small subject numbers in some of these studies and the multiple comparisons being done make some of these findings insufficiently powered to test the validity of the differences or lack of effects noted by them.

Martinez and coworkers asked 30 PD subjects (18 with agoraphobia) and 10 healthy controls (age and sex matched) to rest supine for $10 \mathrm{~min}$ at which time they were tilted to a 60 degree angle for $15 \mathrm{~min}$, which is differs from voluntary standing procedures (Martinez et al., 2010). Ten min into the test, subjects were asked to control their breathing at a rate of 15 breaths/min for 5 min to minimize the effects of breathing on HR and BP. At baseline they observed higher HR, lower HRV, and higher dBP in PD subjects whom also had increased anxiety symptom (not assessed in controls). PD symptom severity in the Panic Disorder Symptom Severity Instrument test was also associated with higher baseline HR. Unlike studies mentioned previously, the tilt procedure increased anxiety symptoms in the PD group, which was highest in the agoraphobic subgroup. The tilt procedure also increased HR higher in the PD group. Additionally, the tilt procedure induced PAs in 23\% of PD patients and no controls. Symptoms reported included $\sim 75-85 \%$ reporting feeling faint and short of breath, and $\sim 50 \%$ feeling afraid. Controlled breathing produced higher HR responses in the PD group.

The contradictory data in the previously mentioned studies could be due to many of the PD subjects that were assessed having been diagnosed with PD for 5-8 years. In an effort to assess autonomic tone closer to the diagnosis of $\mathrm{PD}$, Ito and colleagues analyzed autonomic activity during a tilt table test among 8 newly diagnosed medication free, age-, and sexmatched PD patients with a 6.6 month mean duration of illness and 11 PAs/month, whom they compared to 13 age- and sex-matched healthy controls (Ito et al., 1999). Subjects were all of the same physical fitness. Following $>30$ min of supine rest and with controlled breathing of 15 breaths/min, the motorized table was tilted to $70^{\circ}$ for 5 min which did not induce a PA in any subject. There were no differences in HR or HRV at baseline, nor was there a difference in HR response to tilt. However, during the tilt, HRV analyses revealed that low frequency and high frequency were both higher in PD subjects (suggestive of increases in sympathetic and parasympathetic tone), but there was no difference in overall sympathovagal balance (low frequency and high frequency ratio). Additionally, although PD subjects had increased anxiety symptoms none of these symptoms correlated with physiological variables. Their results suggest that, at least in early stages of PD, co- 
activation of both branches of the autonomic nervous system may be occurring, which may differ from ANS differences observed in panic patients with more severe/longer courses of illness.

\section{4diii. Concluding remarks on autonomic and endocrine responses in PD}

Collectively, the results of these studies are mixed, with some showing no differences in autonomic activity at baseline or during challenges, but more do observe some evidence of parasympathetic withdrawal, sympathetic hyperactivity, or a combination of the two at baseline and more evidence of disruption during autonomic testing. The inconsistencies in these results are not surprising given the complications associated with PD which are difficult to control for (e.g, duration of illness, sex and age, physical fitness, previous and current medications, and comorbidities). PD subjects have a fairly consistent increase in baseline anxiety compared to healthy subjects that can also impact the testing, and there are limitations in certain autonomic assessments such as using plasma norepinephrine as a indices of sympathetic activity.

Given the heterogeneity of the physical symptoms that occur during a the majority of documented PAs associated with the PD diagnosis, and the variability in the timing of objective measures associated with the physical symptoms, it is unlikely that the etiology of PAs is associated with a direct disturbance in the peripheral nervous system. Yet, some conditions associated with clear autonomic disruptions are associated with an increase in the prevalence of PAs and PD. For instance, the incidence of PAs and PD was assessed in normotensive and hypertensive age- and gender-matched patients from one primary care practice. Prevalence of PAs during the last 6 months and in a patient's lifetime was respectively $\sim 11 \%$ and $\sim 22 \%$ for normotensive patients and $\sim 18 \%$ and $\sim 35 \%$ for hypertensive patients, which was significantly higher (Davies et al., 1999). Diagnosis of PD was $\sim 7 \%$ in normotensive patients and $\sim 12.5 \%$ in hypertensive patients. It is not clear if the autonomic disruption led to the PAs and PD, since half the hypertensive patients recalled that the diagnosis of hypertension preceded PA while the other half said the PAs preceded or coincided with the hypertension. The hypertensive patients also had higher anxiety symptoms which may or may not have been present prior to the hypertension. Many of the studies discussed here assessed sympathetic activity in PD and during PAs with plasma assays for norepinephrine and epinephrine, which should be interpreted with caution. The hypertension condition is a persistent increase in blood pressure that is typically associated with increased plasma norepinephrine, which suggests that there is a hyperactive sympathetic nervous system (Goldstein et al., 1983). Yet this is controversial, as is the accuracy of plasma norepinephrine assays in assessing sympathetic activity since most of norepinephrine's effects on target tissues is from postganglionic terminal release at specific targets (Folkow et al., 1983; Goldstein, 1983).

As mentioned in section 2, results from objective measures of cardiovascular activity preceding and during a PA vary, with events such as tachycardia occurring prior to or during the PA, or not at all. In 1986, Clark and colleagues hypothesized that PAs are a catastrophic cognitive misinterpretation of bodily sensations that could include cardiovascular events (Clark, 1986). Some supportive evidence for this comes from a study in 1990, where Balon 
and colleagues i.v. administered $20 \mu \mathrm{g}$ of the non-selective $\beta$-adrenergic agonist isoproterenol to 78 PD subjects and 45 healthy controls which induced PAs in 54 (69\%) PD subjects and no controls (Balon et al., 1990). In patients that panicked to isoproterenol, shortness of breath and fear of going crazy were significantly increased compared to non-panicking patients. In the non-panicking PD group there were more significant reports of fear, pounding heart, and light headedness, and trembling compared to controls. Interestingly, females were more represented among panicking patients, but the study was not sufficiently designed to test for any cognitive patterns that were sex-specific. As the authors state, it is possible that an additional, non-cognitive component may account for some of the symptoms elicited by isoproterenol, so caution should be taken in this study's interepretation, as the infusion rate was significantly different for panicking patients compared to the other groups.

Overall, for the majority of documented PAs associated with the PD diagnosis, the conflicting data on an underlying disruption of autonomic and endocrine tone presented in this section only further supports the complexity and heterogeneity of the physical symptoms associated with PAs. Overall, autonomic disturbances are clearly associated with PAs, but the diverse interactions between genes, environment, development, and comorbidities may lead to unique presentations of cognitive and physical symptoms. In the subsequent section discussing neural circuits associated with PD and PA vulnerability, an ongoing question is whether or not physical symptoms associated with autonomic disruption in PAs can be attributed to pathology associated with one or more of the following: 1) disruption of critical autonomic regulating brainstem regions and/or peripheral nervous system; 2) disruption at panic-generating brain regions such as the PeF, DPAG or amygdala; or 3) loss of cortical inhibition of panic-generating brain regions and brainstem regions involved in autonomic regulation. In defense of the latter explanation, there is evidence that an interplay between genes, environment and development may lead to loss of medial prefrontal cortical inhibition of panic-generating brain regions (e.g, PeF, DPAG, and/or amygdala) resulting in hyper-reactivity of panic-generating brain regions to visceral interoceptive signals being routed through the insula, and may lead to subsequent overgeneralization of fear reactions to aversive signals. This can lead to anticipatory anxiety and ePAs, as well as avoidance of situations associated with previous PAs (i.e, agoraphobia).

\section{Section 5 - Neural Circuits Implicated in Adaptive Panic, and Recurrent Pathological PAs in PD}

\section{5a. Neural circuits implicated in PAs in PD}

Currently, the neuroanatomical circuits underlying the initial vulnerability to PAs or even subsequent repeated PAs in humans are poorly understood. A recent meta-analysis by Dresler and colleagues assessed structural (computed tomography, CT; and magnetic resonance imaging, MRI; Voxel-based morphometry, VBM) and functional (functional MRI; and near infrared spectroscopy) imaging studies in PD subjects (Dresler et al., 2013). In this meta-analysis they acknowledged that functional imaging studies in particular are inherently difficult when studying anxiety disorders such as PD due to previous pharmacological or psychological treatments, and higher baseline anxiety which in many 
cases leads to altered respiration. This alteration may cause hypo or hypercapnia, which induced vasoconstriction or vasodilation, respectively, of blood vessels, which confounds imaging methodologies dependent on cerebral blood flow. These approaches also require the subject to be in a small, confined area where a rapid escape would be difficult, which is a situation associated with agoraphobia and a common trigger of ePAs. As discussed in detail in section 6 and 7, another hurdle is that many panicogenic brain regions and neurochemical systems implicated in PAs in humans and adaptive panic responses in rodents are located in small nuclei in structures such as the hypothalamus and brainstem, and the high vascularization of the former makes these areas difficult to assess. Even less is known about brain activity during naturally-occurring PAs which are hard to assess due to their unpredictable onset in many cases. Although caution should be taken in interpreting the results, functional brain activity has been assessed at baseline, during naturally occurring PAs (a few case studies), and following panicogenic stimuli (e.g., $\mathrm{CO}_{2}, \mathrm{NaLac}$, or pharmacological challenges discussed in section 6) and do provide insight into brain regions showing hypo and hyperactivity in PD subjects. In the subsequent sections we will discuss evidence for structural and functional imaging abnormalities in PD subjects.

\section{5bi. Prefrontal cortex: evidence of hypoactivity in PD patients}

Dresler and colleague initially assessed evidence for structural abnormalities and summarized that PD subjects had fairly consistent reduced volumes in the temporal lobe (Asami et al., 2009; Lai et al., 2010; Sobanski et al., 2010), and limbic structures such as the amygdala (Massana et al., 2003; Hayano et al., 2009; Lai et al., 2010), but also in frontal cortical areas (Protopopescu et al., 2006; Asami et al., 2009; Lai et al., 2010). In functional imaging studies, resting state findings in PD have very mixed results (Dresler et al., 2013). In one study, regional Cerebral Blood Flow (rCBF) in frontal cortical areas was generally lower in the 22 medication-free PD subjects compared to 19 healthy controls (Eren et al., 2003). However, respiration and $\mathrm{pCO}_{2}$ levels were not controlled for, and the differences could be due to such global cerebral blood flow changes. Another resting state study noted that, compared to 22 healthy controls, 12 medication-free PD subjects with higher baseline anxiety had increased glucose uptake in the bilateral amygdala and brainstem indicating hyperactivity that could be a result of loss of frontal cortical inhibition (Sakai et al., 2005). The reduced volumes in frontal cortical regions could be related to aberrant cortical growth and remodeling that occurs during adolescence (see section 3b, and Figure 2b), which could lead to blunted frontal cortical inhibition of fear and panic-generating sites such as the amygdala, perifornical hypothalamus, and dorsal periaqueductal gray (discussed in subsequent sections). Another consideration is that during adolescence a negative synchronization between the mPFC and amygdala occurs; early life stress appear to accelerate this synchronization; and the efficiency of this negative synchronization is associated with reduced anxiety (Gee et al., 2013a). The consequences of hypoactivity in the prefrontal cortex may also explain the tendency of patients with PD to misinterpret bodily sensations as being dangerous or catastrophic during or preceding a PA and have disrupted perception of control that can predispose them to ePAs and agoraphobia [see review (Austin and Richards, 2001)]. In a meta-analysis by Bar-Haim and colleagues they found that, compared to healthy controls, patients with anxiety disorders (including PD) generally tend to interpret non-threatening cues as threatening (Bar-Haim et al., 2007). Yet it is important 
to note that presence of catastrophic cognitions (e.g., catastrophic fear of dying and/or losing control) is not critical for a diagnosis of PD, and these 2 cognitive symptoms are heavily outweighed by the 11 physical symptoms for a diagnosis of $\mathrm{PD}$, which requires 4 of the total 13 symptoms be present. This may explain why studies that have assessed attentional and interpretational biases in PD patient (some of which could qualify as having no fear PAs or no agoraphobia) have had inconsistent results (McNally et al., 1990; McNally and Lukach, 1992; McNally et al., 1992; McNally et al., 1994; Lundh et al., 1999; De Cort et al., 2008). Regardless, there is evidence that catastrophic misinterpretations of bodily sensation and disrupted perception of control can predict PA severity in patients with PD (159 included in study) with or without comorbid agoraphobia (Casey et al., 2004).

Although the amygdala has been shown to be critical for acquisition of fear memories following a traumatic experience, there is evidence that the mPFC plays a critical role in developing coping strategies, and in safety learning (e.g., extinction of fear and retention of extinction) following traumatic experiences that have occurred previously, but that are no longer a threat. For instance, humans with focal lesions of the amygdala (Bechara et al., 1995; LaBar et al., 1995) have impaired acquisition of fear, and fMRI studies have shown that amygdala activity increases during acquisition of fear (Knight et al., 2005), but mPFC activity increases during extinction of fear (Phelps et al., 2004). Furthermore, mPFC thickness is positively correlated with sustained extinction (Milad et al., 2005; Rauch et al., 2005). Overall, this is further support that reduced mPFC activity that is associated with PD could contribute to ePAs, and agoraphobia, but other evidence also suggests reduced mPFC activity could also lead to poor coping strategies. In 2008, Goldin and colleagues showed that exposing women to aversive films (compared to neutral films) increased negative responses and enhanced mPFC, insula and amygdala activity. However, during reappraisal of the negative experience their negative reaction was reduced, which was associated with enhanced mPFC activity, and decreased insula and amygdala activity (Goldin et al., 2008). An important aspect of reappraisal of a negative experience is determining optimal coping strategies, and the ability to control fear responses. Reappraisal is also a critical component of CBTs which are discussed in the following section and if reappraisal methods enhance mPFC activity this could explain the efficacy of CBTs in treating PD and agoraphobia.

\section{5bii. Prefrontal cortex: potential site of efficacy for CBT \& rTMS in treating PAs}

Although psychological therapies such as cognitive behavioral therapy (CBT) are considered the gold standard for treating anxiety disorders, the efficacy of psychological therapies in randomized control trials and effectiveness in real life situation is dependent on several important factors. Specifically, psychological therapies that include CBT, exposure therapy (ET), and relaxation breathing therapies (RBT) have differing results depending on the type of anxiety disorder; the type of psychological therapies used; and if this psychological therapy is used in combination with an additional psychological therapy or in combination with pharmacotherapy (Mitte, 2005; Ost, 2008; Sanchez-Meca et al., 2010; Otte, 2011; Hofmann et al., 2012b; Hofmann et al., 2012a). In regards to the efficacy of psychological therapies on different anxiety disorders, CBT is efficacious in treating PD, but is more efficacious in patients with acute stress disorder or PTSD (Otte, 2011). The type of psychological therapy is also important, as is the combination of them for treating anxiety 
disorders. In 2010, Sanchez-Meca and colleagues conducted a meta-analysis of 65 studies to determine the efficacy and usage of different psychological therapies and combinations of those therapies for treating PD and agoraphobia. This meta-analysis revealed that exposure therapy (ET) was most widely used (55/65 studies with in vivo exposure being most prevalent), following by cognitive behavioral therapy (CBT) (46/65 studies), and relaxation breathing therapies (RBT) (30/65 studies) and in some studies these were done in combination with eachother. For panic symptoms, the most efficacious treatment was a combination of ET+RBT, followed by ET alone or in combination with the other therapies. For agoraphobia symptoms, no single methods was effective, only combinations of these therapies were effective with CBT+RBT's being most effective and other combinations being equivalently effective. Others have compared the efficacy of psychological therapy to pharmacotherapy, and have determined that psychological therapies such as CBT were at least as effective as pharamacotherapies such as TCAs, SSRIs, and benzodiazepines (Mitte, 2005), and there is evidence that the combination of the psychological therapies and pharmacotherapy may be even more efficacious (Hofmann et al., 2009; Otto et al., 2010; Hofmann et al., 2012a). Although psychological therapies engage multiple exteroceptive sensory brain regions sites such as the primary visual cortex, there is evidence that the mPFC may be a critical relay site for efficacy of psychological therapies. One PET study that assessed glucose utilization in PD patients prior to and after successful reductions of panic symptoms post CBT found enhanced activity in the MPFC and decreased activity in the limbic system and brainstem (Sakai et al., 2006). Another study using PET to assess glucose utilization post CBT saw similar increases in PFC activity (Prasko et al., 2004).

\section{5c. Insula as a critical site for sensing and relaying interoceptive cues}

Functional imaging preceding and during a PA is limited to a few case studies that have complicated comorbid diagnoses and, in some cases, were not medication-free. However, the imaging that has been done does provide potential insight into neural circuits relevant to PAs. In one case study, a PA occurred in a subject with specific phobia during the fMRI after they saw a sad face and worried about what they may see next (Dresler et al., 2011). The subject aborted the fMRI once the PA occurred, but an analysis done on the data gathered up to the PA revealed significant increases in activity in the insula that was associated with feelings of discomfort then a subsequent increase in activity in the right amygdala just prior to the PA and discontinuation of the fMRI. In another case study, a female subject with PD treated with escitalopram and CBT was free of apparent anxiety prior to fMRI, but during the fMRI began to develop PA symptoms (i.e., anxiety, sweating, tremor, difficulty breathing, as well as objectively measured tachycardia) followed by more intense hot flashes, dizziness, and palpitations which lasted for 3-5 min (Pfleiderer et al., 2007). In this case, an increase in activity was observed in the left insula during the initial onset of anxiety, followed by increased activity in the right amygdala during the PA. There are also functional studies of PD where a panicogenic challenge was administered. In studies using NaLac, there does appear to be a fairly consistent increase in glucose metabolism and rCBF in the insula in most cases [(Reiman et al., 1989; Dager et al., 1994; Dager et al., 1997) and no effect in other cases (Layton et al., 2001)], and also with a surprising lack of effect within the amygdala and temporal lobe in these studies. As reviewed by Dresler and colleagues, and Shin and Liberzon, panicogenic stimuli such as NaLac, and hyperventilation 
do tend to increase activity in the insula but do not alter activity within the amygdala [see reviews by (Shin and Liberzon, 2010; Dresler et al., 2013).

The significance of insula activation prior to a PA, or following interoceptive challenges, and its activity correlating with feeling queasy and uncomfortable prior to a PA (Dresler et al., 2011) is that the insula is hypothesized to be the primary viscerosensory or interoceptive relay center in the brain [see Figure 2, and review (Palkovits, 2010)]. This ongoing hypothesis is based on the insula's high responsivity to a variety of interoceptive cues, such as restricted breathing (von Leupoldt et al., 2008), bladder distension (Matsuura et al., 2002), and temperature changes (Craig et al., 2000). In a fMRI study, Critchley and colleagues found that increased activity in the right anterior insula predicted the subject's accuracy for detecting his/her heartbeat, which was used to assess visceral awareness (Critchley et al., 2004). Thus, viscerosensory-related stimuli, such as a change in arterial $\mathrm{PCO}_{2}$ levels or a change in cardiovascular activity, would most likely be routed through the insula, where the signal is passed on to emotional and autonomic centers, which collectively produce an awareness of physical symptoms associated with PAs such as feeling short of breath or a pounding or racing heart. The perception of these events can vary greatly depending on the emotional and physical state of the person. A feeling of breathlessness or a strong change in cardiovascular activity during exercise would be perceived as normal, but in other situations these sensations may be perceived as abnormal, and interpreted as something being wrong with the body's internal state. Spiegelhalder and colleagues have argued that the relevance of the insula activity increasing prior to a PA, is to act as an "internal alarm" to relay potentially life-threatening interoceptive stimuli to emotional and autonomic brain regions (Spiegelhalder et al., 2009), which, depending on the emotional state of the person, could produce a variety of emotional reactions. Subjects with PD may be predisposed to perceiving interoceptive stimuli as being negative or aversive since baseline levels of anxiety are higher in PD subjects. Further discussion of the significance of the insula and connections to panic-generating brain regions will be made in section 7 , where animal research related to panic is discussed.

\section{5d. The amygdala's role in uPAs and ePAs}

As discussed in sections $5 \mathrm{a}-\mathrm{b}$, following spontaneous PAs and laboratory induced PAs using $\mathrm{CO}_{2}$ or NaLac, there is an inconsistent increase in activity in the amygdala surrounding the PA event. This is surprising since the amygdala has been shown to play a critical role in learning and memory associated with fearful events in humans, and has been extensively characterized in preclinical rodent studies which are discussed in section 7. For instance, subjects with bilateral calcification/atrophy of the amygdala (due to a rare genetic condition called Urbach-Wiethe disease) have impaired recognition and recall of fearful faces (Adolphs et al., 1994; Adolphs et al., 1995)(see Figure 3). Deep brain stimulation of the amygdala region leads to a variety of emotional symptoms that are aversive in some cases (e.g., fear, depression, anger), but can also be associated with positive emotional states (e.g,. euphoria and laughter) (Penfield, 1952; Chapman et al., 1957; Van Buren, 1961). In some instances, these studies also observed physical symptoms associated with PAs such as pounding heart, and hot flashes and sweating. Additionally, some subjects reported remembering past events with emotional valence. In a more recent study, Meletti and 
colleagues determined that deep brain stimulation of the medial temporal lobe in 74 subjects tested on 79 emotional responses, $85 \%$ were associated with fear, $11 \%$ were pleasant, and $4 \%$ elicited a sad response (Meletti et al., 2006). They also noted that fear responses in women were more common than men. In light of the amygdala's role in emotional responses, Feinstein and colleagues hypothesized that subjects with Urbach-Weithe disease would have reduced panic symptoms following exposure to inhalation of $35 \% \mathrm{CO}_{2}$ (Feinstein et al., 2013). Surprisingly, the $\mathrm{CO}_{2}$-evoked fearalso induced symptoms associated with PAs in the three patients with bilateral amygdala damage. In this particular study, an aversive interoceptive stimuli associated with suffocation did not require an intact amygdala to elicit strong fear and panic symptoms. Another case study also noted that an intact amygdala was not necessary for a subject to experience PAs (Wiest et al., 2006). Thus, in the instance that an interoceptive trigger is the cause of a PA, the amygdala activity may not increase or be involved in the PA. Yet, it is interesting that while healthy control subjects experienced significant anticipatory anxiety prior to a subsequent $\mathrm{CO}_{2}$ inhalation, the subjects with bilateral amygdala damage did not, which demonstrates that the amygdala does appear to be important for anticipatory anxiety responses when in previously aversive situations. This suggests that the amygdala may be very important for ePAs, when the PD subject is in an agoraphobic situation. Overall, the amygdala's involvement in PAs may differ depending on baseline anxiety states, situations in which PAs occur, and the nature of the trigger (i.e., exteroceptive versus interoceptive, or a combination).

\section{5e. Perifornical hypothalamus and dorsal periaqueductal gray as the putative sites for PAs}

So if the amygdala is not the locus of uPAs, what is a likely candidate for such panicgenerating site? There are striking similarities between cognitive and physical symptoms associated with PA and those resulting from deep brain stimulation of subcortical nuclei in the perifornical hypothalamus $(\mathrm{PeF})$ and the dorsal column of the periaqueductal grey (DPAG) (see Figure 3). For instance, deep brain stimulation of the perifornical area in the posterior hypothalamus $(\mathrm{PeF})$ of humans produces cognitive fear symptoms such as selfreported panic and fear of dying, as well as physical symptoms, such as tachycardia, increased blood pressure, and hyperventilation (Rasche et al., 2006; Wilent et al., 2010). In another deep brain stimulation study, stimulating the posterior hypothalamus around the fornix (perifornical) led to increased feelings of anxiety, thermal sensations, and paresthesias (Wilent et al., 2011). Similarly, deep brain stimulation of the DPAG, but not its ventral column, elicited cognitive fear symptoms such as feeling of panic, intense anxiety, or fearing imminent death that were accompanied by physical symptoms such as chest pain, tachycardia, dyspnea, and thermal sensations (Nashold et al., 1969; Young, 1989). As further discussed in section 7, rodent studies have identified that these structures play a critical role as primary visceromotor systems, as well as playing a critical role in fight or flight responses to imminent threats. Rodent studies in Section $\mathbf{7}$ also provides further evidence for the PeF and DPAG in regulating normal and potentially pathological panic responses (e.g., panic responses following local stimulation; their responsiveness to panicogenic stimuli such as $\mathrm{CO}_{2}$ and $\mathrm{NaLac}$; and connections to brain regions implicated in panic attacks and panic response). 
Overall, based on an extensive review of the current and somewhat complicated literature, we would posit our hypothesis (detailed further in section 7) that a combination of genetic, developmental, hormonal, and environmental factors leads to a reduction in ventromedial prefrontal cortical (vmPFC) inhibition of panic generating lower brain regions, underlies the initial 'spontaneous' uPAs. This pathology could be further compounded by the development of hypersensitivity of insula network for interoceptive cues resulting in recurrent PAs. This repeated activation of the panic-generating subcortical sites, with subsequent recruitment and plasticity within the extended amygdala fear-hippocampuscortical circuits, leads to a vulnerability to developing situational ePAs and agoraphobia. Evidence for loss of vmPFC control of panic-generating site is based on the previously mentioned morphological imaging studies showing reduced volumes in frontal cortical areas (Protopopescu et al., 2006; Asami et al., 2009; Lai et al., 2010), which could lead to blunted cortical inhibition of fear and panic generating sites. Thus, more subtle interoceptive sensory input to the insula that is relayed to panic-generating sites may elicit a stronger response of that region if vmPFC inhibition of that region is compromised, which could trigger a false "alarm". Cognitive behavioral therapy (CBT) has been shown to enhance mPFC activity in subjects with anxiety disorders, which may explain why CBT is effective in treating PAs and PD.

\section{Section 6: Neurochemical Systems Implicated in PD: Genes, Triggers and Treatments}

\section{6a. Heritability and genes associated with PD and PA presentation}

As discussed in section 3a, the prevalence of PD in first degree relatives ( 11\%) and monozygotic twins (30-40\%) of PD subjects, compared to $2-5 \%$ in general population, is fairly strong evidence that genetic background is an important contributing factor to PD etiology [see meta-analyses and reviews by (Hettema et al., 2001; Schumacher et al., 2011)]. Yet, as mentioned in section 3a, although a recent meta-analysis of linkage and candidate gene association studies concluded most studies produced inconsistent results, it did observe some promising replicable chromosomal locations, and specific candidate genes (Maron et al., 2010). As discussed by Maron, the advantage of linkage analyses is the ability to perform an unbiased comprehensive genomic search of genes and alleles that may be associated with PD and PAs. The disadvantage is the relative inability to detect and locate specific genes associated with a condition. Conversely, candidate gene studies are hypothetically driven, but are restricted to screening specific genes. It is beyond the scope of this review to discuss all the chromosomal locations and candidate genes associated with PAs and PD.

A number of neurochemical hypothesis are also proposed for the etiology of panic disorder, primarily based on the pharmacological therapies that work in treating PAs and PD. For example, symptoms associated with PAs in PD, and laboratory-induced PAs can be rapidly treated with benzodiazepines (Charney and Heninger, 1985; Tesar and Rosenbaum, 1986; Ballenger et al., 1988) which effectively enhance inhibitory GABAergic tone. Panic attacks associated with PD can also be treated with slower-acting pharmacological therapies that enhance monoaminergic (e.g., serotonin, norepinephrine, epinephrine, dopamine, and 
histamine) activity globally [using tricyclic antidepressants (Rifkin et al., 1981) or monoamine oxidase inhibitors (MAOI) (Kelly et al., 1971)], or by specifically targeting serotonergic or noradrenergic systems with reuptake inhibitors [see review (Cloos and Ferreira, 2009)]. Here, we will focus the discussion on major neurochemical systems implicated in PAs and PD by linkage analyses and candidate gene studies, and how some of these systems are current targets for treating and eliciting PAs.

\section{6b. GABAergic system}

GABA is a major inhibitory neurotransmitter that is synthesized and released throughout the brain, and the panic-generating PeF and DPAG regions are tonically inhibited by GABA. GABA is also heavily implicated in PAs and PD, and most evidence suggests that there is reduced inhibitory GABAergic tone in patients with Panic Disorder. For instance, patients with Panic Disorder have reduced $\mathrm{GABA}_{\mathrm{A}} \mathrm{R}$ binding in the frontal cortex (Nikolaus et al., 2010), and panic patients demonstrate deficits in central GABA concentrations (Goddard et al., 2001b). There is evidence of linkage of PD to region 2q37, as well as other suggestive regional linkages on chromosome 2 (Fyer et al., 2006). The glutamate acid decarboxylase 1 (GAD1) gene which produces the GAD67 enzyme responsible for GABA synthesis, which is located on 2q31.1 has been shown to be associated with PD (Hettema et al., 2005). The effects of loss of central GABAergic tone can be observed in a study where the drug FG-7142, which mostly disenhances GABAergic tone, by acting as an inverse benzodiazepine agonist at most $\mathrm{GABA}_{\mathrm{A}}$ receptors, was shown to induce severe anxiety in humans (Dorow et al., 1983). Collectively, these data most likely explain why benzodiazepines, which enhance GABA activity, are effective at treating panic symptoms (Nutt et al., 2002; Baldwin et al., 2005; Bandelow et al., 2008; Cloos and Ferreira, 2009). Yet, although benzodiazepines represent a fast-acting panicolytic treatment, routine usage makes the drug less effective due to desensitization, and there are many side effects and safety concerns such as sedation and addiction. Furthermore, withdrawal from the benzodiazepine alprazolam leads to rebound PAs and symptoms such as weakness, insomnia, tachycardia, lightheadedness, and dizziness in 15/17 PD subjects (Fyer et al., 1987), which make this treatment mechanism a short term option and a second-line approach to treating PAs and PD. It is interesting to note that in the de Beurs study mentioned in section 2, there were no differences in the number of PAs in PD subjects that were using benzodiazepines and not, but they did report less nocturnal PAs and less severe PA symptoms (de Beurs et al., 1994).

\section{6c. Serotonergic and noradrenergic systems}

Some of the first evidence for involvement of serotonin and noradrenergic involvement in anxiety and PD pathology was due to the effectiveness of tricyclic antidepressants (TCA), such as imipramine and clonipramine, for managing symptoms in these disorders [see metaanalyses (Bakker et al., 2002; Perna et al., 2011)]. Although TCAs have pharmacological actions at many receptors, they primarily act as serotonin and norepinephrine reuptake inhibitors at the serotonin and norepinephrine transporters (5-HTT, and NET, respectively) with low affinity for dopamine transporters, which increases synaptic concentration of the neurotransmitters to enhance neurotransmission. Other lines of evidence came from pharmacological inhibition of monoamine catabolism using monoamine oxidase inhibitors 
(MAOIs) such as phenelzine for the treatment of PAs and PD, but this is considered a thirdor fourth-line approach since it requires a tyramine-restricted diet, and can produce serious side effects such as hypertensive crisis.

Selective serotonin reuptake inhibitors (SSRIs) and norepinephrine reuptake inhibitors (SNRIs) are also effective treatments for PAs and PD, and the safety and efficacy of these compounds will be discussed in the subsequent sections. It is important to note that unlike benzodiazepines, these are not fast-acting panicolytic compounds. In some cases, TCAs (and also SSRIs and NRIs) increase anxiety initially, and begin to show anxiolytic and panicolytic properties after 2-3 weeks of daily treatments. Thus the mechanism by which these compounds are panicolytic are through compensatory changes that occur with repeated use, and a therapeutic option is to initially co-administer a low dose of a benzodiazepine with SSRIs to PD patients, which has been shown to result in a $41 \%$ response rate, compared to $4 \%$ response rate for placebo + SSRI group in the first week of treatment (Goddard et al., 2001a).

Currently SSRIs and NRIs represent the first-line treatment for PAs and PD due to their similar efficacy in treating PAs (Pollack et al., 2007a; Pollack et al., 2007b), with some evidence that SSRIs are more tolerable and safe. There are several FDA-approved SSRIs for treating Pas, including fluoxetine, paroxetine, and sertraline, and NRIs such as venlaflaxine. In regards to efficacy, TCAs are arguably as effective as SSRIs and NRIs, but they are considered a second-line approach for treating PAs and PD due to side effects and tolerability. Bakker's meta-analysis comparing the efficacy of TCAs and SSRIs in treating PAs, found that TCAs and SSRIs were comparable in their efficacy (respectively $60 \%$ and $55 \%$ of PD patients PA free), but the dropout rate was $\sim 33 \%$ for TCAs, and $\sim 18 \%$ for SSRIs. The efficacy for SSRIs and NRIs was also similar, PD patients reported significantly less PA symptoms at $61 \%$ for paroxetine, 55-60\% for venlaflaxine, and 35\% for placebo (Pollack et al., 2007b). Thus, regardless of tolerability and safety issues, targeting serotonergic and/or noradrenergic systems pharmacologically is clearly effective in treating PAs in PD.

Similarly, PAs can be induced in the laboratory with serotonergic and noradrenergic pharmacological agents. For instance, serotonin-enhancing drugs such as the trazadone metabolite meta-chlorophenylpiperazine ( $\mathrm{mCPP}$, which is an agonist at most serotonin receptors, inhibits reuptake, and enhances release of serotonin) elicits PAs at a higher rate in PD subjects $(12 / 23,52 \%)$ that healthy controls $(6 / 19,32 \%)$ following $0.1 \mathrm{mg} / \mathrm{kg}$ i.v. infusions (Charney et al., 1987a). The indirect serotonergic agonist fenfluramine when given orally at $60 \mathrm{mg}$, increases anxiety symptoms in 9/9 PD subjects, but not significant anxiety symptoms in the 9 healthy controls (Targum, 1992). An earlier study by the same group showed PA frequency increased response rate to $60 \mathrm{mg}$ oral fenfluramine which induced PA symptoms in 9/12 patients (75\%) whom had a high incidence of PAs ( $\geq 1 \mathrm{PA} /$ week), and 0/14 PD patients with $\leq 1 \mathrm{PA} /$ month (Targum, 1991). Yohimbine, which enhances noradrenergic activity by blocking presynaptic $\mathrm{a} 2$ adrenergic autoregulation also induces PAs at a higher rate in PD subjects than healthy controls. In one study, yohimbine (4 oral capsules of 5mg) produced PAs in 37/68 (54\%) of PD subjects with agoraphobia, compared to $1 / 20$ healthy controls (5\%) (Charney et al., 1987b). Collectively, these pharmacological 
studies provide compelling evidence that serotonergic and noradrenergic system hyperactivity may contribute to PAs, and that PAs can be effectively treated by targeting either or both systems.

There is also evidence from candidate gene studies that polymorphisms of serotonergic and noradrenergic proteins may contribute to PAs and/or severity of PAs. For serotonergic systems, there have been multiple candidate genes associated with PD or severity of PAs. These include the serotonin transporter, $(5-H T T)$ and the serotonin 2A receptor (HRT2A) (Maron et al., 2005; Maron et al., 2010). Of the two candidates, the polymorphism of the 5HTT gene has gained a lot of attention in regards to anxiety disorders and, more recently, PD. Humans carry a polymorphism in the promoter region of the serotonin transporter (5HTT) gene, where the dominant short (s) allelic variant reduces transcriptional efficiency of the 5-HTT (Lesch et al., 1996), which is evidenced by reduced brain 5-HTT mRNA levels (Little et al., 1998), and reduced 5-HTT binding sites (Heils et al., 1996). Lesch and colleagues also observed that humans with the polymorphism associated with reduced 5HTT transcription had increased anxiety-associated traits. Specifically in regards to PAs and PD, the 5-HTT s-allele polymorphism has not been shown to be associated with increased incidence of PAs, but has been shown to be strongly associated with the severity of panic symptoms (Lonsdorf et al., 2009). Surprisingly, Schruers and colleagues determined that healthy humans with the 5-HTT s-allele polymorphism displayed less fear to the panicogenic interoceptive stimuli $\mathrm{CO}_{2}$ (Schruers et al., 2011). Yet, other clinical studies have shown that humans with this polymorphism have enhanced reactivity of the amygdala (Hariri et al., 2002; Heinz et al., 2007), and better acquisition of fear conditioning (Garpenstrand et al., 2001) than those with only long alleles. Klumpers and colleagues also determined that humans carrying at least one short allele for the 5-HTTLPR polymorphism ( $\mathrm{S} / \mathrm{S}$ or $\mathrm{S} / \mathrm{L}$ ) showed stronger fear-potentiated startle compared to long allele (L/L) homozygotes, but did not show a deficit in the extinction of the fear after the offset of threat, and hypothesized that the variation in 5-HTT function affects the magnitude of an unconditioned defensive reaction, but not the capacity for fear regulation (Klumpers et al., 2012). Given Schruers' data and that the amygdala is not critical for some $\mathrm{CO}_{2}$-induced PAs (Feinstein et al., 2013), the 5-HTT s-allele polymorphism may not predispose PD subjects to some interoceptive induced PAs. However, the amygdala hyperactivity associated with the 5-HTT s-allele polymorphism may predispose PD patients to agoraphobia and ePAs. This polymorphism may also explain why SSRIs are not effective in treating PAs in some PD subjects.

Candidate gene studies have also identified noradrenergic proteins that are associated with PD. Among these, a candidate gene that is more consistently associated with PD is catecholO-methyltransferase (COMT) which maps to 22q11.21, and is involved in the inactivating/ degrading the catecholaminergic neurotransmitters epinephrine, norepinephrine, and dopamine; the first two are implicated in normal and pathological panic (Maron et al., 2010). The specific effect of this polymorphism of COMT associated with PD depends on the ethnicity of population. In a meta-analysis assessing COMT association with PD, Domschke and colleagues found that the COMT $158 \mathrm{Val}$ allele polymorphism is associated with PD in Caucasian samples with higher association in females in some cases, and an association of 
the COMT 158 Met allele polymorphism with PD in Asian female samples (Domschke et al., 2007). The functional significance is the Val polymorphism has greater enzymatic activity than the Met polymorphism. In an fMRI study PD subjects with the COMT 158 Val polymorphism has greater activity in the right amygdala in response to fearful faces (Domschke et al., 2008), and have altered white matter connectivity compared with noncarriers (Kim et al., 2013). Overall, the COMT polymorphism has a fairly strong association with PD, but the functional significance may be complicated.

\section{Section 7: Strengths of Weaknesses of Animal Models of Adaptive and Pathological Panic States}

As discussed in a 2001 NIMH workshop on the development of animal models of anxiety disorders, the relationship between existing animal models of anxiety and fear and clinical anxiety symptoms and syndromes needs much clarification (Shekhar et al., 2001). The focus of this special edition is on the development of translational animal models of panic disorder. Developing a single, 'true' model of a panic disorder that recapitulates all of the characteristics of the human disorder is highly unlikely for the following reasons: 1) PD diagnosis currently relies on self-reported symptom presentation (the accuracy of such patient self-report is a problem; e.g., objectively measured tachycardia not occurring during self-reports of tachycardia) and is not possible to assess in animals; 2) PA symptom presentation, frequency, and severity is fairly heterogeneous; 3) objective measures of physical symptom related activity prior to and during PAs also reveal heterogeneous responses; 4) neural circuits involved in naturally occurring PAs are not entirely clear; and 5) the underlying pathology may be as heterogeneous as the PAs and is most likely an interaction between genetic vulnerability (trait-related) and complex environmental stress (state-related). Yet, as discussed in the following sections, animal models can help us best assess the mechanisms underlying candidate genes and neural circuits implicated in PD (see Figure 5). They can also help characterize normal adaptive behavioral and physiological responses to aversive situations such as: 1) conflict between risks and rewards; 2) where the animal is placed is previously threatening situation; and 3) finally where there is an immediate and imminent threat. There is some evidence that each of these three adaptive strategies may be related to pathology associated with generalized anxiety disorder, posttraumatic stress disorder, and agoraphobia, and panic disorder, respectively. Animal models have other advantages as well. For instance, clinical studies related to PD are complicated for many reasons such as duration of illness; severity and frequency of PAs; previous and current pharmacotherapies; comorbidities; and differences in environment, diet, and racial/ ethnic and cultural background. In animal studies, many of these variables can be better controlled for, including the use of inbred strains to control for differences in genetic background. Molecular biology now also gives us the tools to genetically breed strains of rodents with high anxiety traits, or to assess the function of specific candidate genes (e.g, 5HTT and COMT) by knocking out or over-expressing the gene across development, or acutely silencing a gene with small interfering RNA, or with the use of conditional knockouts. Thus, we can potentially manipulate genes and/or environmental conditions and determine if these conditions lead to aberrant panic responses where animals display panicassociated behavior and physiological responses similar to physical symptoms (e.g., 
cardiovascular, respiratory, and thermal) following interoceptive stimuli such as NaLac and $\mathrm{CO}_{2}$ that provokes PAs in most PD subjects, or display these panic responses or aberrant fear-associated learning when in situations where panic responses have been provoked to model agoraphobia.

An important consideration in modeling panic and pathological panic is the validity of the model which relies on three major criteria. The first criterion is face validity, which is the degree in which the model measures something analogous to PAs. These can include behaviors that may indicate catastrophic fear such as explosive locomotor "flight" behaviors, escape from situations that are associated with risk (e.g., open arm on an elevated plus maze), hugging walls (thigmotaxis), or avoidance of brightly-lit areas. These types of behavioral assessments are fairly easy and high throughput, but an important consideration in modeling panic states and PA-like activity is the assessment of events surrounding the physical symptoms, which requires more exhaustive efforts of assessing autonomic cardiovascular and thermoregulatory events as well as respiratory responses. These techniques can be done in freely-moving, conscious rats using radiotelemetry probes surgically implanted into the abdomen or with pressure transducers inserted into the femoral artery for cardiovascular measures and whole body plethysmography for respiratory measures. The second criterion is postdictive and predictive validity. Postdictive validity is the sensitivity of a test to known panicolytic compounds such as SSRIs and benzodiazepines, or the ability of a known compound to block PA triggers such as $\mathrm{CO}_{2}$ or NaLac. Predictive validity is the ability of the test to predict efficacious panicolytic treatments. Finally, the most difficult type of validity is construct, which reflects the degree in which the animal model is related to the pathophysiological mechanism underlying PAs and PD. The subsequent sections will discuss animal models of adaptive panic and pathological panic vulnerability and the degree in which they meet the three criteria of validity (see also Figure 5 which outlines adaptive and pathological panic models, and their utility).

\section{Section 7a. Animal models of adaptive panic, anxiety and fear memory}

Another approach to expand our understanding of panic pathology utilizing animal models is to elucidate the neural and neurochemical circuits that mobilize normal 'adaptive panic' or risk assessment survival responses, which is in line with the mission of the NIH RDoc. The neurochemical circuits that regulate an animal's ability to cope and effectively respond to aversive stimuli are related, but there are very important differences. Currently, anxiety states are typically assessed in "conflict anxiety" scenarios, which is when a threat is apparent, but not imminent, and is potentially also in conflict with a reward. An example of risk assessment would be to create the need to forage for food, at the risk of being eaten by a predator. This is effectively a "look before you leap" system where risk assessment plays a critical role in survival. Conversely, behavioral assessment of fear-associated memories also measures important adaptive responses to threat where an unconditioned threatening situation (e.g, predator attack) leads to a fear-conditioned memory. In rodents, this typically involves pairing a threatening, unconditioned stimulus such as a foot shock with a conditioned stimulus such as a tone or light. When the rodent is placed in similar environment and presented with only the conditioned stimulus (e.g., tone or light) there is a 
strong behavioral freezing response. The advantage of these types of simple behavioral preparations is that the conditioning induces very reproducible freezing responses, and the neural circuits underlying this phenomenon (e.g., amygdala and prefrontal cortex) are being elucidated. However, this system is best linked to trauma-based pathology such as posttraumatic stress disorder, but is a very important system linked to the development of ePAs and agoraphobia (conditioned fear responses when in situations where previous uPAs have occurred).

Yet, eliciting a true adaptive panic/defensive response typically involves putting an animal in a life-threatening situation (e.g., confrontation with a predator or an aggressive conspecific male). Unlike conflict and fear-associated behaviors which respectively assess uni-dimensional behaviors such as time spent in an area or freezing, assessing the panic response involves measuring multiple and complex somatic motor behaviors such as "flight" like increases in locomotion to attempt to escape the threat, specific patterns of vocalizations, and an array of physiological responses related to sympathetic mobilization and parasympathetic desensitization [e.g., cardiovascular (e.g., tachycardia, increases in blood pressure), and gastrointestinal (e.g., voiding and defecation) responses], as well as respiratory (tachypnea) and endocrine (HPA axis) responses. Although these types of models provide a wealth of data on normal 'defense/panic' circuits, and have been the main models that have helped map some of the brain circuits involved in fear and flight-or-fight' responses, they provide much less information about the possible pathophysiology, or mechanistic approaches to understanding the origins of the human disease. Therefore, another approach that has been utilized is to determine if manipulations of those relevant circuits, genes, or neurochemicals can make animals vulnerable to displaying panic associated responses following interoceptive or exteroceptive triggers, and then also determine if there is evidence of agoraphobia.

\section{Section 7b. Modeling panic through neural circuits implicated in panic in humans}

As discussed in section 5d, there are striking similarities between cognitive and physical symptoms associated with PA and those resulting from deep brain stimulation of subcortical nuclei in the PeF and the DPAG of humans (see Figure 3), which in the PeF produces cognitive fear symptoms such as self-reported panic and fear of dying, as well as physical symptoms, such as tachycardia, increased blood pressure, and hyperventilation (Rasche et al., 2006; Wilent et al., 2010), thermal sensations, and parasthesias (Wilent et al., 2011). Stimulation of the DPAG elicits similar cognitive fear symptoms such as feeling of panic, intense anxiety, or fearing imminent death that are accompanied by physical symptoms such as chest pain, tachycardia, dyspnea, and thermal sensations (Nashold et al., 1969; Young, 1989). Prior to these human studies, cat and rodent studies determined that these structures play a critical role as primary visceromotor systems, as well as playing a critical role in adaptive panic/fight or flight responses to imminent threats.

The notion that the PeF is a critical site for panic is not a new concept. In early studies by Bard and Hess, the hypothalamus was hypothesized to be a critical site for generating a coordinated panic defense reaction that consisted of behavioral and physiological responses appropriate for a "fight or flight" response (Bard, 1928; Hess and Akert, 1955), In the 1940s, 
Hess and colleagues electrically stimulated posterior hypothalamic regions near the $\mathrm{PeF}$ and evoked strong autonomic and somatic responses resembling adaptive panic/defense reactions (e.g., increased blood pressure, piloerection, arching of back) (Hess and Brugger, 1943). Further studies, conducted in rodents, electrically stimulated the PeF region which elicited cardiovascular and behavioral components of the "fight or flight" response including tachycardia, pressor responses, and tachypnea (Lynn, 1969; Markgraf et al., 1991), decreases in visceral blood flow and increases in hind limb blood flow (McCabe et al., 1994) and "agitated" running proportional to stimulus intensity (Duan et al., 1996). Similarly, pharmacologically exciting the DPAG of cats (Carrive et al., 1987; Bandler and Carrive, 1988; Carrive et al., 1988) and rodents (Schenberg and Lovick, 1994; Bittencourt et al., 2004) elicits similar defensive responses as seen in the PeF, as well as tachycardia and increases in blood pressure.

It was later determined that both the PeF and DPAG were under tonic GABAergic inhibition, which is clearly observed by injecting a $\mathrm{GABA}_{\mathrm{A}}$ receptor antagonist into the PeF region and elicits escape and flight behaviors (Shekhar and DiMicco, 1987), anxietyassociated behaviors in validated tests (Shekhar et al., 1990a) which are suggestive of catastrophic fear behaviors, as well as physical signs associated with PAs such as cardiorespiratory responses [e.g., hyperventilation, tachycardia, pressor response and thermal changes (Shekhar and DiMicco, 1987; Anderson and DiMicco, 1990; Shekhar et al., 1990b; Soltis and DiMicco, 1992; Samuels et al., 2002)]. A key brain region that appears to regulate local GABAergic inhibition in this panic-generating site is the medial prefrontal cortex, and specifically ventromedial portion called the infralimbic cortex (ILC). Evidence for this first emerged in the 1920s, when Cannon and Britton found that decorticating cats produced a variety of defensive/panic behaviors (e.g., hissing, arching of back, and attempts to bite) and sympathetic nervous system responses (e.g., increases in blood pressure) to nonthreatening stimuli (Cannon and Britton, 1925). Bard and colleagues later discovered that transections of the cat forebrain produced hyperactive defensive responses, but if the transection were caudal to posterior regions of the hypothalamus where the PeF is located, then this response disappeared (Bard and Mountcastle, 1948). This led Bard to propose that the forebrain cortical regions suppress emotional responses to inconsequential or trivial stimuli by actions in the posterior regions of the hypothalamus, but when the organism is exposed to an imminent threat (e.g., a conspecific male or predator) then tonic inhibition of this region is removed and this produces a defensive 'panic' response. This hypothesis is supported by retrograde tracing in the PeF leading to robust labeling in ILC (Chen and Smith, 2003; Goddard et al., 2004; Johnson et al., 2008b). Since most of the projection neurons in the medial prefrontal cortex (mPFC) are glutamatergic, it is hypothesized that these neurons project to local GABAergic interneurons in the PeF to tonically inhibit their activity, which has been determined to be the case for $\mathrm{MPFC}$ projections to the amygdala.

Additional convergent evidence comes from ex vivo studies that have assessed cellular responses (i.e., immunostaining the protein product of the immediate early gene c-fos, which is expressed following activation of several second messenger receptor cascades) in brain regions following ethologically relevant exteroceptive threats [e.g., predator odor exposure (Dielenberg et al., 2001)], and interoceptive threats [e.g., 5 min exposure to gas containing 
normoxic $20 \% \mathrm{CO}_{2}$ (Johnson et al., 2005; Johnson et al., 2011), i.v. infusions of $0.5 \mathrm{M}$ NaLac (Johnson et al., 2008a; Johnson et al., 2008b)] or panicogenic pharmacological compounds [e.g., yohimbine, FG-7142, D-fenfluramine, and caffeine (Li and Rowland, 1993; Singewald and Sharp, 2000; Singewald et al., 2003)] which is illustrated in Table 1. Further support comes from studies assessing polysynaptic connectivity of brain regions with peripheral cardiovascular and thermoregulatory targets in the rodent, which are respectively, the stellate ganglion (Jansen et al., 1995; Westerhaus and Loewy, 2001), a critical sympathetic ganglia for regulating cardiovascular activity, and the tail (Smith et al., 1998), a critical site for heat dissipation.

Based on this collective work, Shekhar and colleagues chronically inhibited GABA synthesis in the PeF of rats (to effectively reduce cortical inhibition) which made them vulnerable to displaying panic-associated behaviors and cardiorespiratory responses to interoceptive stimuli that provoke PAs in humans (i.e., i.v. 0.5M NaLac infusions).

Specifically, a GABA synthesis inhibitor (1-allylglycine:l-AG) is unilaterally infused into the PeF via an osmotic minipump, which increases anxiety-like behavior in the social interaction (SI) test, defensive burying test, and elevated plus-maze without altering baseline cardiorespiratory activity (Shekhar and DiMicco, 1987; Shekhar et al., 1996; Shekhar and Keim, 1997; Shekhar et al., 2006). However, following exposure to $0.5 \mathrm{M} \mathrm{NaLac}$, these rats have increased anxiety-like behavior (greater than already present from l-AG infusion) and marked and rapid increases in cardiovascular functions (evidenced by either tachycardia and/or a pressor response), tachypnea and an increase in general locomotor activity (Shekhar et al., 1996; Shekhar and Keim, 1997, 2000; Johnson and Shekhar, 2006; Shekhar et al., 2006; Johnson et al., 2008b; Johnson et al., 2010; Molosh et al., 2010). This model of panic vulnerability has been established for over 15 years, and has robust face, predictive, and construct validity [see review (Johnson and Shekhar, 2012)]. The model recapitulates many of the phenotypic features of human panic disorder thus providing face validity. The model's predictive validity is demonstrated by panic responses to both panic-inducing agents (e.g. sodium lactate, yohimbine, and inhalations of $\mathrm{CO}_{2}$ ) and anti-panic effects of therapeutic agents such as alprazolam (Johnson et al., 2010; Shekhar et al., 2011) and group II metabotropic glutamate agonists (Shekhar and Keim, 2000). The construct validity of this model is supported by the fact that neural circuits of the PeF regulate behavioral and autonomic components of an adaptive panic/defense response in rats (Andreatini et al., 2001), panic disorder subjects have reported deficits in central GABA activity (Goddard et al., 2001b) and pharmacological restoration of central GABA activity prevents panic attacks (Goddard et al., 2004), which is consistent with GABA reductions in key brain areas resulting in panic vulnerability as demonstrated with this animal model. This PeF model was also recently used to screen panicolytic properties of a novel GABA enhancer XBD173 drug and group II metabotropic glutamate transporter agonists [PeF model screening (Rupprecht et al., 2009) and (Shekhar and Keim, 2000)] which showed anti-panic properties in later clinical trials [clinical screening (Rupprecht et al., 2009) and (Schoepp et al., 2003; Kellner et al., 2005)].

Even though the PeF is a critical panicogenic site in humans, cats, and rats, the local neurochemical systems that mobilize this panic response had been elusive until 1998 when a novel neuropeptide system called orexin (also known as hypocretin) was determined to be 
exclusively synthesized in neurons around the fornix in the poster regions of the hypothalamus. Initial work noted that dramatic loss of function of the orexin system disrupted sleep, and later clinical studies noted that central orexin tone and orexin neurons were dramatically reduced in narcoleptic patients. The orexin neurons were thought to be mainly located in the lateral hypothalamus, but Johnson and colleagues noted that they were mainly found in the PeF region. Based on this observation and orexin's role in arousal and vigilance, in 2010 Johnson and colleagues determined that the orexin system was critical for panic responses in the PeF rat model of panic vulnerability, and that orexin-1 receptor antagonists were effective in attenuating panic responses provoked with interoceptive stimuli [e.g. i.v. 0.5M NaLac in panic vulnerability model (Johnson et al., 2010) and $20 \% \mathrm{CO}_{2}$ in healthy rats (Johnson et al., 2012c)], and panicogenic drugs (e.g., FG-7142 in healthy rats (Johnson et al., 2012a)). Since orexin's discovery, more studies have demonstrated that this PeF orexin system is capable of mobilizing a coordinated adaptive panic/defense response (anxiety, cardiorespiratory, and endocrine components, and has particularly strong projections to anxiety and panic-associated circuitry such as the locus ceruleus [see review(Ferguson and Samson, 2003; Johnson et al., 2012b)]. A hyperactive orexin system is also linked to anxiety states in humans (Johnson et al., 2010).

\section{Section 7c. Modeling genetic risk factors and assessing candidate genes associated with PD}

Inbred rodents are one method of assessing heritability of anxiety-associated traits where some strains show higher anxiety-associated behaviors than other strains. For instance, some mice and rat strains have been bred to have high anxiety [e.g., S129/SvImJ mice, high anxiety bred rats $(\mathrm{HAB})]$ and others low anxiety [e.g., C57BL/6J mice and low anxiety bred rats (LAB)]. Quantitative trait loci (QTL) analyses can then be utilized to identify associations between a specific phenotypic anxiety-associated behavior and a marker locus for sets of genes. These approaches have linked chromosome 1, 4, and 15 with increased anxiety-associated behaviors:chromosome 1 with exploration, chromosome 4 with locomotor activity, and chromosome 15 with avoidance [see review in (Perez et al., 2013)]. The disadvantage to this approach is that the anxiety traits will result from multiple genetic differences, rather than manipulating one specific gene such as a candidate gene associated with PAs and PD. Another approach is to utilize gene targeting to assessing candidate genes associated with PD or severity of PA. This can be done by silencing or "knocking out" a gene or over-expressing the protein product of that gene by inserting a transgene; in some cases, the human gene can be overexpressed. In knockout mice and rats, the gene is typically altered throughout development. More sophisticated gene targeting can control deletion or insertion of genes globally or in specific brain regions at specific time points during development using inducible techniques, such as the Cre/Lox system. Initially, the gene targets were chosen based on current pharmacological treatments for PAs and PD and candidate genes associated with those treatments (discussed in section 6)including GABAergic, serotonergic, and noradrenergic systems.

As discussed in section 6, overall there is evidence that loss of central GABAergic tone may contribute to PAs and PD, and a GADl polymorphism is associated with PD (Hettema et al., 2005; Hettema et al., 2006). The GAD1 gene encodes the GAD67 enzyme, which is one of 
two enzymes (GAD65 is the other) that synthesize GABA. Although Hettema and colleagues did not assess the effects of these polymorphisms on GABA activity, mice studies suggest that disruption of GABA's synthetic enzymes does increase anxiety-related behaviors. In mice, targeted knockout of GAD67 is lethal (Condie et al., 1997); however mice with the GAD65 knockout, which would also alter GABAergic tone, does lead to increases anxiety-related behaviors in the open field test and elevated zero test, which assesses exploratory behaviors in potentially threatening regions that are brightly lit and away from walls or areas lacking walls (Kash et al., 1999). Transgenic knockouts of the 5HTT gene also increases anxiety-associated behaviors in mice; these mice avoid brightly lit arms in the elevated plus maze and bury fewer marbles in the defensive burying test (Line et al., 2011). Conversely, mice with over-expression of 5-HTT have reduced anxietyassociated behaviors in these same tests (Line et al., 2011). Furthermore, the ability to extinguish fear associated memories is impaired in mice with loss of 5-HTT expression (Wellman et al., 2007), which suggests that disruption of 5-HTT activity in humans could predispose them to ePAs and/or agoraphobia. Loss of COMT gene function due to knockout leads to more avoidance behavior in a light-dark box test, but only in female mice (Gogos et al., 1998), which models aspects of the higher incidence of PD in women. Overall, these genetic manipulations in mice do support a role for these genes as important components of anxiety regulation. Yet, it is important to note that these targeted genetic approaches are designed to assess loss of function (e.g., knockout), or gain of function (e.g., overexpression).

A more desirable approach would be to genetically recreate the polymorphism then determine the biochemical and behavioral consequences of these polymorphisms. As discussed in section 6, the 5-HTT s-allele polymorphism which reduces transcriptional efficiency (Little et al., 1998), is associated with increased anxiety traits (Lesch et al., 1996) and is strongly associated with the severity of panic symptoms in PD (Lonsdorf et al., 2009). As mentioned previously, knockout mice with complete loss of 5-HTT have increased anxiety-associated behaviors. A more suitable model of the reduced efficiency of the 5-HTT in humans are rats with a heterozygous null mutation of the 5-HTT, which similarly reduces transcriptional efficiency by approximately $50 \%$, and are resistant to SSRIs (Homberg et al., 2007). Similar to mice studies, rats with complete loss of the 5-HTT gene have increased baseline levels of anxiety-associated behaviors (Olivier et al., 2008; Joeyen-Waldorf et al., 2009; Johnson et al., 2012d). Yet, baseline levels of anxiety-associated behaviors in rats with the heterozygous null mutation of the 5-HTT gene are normal compared to wildtype controls (Joeyen-Waldorf et al., 2009; Johnson et al., 2012d). However, in a standard fear conditioning procedure using shock as the unconditioned stimulus and tone as the conditioned stimulus, the rats with the heterozygous null mutation of the 5-HTT gene display enhanced acquisition of fear-associated freezing behaviors and are resistant to extinction of fear on subsequent days when only the tone was presented as a cue (Johnson et al., 2012d). These rats also have increased excitatory tone in the amygdala at baseline (Johnson et al., 2012d). These preclinical data are consistent with clinical studies mentioned in section 6 showing that humans with this polymorphism have enhanced reactivity of the amygdala (Hariri et al., 2002; Heinz et al., 2007), and better acquisition of fear conditioning (Garpenstrand et al., 2001) than those with only long alleles. Overall, this provides further 
evidence that reduced 5-HTT efficiency in humans may predispose them to ePAs and or agoraphobia. Future studies of 5-HTT knockout and heterozygous null mutations in rats are needed to assess anxiety and panic-associated behavioral and autonomic responses to exteroceptive and interoceptive stimuli that trigger PAs in PD subjects. The utilization of site- and development-specific knockout rats would also permit a more elegant delineation of specific contributing factors to the development of anxiety phenotypes.

\section{Section 7d. Modeling risk factors such as early life stress and gender}

As discussed in previous sections, there is evidence that significant early life stress (e.g., maternal deprivation) may decrease functional connectivity of the PFC with subcortical panic-generating circuits which is associated with increased anxiety (Milad and Quirk, 2012). Many significant early life stress events such as child abuse, neglect, or loss of parents due to death or abandonment are receiving much attention as contributing factors to anxiety disorders and pathology associated with trauma such as PTSD. Previous trauma as a child or trauma as an adult could be an additional predisposing factor contributing to PAs and PD that may be comorbid with a previous diagnosis such as separation anxiety disorder or current diagnoses such as PTSD [see review by (Gittelman and Klein, 1984)]. In regards to animal modeling, early life stress can be done using methods such as maternal separation or during adolescence using social defeat paradigm (where a smaller male is placed in a cage with an aggressive larger animal) to model bullying and behavioral despair. Currently, there is very little known about how these types of traumatic events contribute to panic vulnerability in rodents. Another major gap in rodent studies is that the vast majority of experiments in anxiety are conducted in males and not females [out of 10,000 assessed experiments, 9,397, or 94\%, were done in males (Griebel and Holmes, 2013)]. Thus, there is a pressing need for studies to assess the effects of sex and traumatic events (that occur during early life, adolescence, and adulthood) on anxiety and panic-associated behaviors as well as panic vulnerability to exteroceptive and interoceptive stimuli where autonomic, respiratory, and endocrine measures are assessed.

\section{Section 8: Gaps in knowledge and Future Direction Conclusion}

Based on the above discussion, there are a numerous gaps in our understanding of the pathophysiology of PAs and PD. One major gap in knowledge is understanding the characteristics associated with early episodes of uPAs, especially PAs prior to frequent recurrence or onset of agoraphobia. Such studies are difficult to conduct due to obvious difficulties of timing and being able to monitor uPAs in real time. However, with increasing application of mobile technologies (e.g. smartphone apps) to monitor a wide range of patient phenotypes and biochemical and physiological measurements, such studies will provide critical information that is needed to understand the pathophysiology of PD onset. There is also great lackdisease biomarkers that predict patient and high risk groups. Studies of cognitive-emotional, autonomic, respiratory, endocrine tone differences, as well as imaging, between control and high risk first degree relatives of PD subjects are also necessary to better define the spectrum of disease phenotypes. Similarly, detailed studies of laboratoryinduced PAs in first degree relatives of PD subjects would be highly informative. Although a few small studies have utilized ambulatory monitoring of PD subjects, there is a need for 
clinical assessment of PAs in relatively non-threatening situations and in situations that are more aversive, and/or where PAs have occurred previously. At the systems and genetic levels, we need more information on the biochemical consequences of more common genetic polymorphisms associated with PAs and PD, as well as rodent work involving targeted gene disruptions and knock-ins similar to polymorphisms associated with PAs and PD. Finally, we need to systematically evaluate novel pathways and mechanisms, utilizing models that have robust validity for aspects of PD phenotype.

Another effort that is underway, under the leadership of the National Institute of Mental Health in the United States, is the development of Research Domain Criteria (RDoc), which hopes to provide some guidance on understanding brain mechanisms-based approaches for psychiatric disorders. This is a bold and broad vision, and specifically could create a new approach to understanding anxiety disorders, not as categorical and discrete disease entities each with unique 'locus' of pathology, but more as complex phenotypic expressions of disturbances in fundamental brain network functions. As this approach evolves, and more and more functional and molecular data get mapped on to brain networks in normal and disease processes, the definitions of different 'subtypes' of PAs and PDs will become richer. Currently, the RDoc process is in its early stages, and much foundational concepts are yet to be defined for wide range of psychiatric symptoms. For example, within the RDoc, the concept of PAs is essentially undefined and at best falls in one of the negative domains, within the 'construct' of acute threat. The most commonly cited approach to studying this domain is utilizing concepts such as fear-conditioned freezing or startle. Simply taking these models at face value would lead one to assume that all PAs would routinely involve 'fear' circuits centered on the amygdala, and its upstream and downstream connections. Yet, it is very clear that many forms of uPAs (early spontaneous PAs) and some challenge-induced PAs (e.g., $\mathrm{CO}_{2}$-induced PAs) do not activate the amygdala and can occur in subjects with bilateral amygdala lesions. Thus, there may well be elements of sub-constructs within construct of 'acute threat' under the 'negative valence systems' that need further delineation, such as a) perceived or explicit threat and b) interoceptive or non-perceived threat networks which lead to the classic PAs. Thus, both at the conceptual level and at the data-gathering level, many gaps exist in our understanding of PD. We hope this review provides a brief overview of the current state of data, and the gaps in our knowledge, about PAs and PD, and an impetus for much work that lies ahead.

\section{Acknowledgments}

This work was supported by K01AG044466 (PLJ), R01 MH52619 (AS), MH065702 (AS) and UL1 TR001108 (AS) through Indiana CTSI Project Development Team Pilot Grant to PLJ.

\section{References}

Abelson JL, Nesse RM, Weg JG, Curtis GC. Respiratory psychophysiology and anxiety: cognitive intervention in the doxapram model of panic. Psychosom Med. 1996; 58:302-313. [PubMed: 8827792]

Abelson JL, Khan S, Liberzon I, Young EA. HPA axis activity in patients with panic disorder: review and synthesis of four studies. Depress Anxiety. 2007; 24:66-76. [PubMed: 16845643] 
Adolphs R, Tranel D, Damasio H, Damasio A. Impaired recognition of emotion in facial expressions following bilateral damage to the human amygdala. Nature. 1994; 372:669-672. [PubMed: 7990957]

Adolphs R, Tranel D, Damasio H, Damasio AR. Fear and the human amygdala. Journal of Neuroscience. 1995; 15:5879-5891. [PubMed: 7666173]

Anderson JJ, DiMicco JA. Effect of local inhibition of gamma-aminobutyric acid uptake in the dorsomedial hypothalamus on extracellular levels of gamma-aminobutyric acid and on stressinduced tachycardia: a study using microdialysis. JPharmacolExpTher. 1990; 255:1399-1407.

Andreatini R, Blanchard C, Blanchard R, Brandao ML, Carobrez AP, Griebel G, Guimaraes FS, Handley SL, Jenck F, Leite JR, Rodgers J, Schenberg LC, Da Cunha C, Graeff FG. The brain decade in debate: II. Panic or anxiety? From animal models to a neurobiological basis. Braz J Med Biol Res. 2001; 34:145-154. [PubMed: 11175489]

Antony MM, Brown TA, Barlow DH. Response to hyperventilation and 5.5\% CO2 inhalation of subjects with types of specific phobia, panic disorder, or no mental disorder. Am J Psychiatry. 1997; 154:1089-1095. [PubMed: 9247394]

Asami T, Yamasue H, Hayano F, Nakamura M, Uehara K, Otsuka T, Roppongi T, Nihashi N, Inoue T, Hirayasu Y. Sexually dimorphic gray matter volume reduction in patients with panic disorder. Psychiatry Res. 2009; 173:128-134. [PubMed: 19560907]

Austin DW, Richards JC. The catastrophic misinterpretation model of panic disorder. Behav Res Ther. 2001; 39:1277-1291. [PubMed: 11686264]

Bailey JE, Argyropoulos SV, Kendrick AH, Nutt DJ. Behavioral and cardiovascular effects of 7.5\% CO2 in human volunteers. Depress Anxiety. 2005; 21:18-25. [PubMed: 15782425]

Bakker A, van Balkom AJ, Spinhoven P. SSRIs vs. TCAs in the treatment of panic disorder: a metaanalysis. Acta Psychiatr Scand. 2002; 106:163-167. [PubMed: 12197851]

Baldwin DS, Anderson IM, Nutt DJ, Bandelow B, Bond A, Davidson JR, den Boer JA, Fineberg NA, Knapp M, Scott J, Wittchen HU. Evidence-based guidelines for the pharmacological treatment of anxiety disorders: recommendations from the British Association for Psychopharmacology. J Psychopharmacol. 2005; 19:567-596. [PubMed: 16272179]

Ballenger JC, Burrows GD, DuPont RL Jr. Lesser IM, Noyes R Jr. Pecknold JC, Rifkin A, Swinson RP. Alprazolam in panic disorder and agoraphobia: results from a multicenter trial. I. Efficacy in short-term treatment. Arch Gen Psychiatry. 1988; 45:413-422. [PubMed: 3282478]

Balon R, Yeragani VK, Pohl R, Muench J, Berchou R. Somatic and psychological symptoms during isoproterenol-induced panic attacks. Psychiatry Res. 1990; 32:103-112. [PubMed: 2195575]

Bandelow B, et al. World Federation of Societies of Biological Psychiatry (WFSBP) guidelines for the pharmacological treatment of anxiety, obsessive-compulsive and post-traumatic stress disorders first revision. World J Biol Psychiatry. 2008; 9:248-312. [PubMed: 18949648]

Bandler R, Carrive P. Integrated defence reaction elicited by excitatory amino acid microinjection in the midbrain periaqueductal grey region of the unrestrained cat. Brain Res. 1988; 439:95-106. [PubMed: 3359200]

Bar-Haim Y, Lamy D, Pergamin L, Bakermans-Kranenburg MJ, van IMH. Threat-related attentional bias in anxious and nonanxious individuals: a meta-analytic study. Psychol Bull. 2007; 133:1-24. [PubMed: 17201568]

Bard P. A diencephalic mechanism for the expression of rage with special reference to the sympathetic nervous system. AmJPhysiol. 1928; 84:490-515.

Bard P, Mountcastle VB. Some forebrain mechanisms involved in the expression of rage with special reference to suppression of angry behavior. ResPublAssocResNervMentDis. 1948; 27:362-404.

Barr, Taylor C.; Telch, MJ.; Havvik, D. Ambulatory heart rate changes during panic attacks. J Psychiatr Res. 1982; 17:261-266. [PubMed: 7187688]

Bechara A, Tranel D, Damasio H, Adolphs R, Rockland C, Damasio AR. Double dissociation of conditioning and declarative knowledge relative to the amygdala and hippocampus in humans. Science. 1995; 269:1115-1118. [PubMed: 7652558]

Beitman BD, Kushner M, Lamberti JW, Mukerji V. Panic disorder without fear in patients with angiographically normal coronary arteries. J Nerv Ment Dis. 1990; 178:307-312. [PubMed: 2338538] 
Bittencourt AS, Carobrez AP, Zamprogno LP, Tufik S, Schenberg LC. Organization of single components of defensive behaviors within distinct columns of periaqueductal gray matter of the rat: role of N-methyl-D-aspartic acid glutamate receptors. Neuroscience. 2004; 125:71-89. [PubMed: 15051147]

Breier A, Charney DS, Heninger GR. Agoraphobia with panic attacks. Development, diagnostic stability, and course of illness. Arch Gen Psychiatry. 1986; 43:1029-1036. [PubMed: 3767595]

Cannon WB, Britton SW. Studies on conditions of activity in endocrine glands. XV. Pseudoaffective medulliadrenal secretion. AmJPhysiol. 1925; 72:283-294.

Carrive P, Dampney RA, Bandler R. Excitation of neurones in a restricted portion of the midbrain periaqueductal grey elicits both behavioural and cardiovascular components of the defence reaction in the unanaesthetised decerebrate cat. NeurosciLett. 1987; 81:273-278.

Carrive P, Bandler R, Dampney RA. Anatomical evidence that hypertension associated with the defence reaction in the cat is mediated by a direct projection from a restricted portion of the midbrain periaqueductal grey to the subretrofacial nucleus of the medulla. Brain Res. 1988; 460:339-345. [PubMed: 2465061]

Casey LM, Oei TP, Newcombe PA, Kenardy J. The role of catastrophic misinterpretation of bodily sensations and panic self-efficacy in predicting panic severity. J Anxiety Disord. 2004; 18:325340. [PubMed: 15125980]

Chapman WP, Singh MM, Schroeder HR, Fager C. Temporal lobe epilepsy: brief review; responses on electrical stimulation of the amygdaloid region in six patients. Am J Med. 1957; 23:107-119. [PubMed: 13444295]

Charney DS, Heninger GR. Noradrenergic function and the mechanism of action of antianxiety treatment. II. The effect of long-term imipramine treatment. ArchGenPsychiatry. 1985; 42:473481.

Charney DS, Woods SW, Goodman WK, Heninger GR. Serotonin function in anxiety. II. Effects of the serotonin agonist MCPP in panic disorder patients and healthy subjects. Psychopharmacology (Berl). 1987a; 92:14-24. [PubMed: 3110824]

Charney DS, Woods SW, Goodman WK, Heninger GR. Neurobiological mechanisms of panic anxiety: biochemical and behavioral correlates of yohimbine-induced panic attacks. Am J Psychiatry. 1987b; 144:1030-1036. [PubMed: 3037926]

Chen J, Tsuchiya M, Kawakami N, Furukawa TA. Non-fearful vs. fearful panic attacks: a general population study from the National Comorbidity Survey. J Affect Disord. 2009; 112:273-278. [PubMed: 18534684]

Chen P, Smith MS. Suckling-induced activation of neuronal input to the dorsomedial nucleus of the hypothalamus: possible candidates for mediating the activation of DMH neuropeptide Y neurons during lactation. Brain Res. 2003; 984:11-20. [PubMed: 12932835]

Clark DM. A cognitive approach to panic. Behav Res Ther. 1986; 24:461-470. [PubMed: 3741311]

Cloos JM, Ferreira V. Current use of benzodiazepines in anxiety disorders. Curr Opin Psychiatry. 2009; 22:90-95. [PubMed: 19122540]

Cohen AS, Barlow DH, Blanchard EB. Psychophysiology of relaxation-associated panic attacks. J Abnorm Psychol. 1985; 94:96-101. [PubMed: 3980861]

Condie BG, Bain G, Gottlieb DI, Capecchi MR. Cleft palate in mice with a targeted mutation in the gamma-aminobutyric acid-producing enzyme glutamic acid decarboxylase 67. Proc Natl Acad Sci U S A. 1997; 94:11451-11455. [PubMed: 9326630]

Coupland NJ, Wilson SJ, Potokar JP, Bell C, Nutt DJ. Increased sympathetic response to standing in panic disorder. Psychiatry Res. 2003; 118:69-79. [PubMed: 12759163]

Cowley DS, Dager SR, Dunner DL. Lactate infusions in major depression without panic attacks. JPsychiatrRes. 1987; 21:243-248.

Cox BJ, Swinson RP, Endler NS, Norton GR. The symptom structure of panic attacks. Compr Psychiatry. 1994; 35:349-353. [PubMed: 7995026]

Craig AD, Chen K, Bandy D, Reiman EM. Thermosensory activation of insular cortex. Nat Neurosci. 2000; 3:184-190. [PubMed: 10649575] 
Craske MG, Kircanski K, Epstein A, Wittchen HU, Pine DS, Lewis-Fernandez R, Hinton D. Panic disorder: a review of DSM-IV panic disorder and proposals for DSM-V. Depress Anxiety. 2010; 27:93-112. [PubMed: 20099270]

Critchley HD, Wiens S, Rotshtein P, Ohman A, Dolan RJ. Neural systems supporting interoceptive awareness. Nat Neurosci. 2004; 7:189-195. [PubMed: 14730305]

Dager SR, Marro KI, Richards TL, Metzger GD. Preliminary application of magnetic resonance spectroscopy to investigate lactate-induced panic. Am J Psychiatry. 1994; 151:57-63. [PubMed: 8267135]

Dager SR, Richards T, Strauss W, Artru A. Single-voxel 1H-MRS investigation of brain metabolic changes during lactate-induced panic. Psychiatry Res. 1997; 76:89-99. [PubMed: 9522401]

Davies SJ, Ghahramani P, Jackson PR, Noble TW, Hardy PG, Hippisley-Cox J, Yeo WW, Ramsay LE. Association of panic disorder and panic attacks with hypertension. Am J Med. 1999; 107:310316. [PubMed: 10527031]

de Beurs E, Garssen B, Buikhuisen M, Lange A, van Balkom A, Van Dyck R. Continuous monitoring of panic. Acta Psychiatr Scand. 1994; 90:38-45. [PubMed: 7976447]

De Cort K, Hermans D, Spruyt A, Griez E, Schruers K. A specific attentional bias in panic disorder? Depress Anxiety. 2008; 25:951-955. [PubMed: 17932961]

Dielenberg RA, Hunt GE, McGregor IS. "When a rat smells a cat": the distribution of Fos immunoreactivity in rat brain following exposure to a predatory odor. Neuroscience. 2001; 104:1085-1097. [PubMed: 11457592]

Domschke K, Deckert J, O’Donovan MC, Glatt SJ. Meta-analysis of COMT val158met in panic disorder: ethnic heterogeneity and gender specificity. Am J Med Genet B Neuropsychiatr Genet. 2007; 144B:667-673. [PubMed: 17357147]

Domschke K, Ohrmann P, Braun M, Suslow T, Bauer J, Hohoff C, Kersting A, Engelien A, Arolt V, Heindel W, Deckert J, Kugel H. Influence of the catechol-O-methyltransferase val158met genotype on amygdala and prefrontal cortex emotional processing in panic disorder. Psychiatry Res. 2008; 163:13-20. [PubMed: 18440204]

Dorow R, Horowski R, Paschelke G, Amin M. Severe anxiety induced by FG 7142, a beta-carboline ligand for benzodiazepine receptors. Lancet. 1983; 2:98-99. [PubMed: 6134976]

Dresler T, Guhn A, Tupak SV, Ehlis AC, Herrmann MJ, Fallgatter AJ, Deckert J, Domschke K. Revise the revised? New dimensions of the neuroanatomical hypothesis of panic disorder. J Neural Transm. 2013; 120:3-29. [PubMed: 22692647]

Dresler T, Hahn T, Plichta MM, Ernst LH, Tupak SV, Ehlis AC, Warrings B, Deckert J, Fallgatter AJ. Neural correlates of spontaneous panic attacks. J Neural Transm. 2011; 118:263-269. [PubMed: 21203784]

DSM-V. Diagnostic and Statistical Manual - Fifth Edn. (DSM - V). Washington, DC: American Psychiatric Association; 2013.

Duan YF, Winters R, McCabe PM, Green EJ, Huang Y, Schneiderman N. Behavioral characteristics of defense and vigilance reactions elicited by electrical stimulation of the hypothalamus in rabbits. BehavBrain Res. 1996; 81:33-41.

Ehlers A, Breuer P. How good are patients with panic disorder at perceiving their heartbeats? Biol Psychol. 1996; 42:165-182. [PubMed: 8770377]

Eren I, Tukel R, Polat A, Karaman R, Unal S. Evaluation of regional cerebral blood flow changes in panic disorder with Tc99m-HMPAO SPECT. Psychiatry Res. 2003; 123:135-143. [PubMed: 12850252]

Feinstein JS, Buzza C, Hurlemann R, Follmer RL, Dahdaleh NS, Coryell WH, Welsh MJ, Tranel D, Wemmie JA. Fear and panic in humans with bilateral amygdala damage. Nat Neurosci. 2013; 16:270-272. [PubMed: 23377128]

Ferguson AV, Samson WK. The orexin/hypocretin system: a critical regulator of neuroendocrine and autonomic function. Front Neuroendocrinol. 2003; 24:141-150. [PubMed: 14596809]

Folkow B, Di Bona GF, Hjemdahl P, Toren PH, Wallin BG. Measurements of plasma norepinephrine concentrations in human primary hypertension. A word of caution on their applicability for assessing neurogenic contributions. Hypertension. 1983; 5:399-403. [PubMed: 6345355] 
Forsyth JP, Eifert GH. Response intensity in content-specific fear conditioning comparing $20 \%$ versus 13\% CO2-enriched air as unconditioned stimuli. J Abnorm Psychol. 1998; 107:291-304. [PubMed: 9604558]

Forsyth JP, Lejuez CW, Finlay C. Anxiogenic effects of repeated administrations of $20 \%$ CO2enriched air: stability within sessions and habituation across time. J Behav Ther Exp Psychiatry. 2000a; 31:103-121. [PubMed: 11132115]

Forsyth JP, Eifert GH, Canna MA. Evoking analogue subtypes of panic attacks in a nonclinical population using carbon dioxide-enriched air. Behav Res Ther. 2000b; 38:559-572. [PubMed: 10846805]

Friedman SD, Mathis CM, Hayes C, Renshaw P, Dager SR. Brain pH response to hyperventilation in panic disorder: preliminary evidence for altered acid-base regulation. Am J Psychiatry. 2006; 163:710-715. [PubMed: 16585448]

Fyer AJ, Liebowitz MR, Gorman JM, Campeas R, Levin A, Davies SO, Goetz D, Klein DF. Discontinuation of alprazolam treatment in panic patients. Am J Psychiatry. 1987; 144:303-308. [PubMed: 3826428]

Fyer AJ, Hamilton SP, Durner M, Haghighi F, Heiman GA, Costa R, Evgrafov O, Adams P, de Leon AB, Taveras N, Klein DF, Hodge SE, Weissman MM, Knowles JA. A third-pass genome scan in panic disorder: evidence for multiple susceptibility loci. Biol Psychiatry. 2006; 60:388-401. [PubMed: 16919526]

Garpenstrand H, Annas P, Ekblom J, Oreland L, Fredrikson M. Human fear conditioning is related to dopaminergic and serotonergic biological markers. Behav Neurosci. 2001; 115:358-364. [PubMed: 11345960]

Gee DG, Gabard-Durnam LJ, Flannery J, Goff B, Humphreys KL, Telzer EH, Hare TA, Bookheimer SY, Tottenham N. Early developmental emergence of human amygdala-prefrontal connectivity after maternal deprivation. Proc Natl Acad Sci U S A. 2013a; 110:15638-15643. [PubMed: 24019460]

Gee DG, Humphreys KL, Flannery J, Goff B, Telzer EH, Shapiro M, Hare TA, Bookheimer SY, Tottenham N. A developmental shift from positive to negative connectivity in human amygdalaprefrontal circuitry. J Neurosci. 2013b; 33:4584-4593. [PubMed: 23467374]

Gee DG, Karlsgodt KH, van Erp TG, Bearden CE, Lieberman MD, Belger A, Perkins DO, Olvet DM, Cornblatt BA, Constable T, Woods SW, Addington J, Cadenhead KS, McGlashan TH, Seidman LJ, Tsuang MT, Walker EF, Cannon TD. Altered age-related trajectories of amygdala-prefrontal circuitry in adolescents at clinical high risk for psychosis: a preliminary study. Schizophr Res. 2012; 134:1-9. [PubMed: 22056201]

George DT, Lindquist T, Nutt DJ, Ragan PW, Alim T, McFarlane V, Leviss J, Eckardt MJ, Linnoila M. Effect of chloride or glucose on the incidence of lactate-induced panic attacks. AmJPsychiatry. 1995; 152:692-697.

Gittelman R, Klein DF. Relationship between separation anxiety and panic and agoraphobic disorders. Psychopathology 17 Suppl. 1984; 1:56-65.

Goddard AW, Brouette T, Almai A, Jetty P, Woods SW, Charney D. Early coadministration of clonazepam with sertraline for panic disorder. Arch Gen Psychiatry. 2001a; 58:681-686. [PubMed: 11448376]

Goddard AW, Mason GF, Appel M, Rothman DL, Gueorguieva R, Behar KL, Krystal JH. Impaired GABA neuronal response to acute benzodiazepine administration in panic disorder. Am $\mathbf{J}$ Psychiatry. 2004; 161:2186-2193. [PubMed: 15569888]

Goddard AW, Mason GF, Almai A, Rothman DL, Behar KL, Petroff OA, Charney DS, Krystal JH. Reductions in occipital cortex GABA levels in panic disorder detected with $1 \mathrm{~h}-$ magnetic resonance spectroscopy. Archives of General Psychiatry. 2001b; 58:556-561. [PubMed: 11386984]

Goetz RR, Gorman JM, Dillon DJ, Papp LA, Hollander E, Fyer AJ, Liebowitz MR, Klein DF. Do panic disorder patients indiscriminately endorse somatic complaints? Psychiatry Res. 1989; 29:207-213. [PubMed: 2798599] 
Gogos JA, Morgan M, Luine V, Santha M, Ogawa S, Pfaff D, Karayiorgou M. Catechol-Omethyltransferase-deficient mice exhibit sexually dimorphic changes in catecholamine levels and behavior. Proc Natl Acad Sci U S A. 1998; 95:9991-9996. [PubMed: 9707588]

Goldin PR, McRae K, Ramel W, Gross JJ. The neural bases of emotion regulation: reappraisal and suppression of negative emotion. Biol Psychiatry. 2008; 63:577-586. [PubMed: 17888411]

Goldstein DS. Plasma catecholamines and essential hypertension. An analytical review. Hypertension. 1983; 5:86-99. [PubMed: 6336721]

Goldstein DS, Horwitz D, Keiser HR, Polinsky RJ, Kopin IJ. Plasma 1-[3H]norepinephrine, d[14C]norepinephrine, and d,1-[3H]isoproterenol kinetics in essential hypertension. J Clin Invest. 1983; 72:1748-1758. [PubMed: 6630523]

Goodwin RD, Faravelli C, Rosi S, Cosci F, Truglia E, de Graaf R, Wittchen HU. The epidemiology of panic disorder and agoraphobia in Europe. Eur Neuropsychopharmacol. 2005; 15:435-443. [PubMed: 15925492]

Gorman JM, Kent JM, Sullivan GM, Coplan JD. Neuroanatomical hypothesis of panic disorder, revised. AmJPsychiatry. 2000; 157:493-505.

Gorman JM, Askanazi J, Liebowitz MR, Fyer AJ, Stein J, Kinney JM, Klein DF. Response to hyperventilation in a group of patients with panic disorder. Am J Psychiatry. 1984; 141:857-861. [PubMed: 6428243]

Gorman JM, Liebowitz MR, Fyer AJ, Dillon D, Davies SO, Stein J, Klein DF. Lactate infusions in obsessive-compulsive disorder. AmJPsychiatry. 1985; 142:864-866.

Gorman JM, Cohen BS, Liebowitz MR, Fyer AJ, Ross D, Davies SO, Klein DF. Blood gas changes and hypophosphatemia in lactate-induced panic. Arch Gen Psychiatry. 1986; 43:1067-1071. [PubMed: 3094475]

Gorman JM, Papp LA, Coplan JD, Martinez JM, Lennon S, Goetz RR, Ross D, Klein DF. Anxiogenic effects of $\mathrm{CO} 2$ and hyperventilation in patients with panic disorder. AmJPsychiatry. 1994; 151:547-553.

Gorman JM, Battista D, Goetz RR, Dillon DJ, Liebowitz MR, Fyer AJ, Kahn JP, Sandberg D, Klein DF. A comparison of sodium bicarbonate and sodium lactate infusion in the induction of panic attacks. ArchGenPsychiatry. 1989; 46:145-150.

Grassi M, Caldirola D, Vanni G, Guerriero G, Piccinni M, Valchera A, Perna G. Baseline respiratory parameters in panic disorder: a meta-analysis. J Affect Disord. 2013; 146:158-173. [PubMed: 23107756]

Griebel G, Holmes A. 50 years of hurdles and hope in anxiolytic drug discovery. Nature reviews. $2013 ; 12: 667-687$.

Guyenet PG, Stornetta RL, Abbott SB, Depuy SD, Fortuna MG, Kanbar R. Central CO2 chemoreception and integrated neural mechanisms of cardiovascular and respiratory control. J Appl Physiol. 2010; 108:995-1002. [PubMed: 20075262]

Hariri AR, Mattay VS, Tessitore A, Kolachana B, Fera F, Goldman D, Egan MF, Weinberger DR. Serotonin transporter genetic variation and the response of the human amygdala. Science. 2002; 297:400-403. [PubMed: 12130784]

Hayano F, Nakamura M, Asami T, Uehara K, Yoshida T, Roppongi T, Otsuka T, Inoue T, Hirayasu Y. Smaller amygdala is associated with anxiety in patients with panic disorder. Psychiatry Clin Neurosci. 2009; 63:266-276. [PubMed: 19566756]

Heils A, Teufel A, Petri S, Stober G, Riederer P, Bengel D, Lesch KP. Allelic variation of human serotonin transporter gene expression. J Neurochem. 1996; 66:2621-2624. [PubMed: 8632190]

Heinz A, Smolka MN, Braus DF, Wrase J, Beck A, Flor H, Mann K, Schumann G, Buchel C, Hariri AR, Weinberger DR. Serotonin transporter genotype (5-HTTLPR): effects of neutral and undefined conditions on amygdala activation. Biol Psychiatry. 2007; 61:1011-1014. [PubMed: 17157270]

Hess WR, Brugger M. Das subkortikake Zenrrumder affektriven Abwehrreaktion. HelvPhysiolActa. $1943 ; 1: 33-52$.

Hess WR, Akert K. Experimental data on role of hypothalamus in mechanism of emotional behavior. AMAArchNeurolPsychiatry. 1955; 73:127-129. 
Hettema JM, Neale MC, Kendler KS. A review and meta-analysis of the genetic epidemiology of anxiety disorders. Am J Psychiatry. 2001; 158:1568-1578. [PubMed: 11578982]

Hettema JM, Prescott CA, Myers JM, Neale MC, Kendler KS. The structure of genetic and environmental risk factors for anxiety disorders in men and women. Arch Gen Psychiatry. 2005; 62:182-189. [PubMed: 15699295]

Hettema JM, An SS, Neale MC, Bukszar J, van den Oord EJ, Kendler KS, Chen X. Association between glutamic acid decarboxylase genes and anxiety disorders, major depression, and neuroticism. Mol Psychiatry. 2006

Hoehn-Saric R, McLeod DR, Funderburk F, Kowalski P. Somatic symptoms and physiologic responses in generalized anxiety disorder and panic disorder: an ambulatory monitor study. Arch Gen Psychiatry. 2004; 61:913-921. [PubMed: 15351770]

Hofmann SG, Sawyer AT, Asnaani A. D-cycloserine as an augmentation strategy for cognitive behavioral therapy for anxiety disorders: an update. Current pharmaceutical design. 2012a; 18:5659-5662. [PubMed: 22632472]

Hofmann SG, Sawyer AT, Korte KJ, Smits JA. Is it Beneficial to Add Pharmacotherapy to CognitiveBehavioral Therapy when Treating Anxiety Disorders? A Meta-Analytic Review. International journal of cognitive therapy. 2009; 2:160-175. [PubMed: 19714228]

Hofmann SG, Asnaani A, Vonk IJ, Sawyer AT, Fang A. The Efficacy of Cognitive Behavioral Therapy: A Review of Meta-analyses. Cognitive therapy and research. 2012b; 36:427-440. [PubMed: 23459093]

Homberg JR, Olivier JD, Smits BM, Mul JD, Mudde J, Verheul M, Nieuwenhuizen OF, Cools AR, Ronken E, Cremers T, Schoffelmeer AN, Ellenbroek BA, Cuppen E. Characterization of the serotonin transporter knockout rat: a selective change in the functioning of the serotonergic system. Neuroscience. 2007; 146:1662-1676. [PubMed: 17467186]

Huckstepp RT, Dale N. Redefining the components of central CO2 chemosensitivity--towards a better understanding of mechanism. J Physiol. 2011; 589:5561-5579. [PubMed: 22005672]

Huttenlocher PR. Synaptic density in human frontal cortex - developmental changes and effects of aging. Brain Res. 1979; 163:195-205. [PubMed: 427544]

Huttenlocher PR. Synapse elimination and plasticity in developing human cerebral cortex. American journal of mental deficiency. 1984; 88:488-496. [PubMed: 6731486]

Insel TR. Rethinking schizophrenia. Nature. 2010; 468:187-193. [PubMed: 21068826]

Ito T, Inoue Y, Sugihara T, Yamada H, Katayama S, Kawahara R. Autonomic function in the early stage of panic disorder: power spectral analysis of heart rate variability. Psychiatry Clin Neurosci. 1999; 53:667-672. [PubMed: 10687748]

Jansen AS, Wessendorf MW, Loewy AD. Transneuronal labeling of CNS neuropeptide and monoamine neurons after pseudorabies virus injections into the stellate ganglion. Brain Res. 1995; 683:1-24. [PubMed: 7552333]

Jensen CF, Peskind ER, Keller TW, McFall ME, Raskind MA. Comparison of sodium lactate-induced panic symptoms between panic disorder and posttraumatic stress disorder. DepressAnxiety. 1998; 7:122-125.

Joeyen-Waldorf J, Edgar N, Sibille E. The roles of sex and serotonin transporter levels in age- and stress-related emotionality in mice. Brain Res. 2009; 1286:84-93. [PubMed: 19577546]

Johnson P, Lowry C, Truitt W, Shekhar A. Disruption of GABAergic tone in the dorsomedial hypothalamus attenuates responses in a subset of serotonergic neurons in the dorsal raphe nucleus following lactate-induced panic. J Psychopharmacol. 2008a; 22:642-652. [PubMed: 18308791]

Johnson, PJ.; Samuels, BC.; Fitz, SD.; Federici, LM.; Hammes, N.; Early, MC.; Truitt, W.; Lowry, CA.; Shekhar, A. Orexin 1 receptors are a novel target to modulate panic responses and the panic brain network. Physiol Behav in press. 2012a.

Johnson PL, Shekhar A. Panic-prone state induced in rats with GABA dysfunction in the dorsomedial hypothalamus is mediated by NMDA receptors. J Neurosci. 2006; 26:7093-7104. [PubMed: 16807338] 
Johnson PL, Shekhar A. An animal model of panic vulnerability with chronic disinhibition of the dorsomedial/perifornical hypothalamus. Physiol Behav. 2012; 107:686-698. [PubMed: 22484112]

Johnson PL, Hollis JH, Moratalla R, Lightman SL, Lowry CA. Acute hypercarbic gas exposure reveals functionally distinct subpopulations of serotonergic neurons in rats. J Psychopharmacol. 2005; 19:327-341. [PubMed: 15982987]

Johnson PL, Truitt WA, Fitz SD, Lowry CA, Shekhar A. Neural pathways underlying lactate-induced panic. Neuropsychopharmacology. 2008b; 33:2093-2107. [PubMed: 18059441]

Johnson PL, Molosh A, Fitz SD, Truitt WA, Shekhar A. Orexin, stress, and anxiety/panic states. Prog Brain Res. 2012b; 198:133-161. [PubMed: 22813973]

Johnson PL, Samuels BC, Fitz SD, Lightman SL, Lowry CA, Shekhar A. Activation of the orexin 1 receptor is a critical component of $\mathrm{CO} 2$-mediated anxiety and hypertension but not bradycardia. Neuropsychopharmacology. 2012c; 37:1911-1922. [PubMed: 22453138]

Johnson PL, Fitz SD, Hollis JH, Moratalla R, Lightman SL, Shekhar A, Lowry CA. Induction of c-Fos in 'panic/defence'-related brain circuits following brief hypercarbic gas exposure. J Psychopharmacol. 2011; 25:26-36. [PubMed: 20080924]

Johnson, PL.; Federici, LM.; Fitz, SD.; Molosh, AI.; Truitt, W.; Lowry, CA.; Shekhar, A. Serotonin Transporter Deficient Rats Exhibit Enhanced Acquisition and Disrupted Extinction of Conditioned Fear; 52nd American College of Neuropsychopharmacology Meeting; 2012d.

Johnson PL, Truitt W, Fitz SD, Minick PE, Dietrich A, Sanghani S, Traskman-Bendz L, Goddard AW, Brundin L, Shekhar A. A key role for orexin in panic anxiety. Nature medicine. 2010; 16:111115.

Jones M, Mellersh V. A comparison of the exercise response in anxiety states and normal controls. Psychosom Med. 1946; 8:180-187. [PubMed: 20984314]

Kash SF, Tecott LH, Hodge C, Baekkeskov S. Increased anxiety and altered responses to anxiolytics in mice deficient in the $65-\mathrm{kDa}$ isoform of glutamic acid decarboxylase. Proc Natl Acad Sci U S A. 1999; 96:1698-1703. [PubMed: 9990087]

Kellner M, Muhtz C, Stark K, Yassouridis A, Arlt J, Wiedemann K. Effects of a metabotropic glutamate(2/3) receptor agonist (LY544344/LY354740) on panic anxiety induced by cholecystokinin tetrapeptide in healthy humans: preliminary results. Psychopharmacology (Berl). 2005; 179:310-315. [PubMed: 15821951]

Kelly D, Mitchell-Heggs N, Sherman D. Anxiety and the effects of sodium lactate assessed clinically and physiologically. BrJPsychiatry. 1971; 119:129-141.

Kessler RC, Ruscio AM, Shear K, Wittchen HU. Epidemiology of anxiety disorders. Current topics in behavioral neurosciences. 2010; 2:21-35. [PubMed: 21309104]

Kessler RC, Chiu WT, Jin R, Ruscio AM, Shear K, Walters EE. The epidemiology of panic attacks, panic disorder, and agoraphobia in the National Comorbidity Survey Replication. Arch Gen Psychiatry. 2006; 63:415-424. [PubMed: 16585471]

Kheirbek MA, Klemenhagen KC, Sahay A, Hen R. Neurogenesis and generalization: a new approach to stratify and treat anxiety disorders. Nat Neurosci. 2012; 15:1613-1620. [PubMed: 23187693]

Kim B, Yoo E, Lee JY, Lee KS, Choe AY, Lee JE, Kwack K, Yook KH, Choi TK, Lee SH. The effects of the catechol-O-methyltransferase val158met polymorphism on white matter connectivity in patients with panic disorder. J Affect Disord. 2013; 147:64-71. [PubMed: 23141115]

Klein DF. False suffocation alarms, spontaneous panics, and related conditions. An integrative hypothesis. ArchGenPsychiatry. 1993; 50:306-317.

Klumpers F, Heitland I, Oosting RS, Kenemans JL, Baas JM. Genetic variation in serotonin transporter function affects human fear expression indexed by fear-potentiated startle. Biol Psychol. 2012; 89:277-282. [PubMed: 22061270]

Knight DC, Nguyen HT, Bandettini PA. The role of the human amygdala in the production of conditioned fear responses. NeuroImage. 2005; 26:1193-1200. [PubMed: 15961053]

LaBar KS, LeDoux JE, Spencer DD, Phelps EA. Impaired fear conditioning following unilateral temporal lobectomy in humans. J Neurosci. 1995; 15:6846-6855. [PubMed: 7472442] 
Lai CH, Hsu YY, Wu YT. First episode drug-naive major depressive disorder with panic disorder: gray matter deficits in limbic and default network structures. Eur Neuropsychopharmacol. 2010; 20:676-682. [PubMed: 20599363]

Layton ME, Friedman SD, Dager SR. Brain metabolic changes during lactate-induced panic: effects of gabapentin treatment. DepressAnxiety. 2001; 14:251-254.

Lesch KP, Bengel D, Heils A, Sabol SZ, Greenberg BD, Petri S, Benjamin J, Muller CR, Hamer DH, Murphy DL. Association of anxiety-related traits with a polymorphism in the serotonin transporter gene regulatory region. Science. 1996; 274:1527-1531. [PubMed: 8929413]

Ley R. The "suffocation alarm" theory of panic attacks: a critical commentary. J Behav Ther Exp Psychiatry. 1994; 25:269-273. [PubMed: 7706503]

Li BH, Rowland NE. Dexfenfluramine induces Fos-like immunoreactivity in discrete brain regions in rats. Brain Res Bull. 1993; 31:43-48. [PubMed: 8453494]

Liebowitz MR, Fyer AJ, Gorman JM, Dillon D, Davies S, Stein JM, Cohen BS, Klein DF. Specificity of lactate infusions in social phobia versus panic disorders. AmJPsychiatry. 1985a; 142:947-950.

Liebowitz MR, Fyer AJ, Gorman JM, Dillon D, Appleby IL, Levy G, Anderson S, Levitt M, Palij M, Davies SO. Lactate provocation of panic attacks. I. Clinical and behavioral findings. ArchGenPsychiatry. 1984; 41:764-770.

Liebowitz MR, Gorman JM, Fyer AJ, Levitt M, Dillon D, Levy G, Appleby IL, Anderson S, Palij M, Davies SO, et al. Lactate provocation of panic attacks. II. Biochemical and physiological findings. Arch Gen Psychiatry. 1985b; 42:709-719. [PubMed: 4015313]

Line SJ, Barkus C, Coyle C, Jennings KA, Deacon RM, Lesch KP, Sharp T, Bannerman DM. Opposing alterations in anxiety and species-typical behaviours in serotonin transporter overexpressor and knockout mice. Eur Neuropsychopharmacol. 2011; 21:108-116. [PubMed: 20863670]

Little KY, McLaughlin DP, Zhang L, Livermore CS, Dalack GW, McFinton PR, DelProposto ZS, Hill E, Cassin BJ, Watson SJ, Cook EH. Cocaine, ethanol, and genotype effects on human midbrain serotonin transporter binding sites and mRNA levels. Am J Psychiatry. 1998; 155:207-213. [PubMed: 9464199]

Lonsdorf TB, Ruck C, Bergstrom J, Andersson G, Ohman A, Schalling M, Lindefors N. The symptomatic profile of panic disorder is shaped by the 5-HTTLPR polymorphism. Prog Neuropsychopharmacol Biol Psychiatry. 2009; 33:1479-1483. [PubMed: 19683026]

Lundh LG, Wikstrom J, Westerlund J, Ost LG. Preattentive bias for emotional information in panic disorder with agoraphobia. J Abnorm Psychol. 1999; 108:222-232. [PubMed: 10369032]

Lynn R. National rates of economic growth, anxiety and suicide. Nature. 1969; 222:494. [PubMed: 5768635]

Margraf J, Taylor B, Ehlers A, Roth WT, Agras WS. Panic attacks in the natural environment. J Nerv Ment Dis. 1987; 175:558-565. [PubMed: 3655782]

Markgraf CG, Winters RW, Liskowsky DR, McCabe PM, Green EJ, Schneiderman N. Hypothalamic, midbrain and bulbar areas involved in the defense reaction in rabbits. Physiol Behav. 1991; 49:493-500. [PubMed: 2062925]

Maron E, Hettema JM, Shlik J. Advances in molecular genetics of panic disorder. Mol Psychiatry. 2010; 15:681-701. [PubMed: 20048750]

Maron E, Nikopensius T, Koks S, Altmae S, Heinaste E, Vabrit K, Tammekivi V, Hallast P, Koido K, Kurg A, Metspalu A, Vasar E, Vasar V, Shlik J. Association study of 90 candidate gene polymorphisms in panic disorder. Psychiatr Genet. 2005; 15:17-24. [PubMed: 15722953]

Martinez JM, Garakani A, Kaufmann H, Aaronson CJ, Gorman JM. Heart rate and blood pressure changes during autonomic nervous system challenge in panic disorder patients. Psychosom Med. 2010; 72:442-449. [PubMed: 20368476]

Massana G, Serra-Grabulosa JM, Salgado-Pineda P, Gasto C, Junque C, Massana J, Mercader JM, Gomez B, Tobena A, Salamero M. Amygdalar atrophy in panic disorder patients detected by volumetric magnetic resonance imaging. Neuroimage. 2003; 19:80-90. [PubMed: 12781728]

Matsuura S, Kakizaki H, Mitsui T, Shiga T, Tamaki N, Koyanagi T. Human brain region response to distention or cold stimulation of the bladder: a positron emission tomography study. J Urol. 2002; 168:2035-2039. [PubMed: 12394703] 
McDowall LM, Horiuchi J, Killinger S, Dampney RA. Modulation of the baroreceptor reflex by the dorsomedial hypothalamic nucleus and perifornical area. Am J Physiol Regul Integr Comp Physiol. 2006; 290:R1020-R1026. [PubMed: 16284085]

McNally RJ, Lukach BM. Are panic attacks traumatic stressors? Am J Psychiatry. 1992; 149:824-826. [PubMed: 1590501]

McNally RJ, Riemann BC, Kim E. Selective processing of threat cues in panic disorder. Behav Res Ther. 1990; 28:407-412. [PubMed: 2256899]

McNally RJ, Riemann BC, Louro CE, Lukach BM, Kim E. Cognitive processing of emotional information in panic disorder. Behav Res Ther. 1992; 30:143-149. [PubMed: 1567343]

McNally RJ, Amir N, Louro CE, Lukach BM, Riemann BC, Calamari JE. Cognitive processing of idiographic emotional information in panic disorder. Behav Res Ther. 1994; 32:119-122. [PubMed: 8135709]

Meletti S, Tassi L, Mai R, Fini N, Tassinari CA, Russo GL. Emotions induced by intracerebral electrical stimulation of the temporal lobe. Epilepsia. 2006; 47(Suppl 5):47-51. [PubMed: 17239106]

Meuret AE, White KS, Ritz T, Roth WT, Hofmann SG, Brown TA. Panic attack symptom dimensions and their relationship to illness characteristics in panic disorder. J Psychiatr Res. 2005

Milad MR, Quirk GJ. Fear extinction as a model for translational neuroscience: ten years of progress. Annu Rev Psychol. 2012; 63:129-151. [PubMed: 22129456]

Milad MR, Quinn BT, Pitman RK, Orr SP, Fischl B, Rauch SL. Thickness of ventromedial prefrontal cortex in humans is correlated with extinction memory. Proc Natl Acad Sci U S A. 2005; 102:10706-10711. [PubMed: 16024728]

Milad MR, Zeidan MA, Contero A, Pitman RK, Klibanski A, Rauch SL, Goldstein JM. The influence of gonadal hormones on conditioned fear extinction in healthy humans. Neuroscience. 2010; 168:652-658. [PubMed: 20412837]

Mitte K. A meta-analysis of the efficacy of psycho- and pharmacotherapy in panic disorder with and without agoraphobia. J Affect Disord. 2005; 88:27-45. [PubMed: 16005982]

Molosh AI, Johnson PL, Fitz SD, Dimicco JA, Herman JP, Shekhar A. Changes in Central Sodium and not Osmolarity or Lactate Induce Panic-Like Responses in a Model of Panic Disorder. Neuropsychopharmacology. 2010

Nardi AE, Valenca AM, Nascimento I, Zin WA. Hyperventilation challenge test in panic disorder and depression with panic attacks. Psychiatry Research. 2001; 105:57-65. [PubMed: 11740975]

Nardi AE, Valenca AM, Nascimento I, Mezzasalma MA, Zin W. Panic disorder and hyperventilation. Arquivos de Neuro-Psiquiatria. 1999; 57:932-936. [PubMed: 10683682]

Nashold BS Jr. Wilson WP, Slaughter DG. Sensations evoked by stimulation in the midbrain of man. JNeurosurg. 1969; 30:14-24. [PubMed: 4885810]

Nikolaus S, Antke C, Beu M, Muller HW. Cortical GABA, striatal dopamine and midbrain serotonin as the key players in compulsive and anxiety disorders--results from in vivo imaging studies. Reviews in the neurosciences. 2010; 21:119-139. [PubMed: 20614802]

Nillni YI, Toufexis DJ, Rohan KJ. Anxiety sensitivity, the menstrual cycle, and panic disorder: a putative neuroendocrine and psychological interaction. Clinical psychology review. 2011; 31:1183-1191. [PubMed: 21855828]

Nutt DJ, Ballenger JC, Sheehan D, Wittchen HU. Generalized anxiety disorder: comorbidity, comparative biology and treatment. Int J Neuropsychopharmacol. 2002; 5:315-325. [PubMed: 12466031]

Olivier JD, Van Der Hart MG, Van Swelm RP, Dederen PJ, Homberg JR, Cremers T, Deen PM, Cuppen E, Cools AR, Ellenbroek BA. A study in male and female 5-HT transporter knockout rats: an animal model for anxiety and depression disorders. Neuroscience. 2008; 152:573-584. [PubMed: 18295409]

Ost LG. Cognitive behavior therapy for anxiety disorders: 40 years of progress. Nordic journal of psychiatry 62 Suppl. 2008; 47:5-10.

Otte C. Cognitive behavioral therapy in anxiety disorders: current state of the evidence. Dialogues in clinical neuroscience. 2011; 13:413-421. [PubMed: 22275847] 
Otto MW, Tolin DF, Simon NM, Pearlson GD, Basden S, Meunier SA, Hofmann SG, Eisenmenger K, Krystal JH, Pollack MH. Efficacy of d-cycloserine for enhancing response to cognitive-behavior therapy for panic disorder. Biol Psychiatry. 2010; 67:365-370. [PubMed: 19811776]

Palkovits M. [Insula, a "mysterious" island in our brain -- minireview]. Orvosi hetilap. 2010; 151:1924-1929. [PubMed: 21071302]

Penfield W. Memory mechanisms. AMA archives of neurology and psychiatry. 1952; 67:178-198.

Perez, JA.; Otowa, T.; Roberson-Nay, R.; Hettema, JM. Genetics of Anxiety Disorders. In: Charney, D.; Sklar, P.; Buxbaum, JD.; Nestler, EJ., editors. Neurobiology of Mental Illness. 4th Edition. New York, NY: Oxford University Press; 2013.

Perna G, Guerriero G, Caldirola D. Emerging drugs for panic disorder. Expert Opin Emerg Drugs. 2011; 16:631-645. [PubMed: 21999303]

Peskind ER, Jensen CF, Pascualy M, Tsuang D, Cowley D, Martin DC, Wilkinson CW, Raskind MA. Sodium lactate and hypertonic sodium chloride induce equivalent panic incidence, panic symptoms, and hypernatremia in panic disorder. BiolPsychiatry. 1998; 44:1007-1016.

Pfleiderer B, Zinkirciran S, Arolt V, Heindel W, Deckert J, Domschke K. fMRI amygdala activation during a spontaneous panic attack in a patient with panic disorder. World J Biol Psychiatry. 2007; 8:269-272. [PubMed: 17853295]

Phelps EA, Delgado MR, Nearing KI, LeDoux JE. Extinction learning in humans: role of the amygdala and vmPFC. Neuron. 2004; 43:897-905. [PubMed: 15363399]

Pitts FN Jr. McClure JN Jr. Lactate metabolism in anxiety neurosis. NEnglJMed. 1967; 277:1329_ 1336.

Pollack M, Mangano R, Entsuah R, Tzanis E, Simon NM, Zhang Y. A randomized controlled trial of venlafaxine ER and paroxetine in the treatment of outpatients with panic disorder. Psychopharmacology (Berl). 2007a; 194:233-242. [PubMed: 17589833]

Pollack MH, Lepola U, Koponen H, Simon NM, Worthington JJ, Emilien G, Tzanis E, Salinas E, Whitaker T, Gao B. A double-blind study of the efficacy of venlafaxine extended-release, paroxetine, and placebo in the treatment of panic disorder. Depress Anxiety. 2007b; 24:1-14. [PubMed: 16894619]

Pollock RA, Carter AS, Amir N, Marks LE. Anxiety sensitivity and auditory perception of heartbeat. Behav Res Ther. 2006

Prasko J, Horacek J, Zalesky R, Kopecek M, Novak T, Paskova B, Skrdlantova L, Belohlavek O, Hoschl C. The change of regional brain metabolism (18FDG PET) in panic disorder during the treatment with cognitive behavioral therapy or antidepressants. Neuro Endocrinol Lett. 2004; 25:340-348. [PubMed: 15580167]

Protopopescu X, Pan H, Tuescher O, Cloitre M, Goldstein M, Engelien A, Yang Y, Gorman J, LeDoux J, Stern E, Silbersweig D. Increased brainstem volume in panic disorder: a voxel-based morphometric study. Neuroreport. 2006; 17:361-363. [PubMed: 16514359]

Rasche D, Foethke D, Gliemroth J, Tronnier VM. [Deep brain stimulation in the posterior hypothalamus for chronic cluster headache. Case report and review of the literature]. Schmerz. 2006; 20:439-444. [PubMed: 16404629]

Rauch SL, Milad MR, Orr SP, Quinn BT, Fischl B, Pitman RK. Orbitofrontal thickness, retention of fear extinction, and extraversion. Neuroreport. 2005; 16:1909-1912. [PubMed: 16272877]

Reed V, Wittchen HU. DSM-IV panic attacks and panic disorder in a community sample of adolescents and young adults: how specific are panic attacks? J Psychiatr Res. 1998; 32:335-345. [PubMed: 9844949]

Reiman EM, Raichle ME, Robins E, Mintun MA, Fusselman MJ, Fox PT, Price JL, Hackman KA. Neuroanatomical correlates of a lactate-induced anxiety attack. ArchGenPsychiatry. 1989; 46:493-500.

Rifkin A, Klein DF, Dillon D, Levitt M. Blockade by imipramine or desipramine of panic induced by sodium lactate. Am J Psychiatry. 1981; 138:676-677. [PubMed: 7235068]

Rupprecht R, et al. Translocator protein $(18 \mathrm{kD})$ as target for anxiolytics without benzodiazepine-like side effects. Science. 2009; 325:490-493. [PubMed: 19541954] 
Sakai Y, Kumano H, Nishikawa M, Sakano Y, Kaiya H, Imabayashi E, Ohnishi T, Matsuda H, Yasuda A, Sato A, Diksic M, Kuboki T. Cerebral glucose metabolism associated with a fear network in panic disorder. Neuroreport. 2005; 16:927-931. [PubMed: 15931063]

Sakai Y, Kumano H, Nishikawa M, Sakano Y, Kaiya H, Imabayashi E, Ohnishi T, Matsuda H, Yasuda A, Sato A, Diksic M, Kuboki T. Changes in cerebral glucose utilization in patients with panic disorder treated with cognitive-behavioral therapy. NeuroImage. 2006; 33:218-226. [PubMed: 16889985]

Samuels BC, Zaretsky DV, DiMicco JA. Tachycardia evoked by disinhibition of the dorsomedial hypothalamus in rats is mediated through medullary raphe. JPhysiol. 2002; 538:941-946. [PubMed: 11826177]

Sanchez-Meca J, Rosa-Alcazar AI, Marin-Martinez F, Gomez-Conesa A. Psychological treatment of panic disorder with or without agoraphobia: a meta-analysis. Clinical psychology review. 2010; 30:37-50. [PubMed: 19775792]

Sanderson WC, Rapee RM, Barlow DH. Panic induction via inhalation of 5.5\% CO2 enriched air: a single subject analysis of psychological and physiological effects. Behav Res Ther. 1988; 26:333-335. [PubMed: 3145734]

Schenberg LC, Lovick TA. Neurones in the medullary raphe nuclei attenuate the cardiovascular responses evoked from the dorsolateral periaqueductal grey matter. Brain Res. 1994; 651:236240. [PubMed: 7922570]

Schmidt NB, Zvolensky MJ. Anxiety sensitivity and CO2 challenge reactivity as unique and interactive prospective predictors of anxiety pathology. Depress Anxiety. 2007; 24:527-536. [PubMed: 17136755]

Schoepp DD, Wright RA, Levine LR, Gaydos B, Potter WZ. LY354740, an mGlu2/3 receptor agonist as a novel approach to treat anxiety/stress. Stress. 2003; 6:189-197. [PubMed: 13129812]

Schruers K, Esquivel G, van Duinen M, Wichers M, Kenis G, Colasanti A, Knuts I, Goossens L, Jacobs N, van Rozendaal J, Smeets H, van Os J, Griez E. Genetic moderation of CO2-induced fear by 5-HTTLPR genotype. J Psychopharmacol. 2011; 25:37-42. [PubMed: 20584994]

Schumacher J, Kristensen AS, Wendland JR, Nothen MM, Mors O, McMahon FJ. The genetics of panic disorder. Journal of medical genetics. 2011; 48:361-368. [PubMed: 21493958]

Sheikh JI, Leskin GA, Klein DF. Gender differences in panic disorder: findings from the National Cormobidity Survey. AmJPsychiatry. 2002; 159:55-58.

Shekhar A, DiMicco JA. Defense reaction elicited by injection of GABA antagonists and synthesis inhibitors into the posterior hypothalamus in rats. Neuropharmacology. 1987; 26:407-417. [PubMed: 3037412]

Shekhar A, Keim SR. The circumventricular organs form a potential neural pathway for lactate sensitivity: implications for panic disorder. J Neurosci. 1997; 17:9726-9735. [PubMed: 9391025]

Shekhar A, Keim SR. LY354740, a potent group II metabotropic glutamate receptor agonist prevents lactate-induced panic-like response in panic-prone rats. Neuropharmacology. 2000; 39:1139_ 1146. [PubMed: 10760357]

Shekhar A, Hingtgen JN, DiMicco JA. GABA receptors in the posterior hypothalamus regulate experimental anxiety in rats. Brain Res. 1990a; 512:81-88. [PubMed: 2159830]

Shekhar A, Hingtgen JN, DiMicco JA. GABA receptors in the posterior hypothalamus regulate experimental anxiety in rats. Brain Res. 1990b; 512:81-88. [PubMed: 2159830]

Shekhar A, Keim SR, Simon JR, McBride WJ. Dorsomedial hypothalamic GABA dysfunction produces physiological arousal following sodium lactate infusions. Pharmacol Biochem Behav. 1996; 55:249-256. [PubMed: 8951961]

Shekhar A, Johnson PL, Fitz SD, Nakazato A, Chaki S, Steckler T, Schmidt M. A selective, nonpeptide CRF receptor 1 antagonist prevents sodium lactate-induced acute panic-like responses. Int J Neuropsychopharmacol. 2011; 14:355-365. [PubMed: 21087553]

Shekhar A, Johnson PL, Sajdyk TJ, Fitz SD, Keim SR, Kelley PE, Gehlert DR, DiMicco JA. Angiotensin-II is a putative neurotransmitter in lactate-induced panic-like responses in rats with disruption of GABAergic inhibition in the dorsomedial hypothalamus. J Neurosci. 2006; 26:9205-9215. [PubMed: 16957077] 
Shekhar A, McCann UD, Meaney MJ, Blanchard DC, Davis M, Frey KA, Liberzon I, Overall KL, Shear MK, Tecott LH, Winsky L. Summary of a National Institute of Mental Health workshop: developing animal models of anxiety disorders. Psychopharmacology (Berl). 2001; 157:327-339. [PubMed: 11605091]

Shin LM, Liberzon I. The neurocircuitry of fear, stress, and anxiety disorders. Neuropsychopharmacology. 2010; 35:169-191. [PubMed: 19625997]

Shulman ID, Cox BJ, Swinson RP, Kuch K, Reichman JT. Precipitating events, locations and reactions associated with initial unexpected panic attacks. Behav Res Ther. 1994; 32:17-20. [PubMed: 8135717]

Singewald N, Sharp T. Neuroanatomical targets of anxiogenic drugs in the hindbrain as revealed by Fos immunocytochemistry. Neuroscience. 2000; 98:759-770. [PubMed: 10891619]

Singewald N, Salchner P, Sharp T. Induction of c-Fos expression in specific areas of the fear circuitry in rat forebrain by anxiogenic drugs. BiolPsychiatry. 2003; 53:275-283.

Smith JE, Jansen AS, Gilbey MP, Loewy AD. CNS cell groups projecting to sympathetic outflow of tail artery: neural circuits involved in heat loss in the rat. Brain Res. 1998; 786:153-164. [PubMed: 9554992]

Sobanski T, Wagner G, Peikert G, Gruhn U, Schluttig K, Sauer H, Schlosser R. Temporal and right frontal lobe alterations in panic disorder: a quantitative volumetric and voxel-based morphometric MRI study. Psychol Med. 2010; 40:1879-1886. [PubMed: 20056020]

Soltis RP, DiMicco JA. Hypothalamic excitatory amino acid receptors mediate stress-induced tachycardia in rats. AmJPhysiol. 1992; 262:R689-R697.

Spear LP. The adolescent brain and age-related behavioral manifestations. Neurosci Biobehav Rev. 2000; 24:417-463. [PubMed: 10817843]

Spiegelhalder K, Hornyak M, Kyle SD, Paul D, Blechert J, Seifritz E, Hennig J, Tebartz van Elst L, Riemann D, Feige B. Cerebral correlates of heart rate variations during a spontaneous panic attack in the fMRI scanner. Neurocase. 2009; 15:527-534. [PubMed: 19657971]

Stein DJ, Bouwer C. A neuro-evolutionary approach to the anxiety disorders. JAnxietyDisord. 1997; 11:409-429.

Stein MB, Asmundson GJ. Autonomic function in panic disorder: cardiorespiratory and plasma catecholamine responsivity to multiple challenges of the autonomic nervous system. Biol Psychiatry. 1994; 36:548-558. [PubMed: 7827218]

Stein MB, Tancer ME, Uhde TW. Heart rate and plasma norepinephrine responsivity to orthostatic challenge in anxiety disorders. Comparison of patients with panic disorder and social phobia and normal control subjects. Arch Gen Psychiatry. 1992; 49:311-317. [PubMed: 1558465]

Street LL, Craske MG, Barlow DH. Sensations, cognitions and the perception of cues associated with expected and unexpected panic attacks. Behav Res Ther. 1989; 27:189-198. [PubMed: 2930445]

Targum SD. Panic attack frequency and vulnerability to anxiogenic challenge studies. Psychiatry Res. 1991; 36:75-83. [PubMed: 2017525]

Targum SD. Cortisol response during different anxiogenic challenges in panic disorder patients. Psychoneuroendocrinology. 1992; 17:453-458. [PubMed: 1484913]

Taylor CB, Sheikh J, Agras WS, Roth WT, Margraf J, Ehlers A, Maddock RJ, Gossard D. Ambulatory heart rate changes in patients with panic attacks. Am J Psychiatry. 1986; 143:478-482. [PubMed: 3953890]

Tesar GE, Rosenbaum JF. Successful use of clonazepam in patients with treatment-resistant panic disorder. J Nerv Ment Dis. 1986; 174:477-482. [PubMed: 3734770]

Van Buren JM. Sensory, motor and autonomic effects of mesial temporal stimulation in man. J Neurosurg. 1961; 18:273-288. [PubMed: 13779877]

van den Heuvel OA, Veltman DJ, Groenewegen HJ, Witter MP, Merkelbach J, Cath DC, van Balkom AJ, van Oppen P, van Dyck R. Disorder-specific neuroanatomical correlates of attentional bias in obsessive-compulsive disorder, panic disorder, and hypochondriasis. Arch Gen Psychiatry. 2005; 62:922-933. [PubMed: 16061770]

Vickers K, McNally RJ. Respiratory symptoms and panic in the National Comorbidity Survey: a test of Klein's suffocation false alarm theory. Behav Res Ther. 2005; 43:1011-1018. [PubMed: 15967172] 
von Leupoldt A, Sommer T, Kegat S, Baumann HJ, Klose H, Dahme B, Buchel C. The unpleasantness of perceived dyspnea is processed in the anterior insula and amygdala. Am J Respir Crit Care Med. 2008; 177:1026-1032. [PubMed: 18263796]

Weissman NJ, Shear MK, Kramer-Fox R, Devereux RB. Contrasting patterns of autonomic dysfunction in patients with mitral valve prolapse and panic attacks. Am J Med. 1987; 82:880 888. [PubMed: 3578358]

Wellman CL, Izquierdo A, Garrett JE, Martin KP, Carroll J, Millstein R, Lesch KP, Murphy DL, Holmes A. Impaired stress-coping and fear extinction and abnormal corticolimbic morphology in serotonin transporter knock-out mice. J Neurosci. 2007; 27:684-691. [PubMed: 17234600]

Westerhaus MJ, Loewy AD. Central representation of the sympathetic nervous system in the cerebral cortex. Brain Res. 2001; 903:117-127. [PubMed: 11382395]

Wiest G, Lehner-Baumgartner E, Baumgartner C. Panic attacks in an individual with bilateral selective lesions of the amygdala. Archives of neurology. 2006; 63:1798-1801. [PubMed: 17172622]

Wilent WB, Oh MY, Buetefisch CM, Bailes JE, Cantella D, Angle C, Whiting DM. Induction of panic attack by stimulation of the ventromedial hypothalamus. J Neurosurg. 2010; 112:1295-1298. [PubMed: 19852539]

Wilent WB, Oh MY, Buetefisch C, Bailes JE, Cantella D, Angle C, Whiting DM. Mapping of microstimulation evoked responses and unit activity patterns in the lateral hypothalamic area recorded in awake humans. Technical note. J Neurosurg. 2011; 115:295-300. [PubMed: 21495826]

Wilkinson DJ, Thompson JM, Lambert GW, Jennings GL, Schwarz RG, Jefferys D, Turner AG, Esler MD. Sympathetic activity in patients with panic disorder at rest, under laboratory mental stress, and during panic attacks. Arch Gen Psychiatry. 1998; 55:511-520. [PubMed: 9633669]

Wilson KA, Hayward C. A prospective evaluation of agoraphobia and depression symptoms following panic attacks in a community sample of adolescents. J Anxiety Disord. 2005; 19:87-103. [PubMed: 15488369]

Wittchen HU, Gloster AT, Beesdo-Baum K, Fava GA, Craske MG. Agoraphobia: a review of the diagnostic classificatory position and criteria. Depress Anxiety. 2010; 27:113-133. [PubMed: 20143426]

Woods SW, Charney DS, Goodman WK, Heninger GR. Carbon dioxide-induced anxiety. Behavioral, physiologic, and biochemical effects of carbon dioxide in patients with panic disorders and healthy subjects. Arch Gen Psychiatry. 1988; 45:43-52. [PubMed: 3122696]

Woods SW, Charney DS, McPherson CA, Gradman AH, Heninger GR. Situational panic attacks. Behavioral, physiologic, and biochemical characterization. Arch Gen Psychiatry. 1987; 44:365375. [PubMed: 2882735]

Woods SW, Charney DS, Loke J, Goodman WK, Redmond DE Jr. Heninger GR. Carbon dioxide sensitivity in panic anxiety. Ventilatory and anxiogenic response to carbon dioxide in healthy subjects and patients with panic anxiety before and after alprazolam treatment. ArchGenPsychiatry. 1986; 43:900-909.

Yeragani VK, Pohl R, Balon R, Weinberg P, Berchou R, Rainey JM. Preinfusion anxiety predicts lactate-induced panic attacks in normal controls. Psychosom Med. 1987; 49:383-389. [PubMed: 3615766]

Yeragani VK, Meiri PC, Pohl R, Balon R, Desai N, Golec S. Heart rate and blood pressure changes during postural change and isometric handgrip exercise in patients with panic disorder and normal controls. Acta Psychiatr Scand. 1990; 81:9-13. [PubMed: 2330838]

Young RF. Brain and spinal stimulation: how and to whom! Clinical neurosurgery. 1989; 35:429-447. [PubMed: 2783566]

Zeidan MA, Igoe SA, Linnman C, Vitalo A, Levine JB, Klibanski A, Goldstein JM, Milad MR. Estradiol modulates medial prefrontal cortex and amygdala activity during fear extinction in women and female rats. Biol Psychiatry. 2011; 70:920-927. [PubMed: 21762880] 


\section{Highlights}

1. Panic Disorder and Panic Attack Symptoms and Signs (DSM-III through V)

2. Biological Basis of Unexpected and Expected Panic Attacks

3. Panic Attacks Triggers - Laboratory-induced and Naturally Occurring

4. Neurochemical Circuits Implicated in Adaptive and Pathological Panic

5. Animal Models of Adaptive and Pathological Panic States 


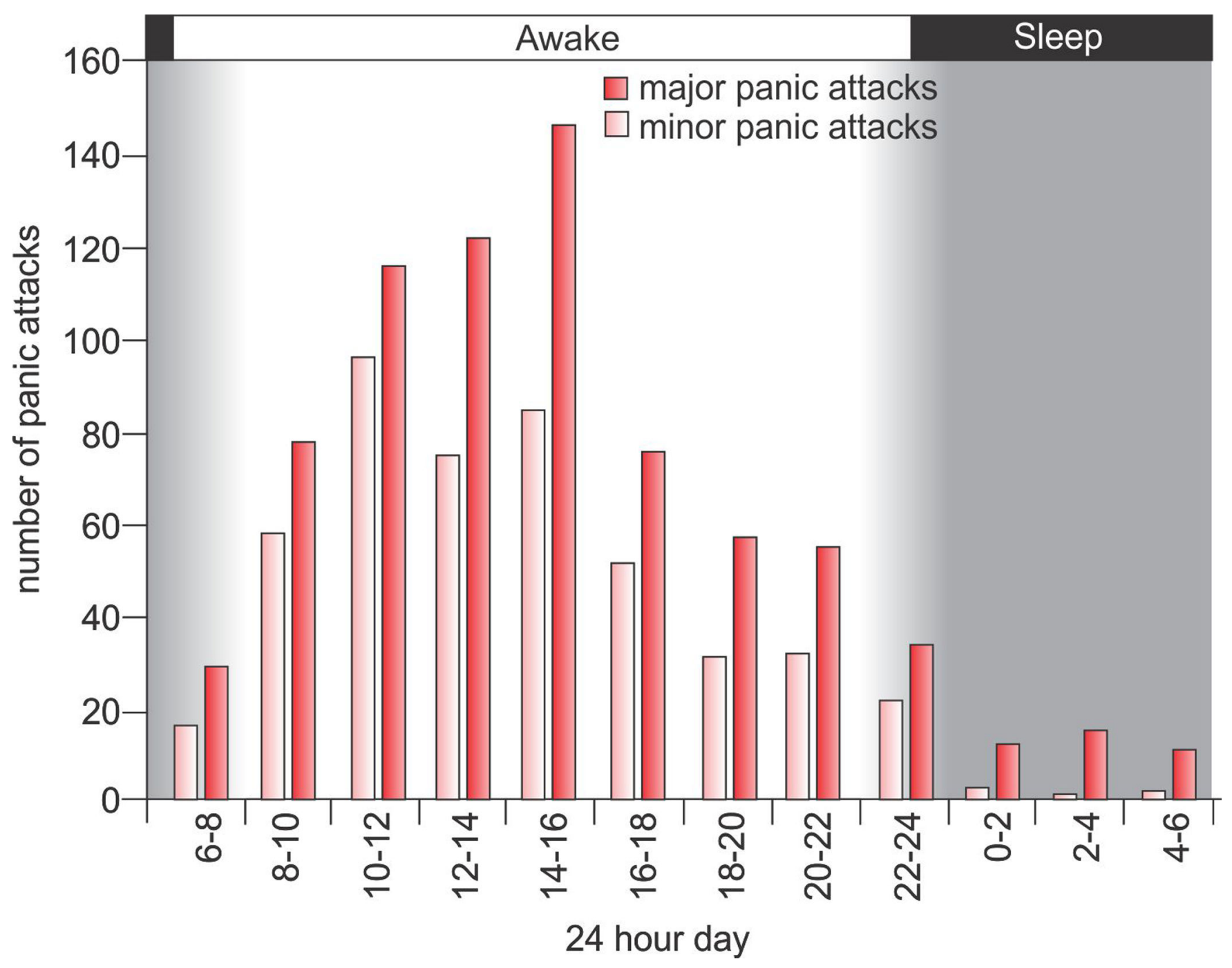

Figure 1.

This bar graph represents the number of minor and major panic attacks that occur throughout the day from 97 PD subjects and from a total number of ambulatory monitored panic attacks. Major attacks are shaded red and minor attacks are shaded pink. Gray background shading represents typical time for sleep and white background represents typical wake times of an adult. Adapted and reproduced with permission from (de Beurs et al., 1994) 


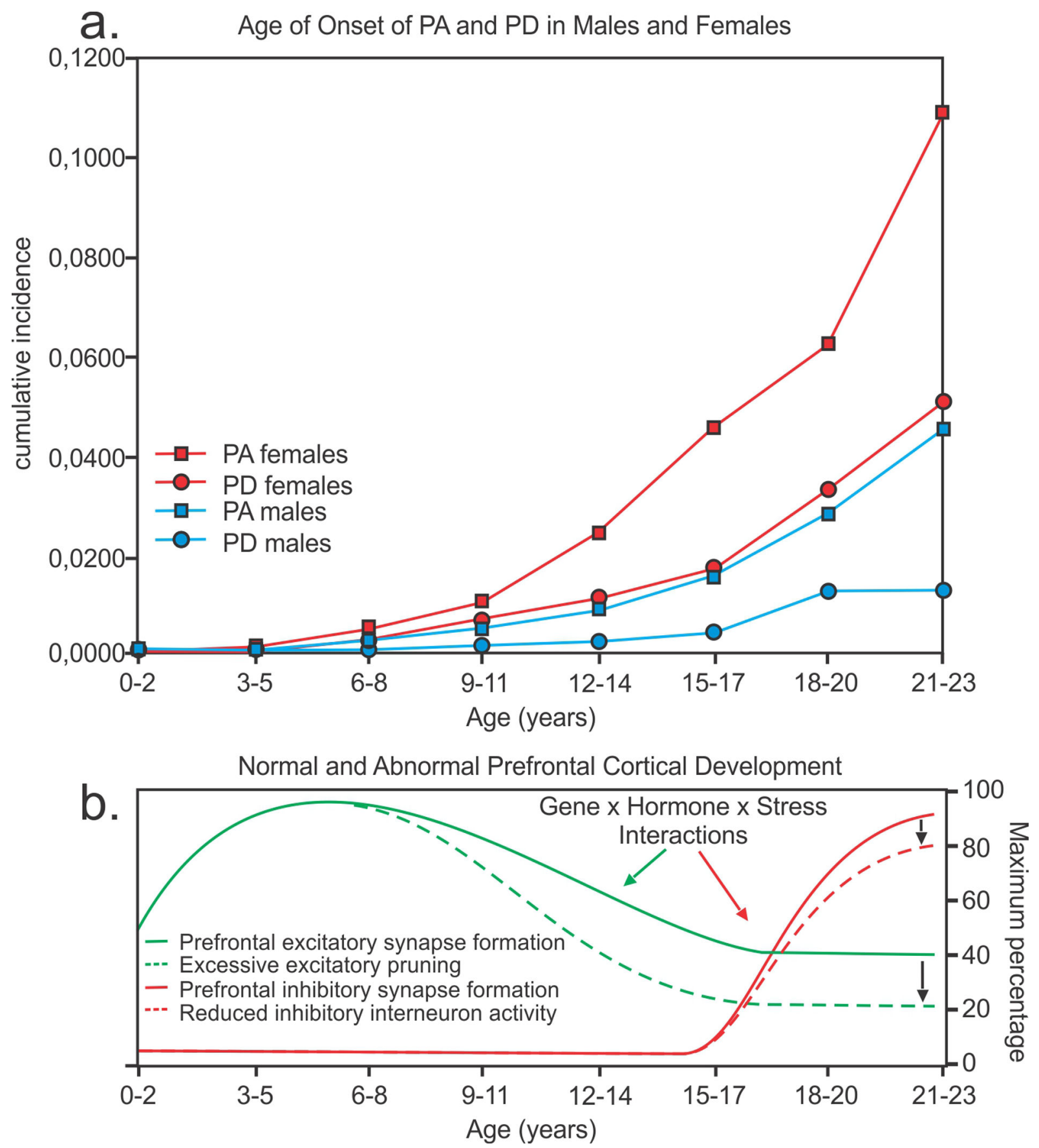

Figure 2.

a) Cumulative incidence of panic attacks and panic disorder over early life development until early adult stage in male and females. Figure adapted from (Reed and Wittchen, 1998) with permission. b) Note that PAs and PD begin to develop during adolescence when prefrontal cortical remodeling of local glutamatergic and GABAergic synapses is occurring. In support of a cortical developmental contribution to PAs and PD pathology, gene $\mathrm{x}$ hormone $\mathrm{x}$ environmental stress interactions may collectively contribute to abnormal PFC development, and loss of tonic inhibition of subcortical panic generating brain regions such 
as the perifornical hypothalamus and dorsal periaqueductal gray, which could contribute to the onset of PAs and PD. Figure 1b adapted from figure 1 in (Insel, 2010) with permission. 


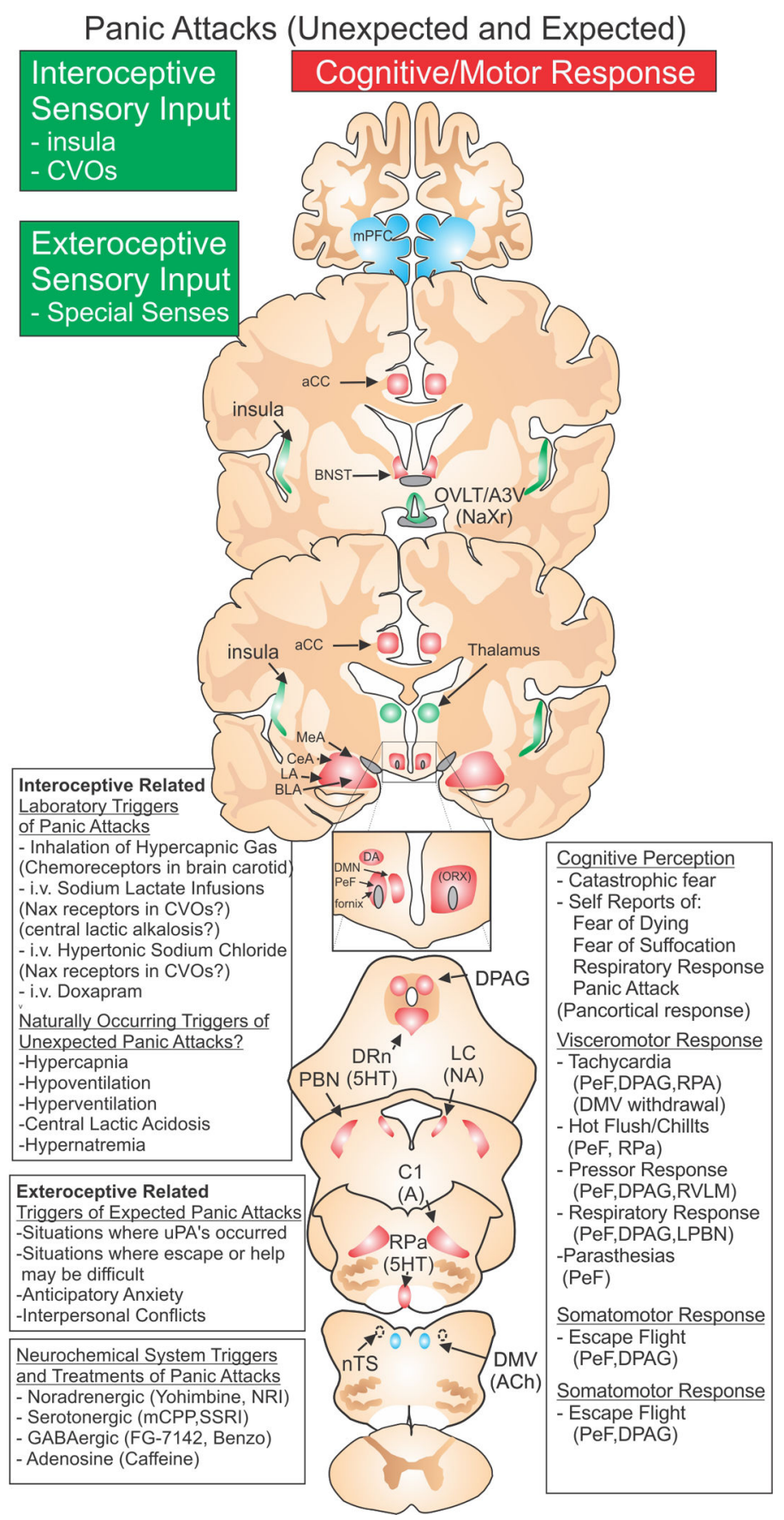

Figure 3.

Represents a hypothetical graphical illustration of rostrocaudal coronal sections from the human brain that are relevant to panic disorder (PD) and panic attacks (PAs) with: sensory input centers indicated by green shading; hypofrontality indicated by blue shading; and brain regions implicated in cognitive catastrophic fear and physiological components (e.g., cardiovascular, respiratory, thermal) responses indicated in red. Illustrations were generated from histological coronal brain sections posted on the "Brain Biodiversity Bank" from Michigan State University Website, which was supported by the National Science 
Foundation Grants 0131267, 013182, and 0131028. Abbreviations are the following: 5-HT, serotonin; A, adrenergic; A3V, anteroventral $3^{\text {rd }}$ ventricle region; $\mathrm{ACh}$, acetylcholine; aCC, anterior cingulate cortex; BLA, basolateral amygdala; BNST, bed nucleus of the stria terminalus; $\mathrm{C} 1, \mathrm{C} 1$ adrenergic neurons; $\mathrm{CeA}$, central amydala; $\mathrm{CVO}$, circumventricular organ; DA, dorsal hypothalamic area; DMN, dorsomedial hypothalamic nuclei; DMV, dorsal motor nucleus of the vagus; DPAG, dorsal periaqueductal gray; DRn, dorsal raphe nucleus; LA, lateral amygdala; LC, locus ceruleus; MeA, medial amygdala; NA, noradrenergic; nTS, nucleus of the solitary tract; ORX, orexin; OVLT, organum vasculosum lamina terminalis; PBN, parabrachial nucleus; RPa, raphe pallidus. 


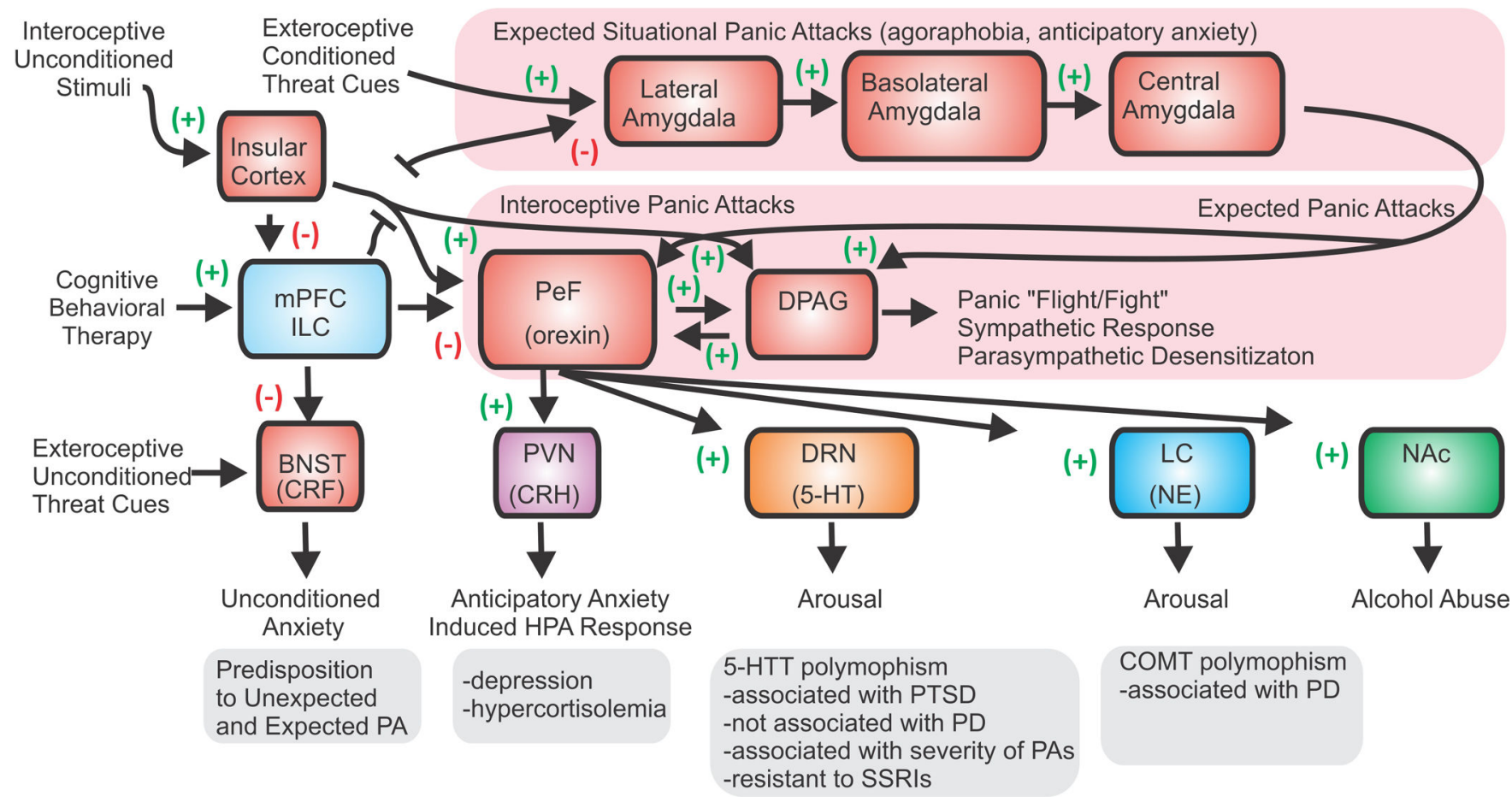

Figure 4.

Represents a hypothetical illustration of potential interoceptive and exteroceptive triggers of PAs and proposed pathways and brain regions that are important sensory and relay sites for components of PAs. When applicable, neuropeptide and neurotransmitter systems associated with each brain region are listed below in parentheses. 


\section{a. Adaptive/Pathological Panic Models}

\begin{tabular}{|l|l|}
\hline \multicolumn{2}{|l|}{ BehaviorTests as independent and dependent variable } \\
(Elevated T-Maze - assessing latency to escape open arm)
\end{tabular}

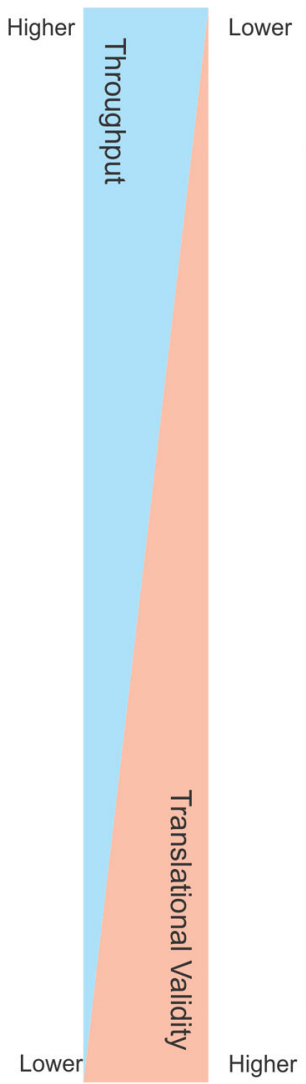

b. Utility of Rodent Panic Models

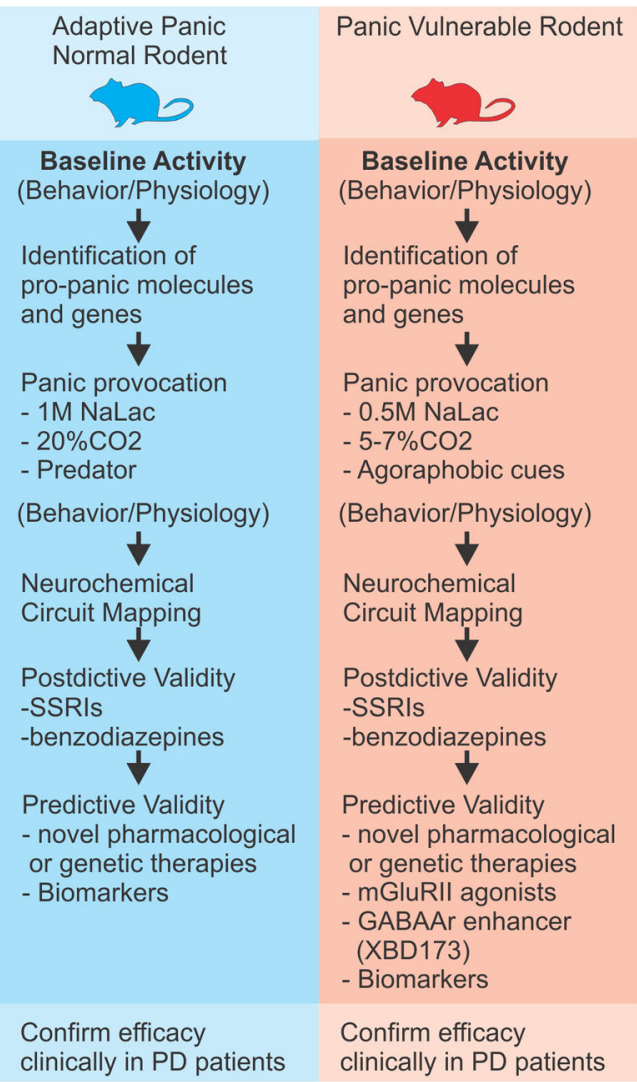

Figure 5.

a) the $1^{\text {st }}$ Column represents methods of inducing panic states in normal rats (blue shaded region)or panic vulnerable rats (red shaded region) by interoceptive, or exteroceptive panicogenic challenges, or by deep brain stimulation of panicogenic brain regions. The $2^{\text {nd }}$ column represents assessments of panic with behavioral tests only, or in combination with autonomic and or respiratory assessments. The scale to right represents the level of difficulty of the experiment (thoughput) and the level of translational validity. b) represents the utility of rodent panic models. 


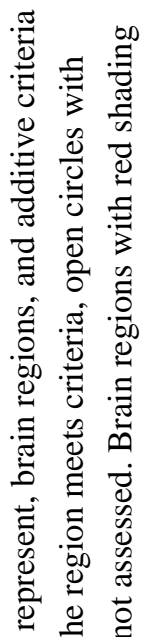

궁

:

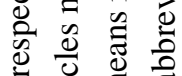

ज)

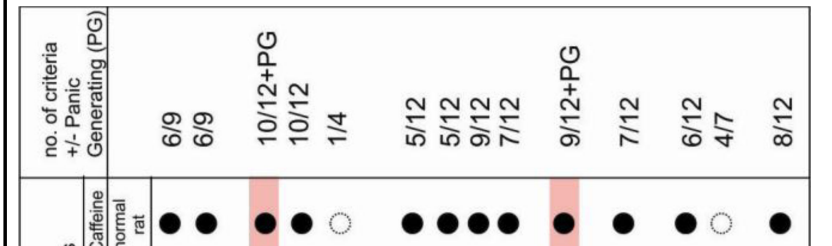
- $\dot{2} \dot{2} \overline{0}$

๑ Z

है

产.

के च :

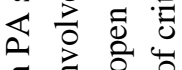

$\Xi \nexists$ के

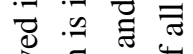

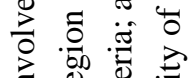

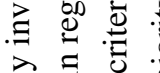

寻

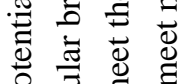

苛

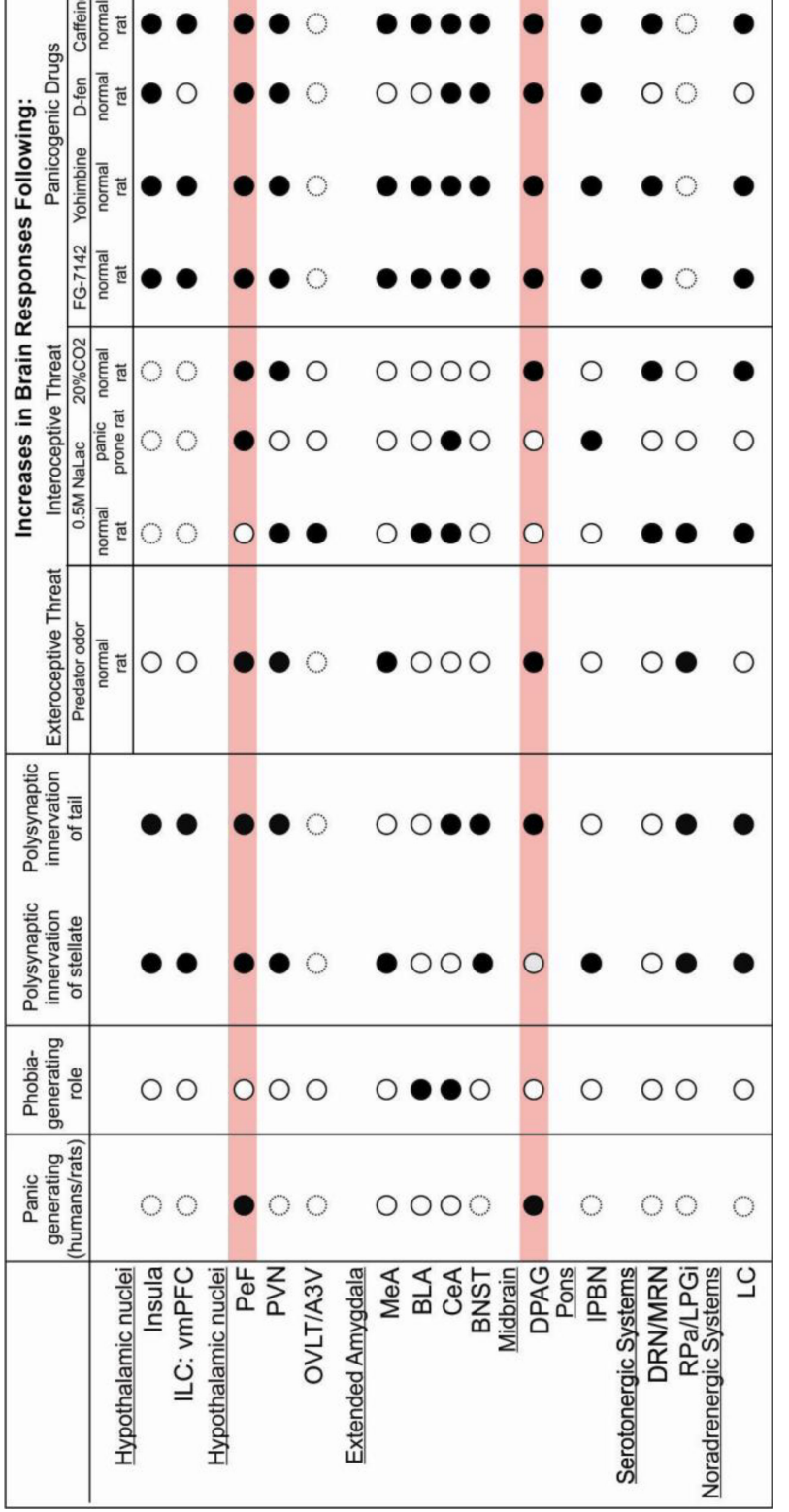

